University of Louisville ThinkIR: The University of Louisville's Institutional Repository

Electronic Theses and Dissertations

$5-2016$

\title{
Same-sex child molestation within the Boy Scouts of America initiation and termination in victim narratives.
}

Leah Catherine Jihee Shon

University of Louisville

Follow this and additional works at: https://ir.library.louisville.edu/etd

Part of the Criminology and Criminal Justice Commons

\section{Recommended Citation}

Shon, Leah Catherine Jihee, "Same-sex child molestation within the Boy Scouts of America initiation and termination in victim narratives." (2016). Electronic Theses and Dissertations. Paper 2478.

https://doi.org/10.18297/etd/2478

This Doctoral Dissertation is brought to you for free and open access by ThinkIR: The University of Louisville's Institutional Repository. It has been accepted for inclusion in Electronic Theses and Dissertations by an authorized administrator of ThinkIR: The University of Louisville's Institutional Repository. This title appears here courtesy of the author, who has retained all other copyrights. For more information, please contact thinkir@louisville.edu. 


\title{
SAME-SEX CHILD MOLESTATION \\ WITHIN THE BOY SCOUTS OF AMERICA \\ INITIATION AND TERMINATION IN VICTIM NARRATIVES
}

\author{
By \\ Leah Catherine Jihee Shon \\ B.A., Sookmyung Women's University, 2002 \\ B.H.J, University of Regina, 2006 \\ M.S., Indiana State University, 2012
}

\begin{abstract}
A Dissertation
Submitted to the Faculty of the

College of Arts and Sciences of the University of Louisville in Partial Fulfillment of the Requirements for the Degree of
\end{abstract}

Doctor of Philosophy in Criminal Justice

Department of Criminal Justice

University of Louisville

Louisville, Kentucky

May 2016 
Copyright 2016 by Leah Catherine Jihee Shon

All rights reserved 



\title{
SAME-SEX CHILD MOLESTATION \\ WITHIN THE BOY SCOUTS OF AMERICA INITIATION AND TERMINATION IN VICTIM NARRATIVES
}

\author{
By \\ Leah Catherine Jihee Shon \\ B.A., Sookmyung Women's University, 2002 \\ B.H.J, University of Regina, 2006 \\ M.S., Indiana State University, 2012
}

A Dissertation Approved on

June 24, 2016

By the following Dissertation Committee:

Dissertation Director

Dr. Richard Tewksbury

Dr. Viviana Andreescu

Dr. Kristin Swartz

Dr. Ryan Schroeder 


\section{DEDICATION}

This dissertation is dedicated to my mother

\section{Hyun Rye Kim}

who has given me immeasurable love and support. 


\section{ACKNOWLEDGEMENTS}

First and foremost, I would like to express my sincere appreciation to my supervisor and mentor, Dr. Richard Tewksbury, for his assistance, support, understanding, and patience throughout my doctoral program experience. He has continually and convincingly encouraged and challenged me to persevere in the face of adversity. Without his guidance and persistent help, this dissertation would not have been possible.

I would also like to thank my helpful committee, Dr. Viviana Andreescu, Dr. Kristin Swartz, and Dr. Ryan Schroeder for having served on my committee. Their advice, encouragement, and fruitful feedback throughout the Dissertation project were greatly valued.

I would like to recognize my family — my mother, brother, and nephew_-for their unyielding support, love, and trust. Finally, I would like to thank my husband, Yoha, who gave me endless support, boundless patience, and immeasurable love. I love you. 


\section{ABSTRACT \\ SAME-SEX CHILD MOLESTATION \\ WITHIN THE BOY SCOUTS OF AMERICA \\ INITIATION AND TERMINATION IN VICTIM NARRATIVES}

Leah Catherine Jihee Shon

June 24, 2016

Previous studies of child molestation have largely used a sample of either incarcerated or convicted sex offenders. Previous studies have also failed to provide substantial analyses regarding how physical contacts between child victims and adult perpetrators were initiated and terminated at the crime scene; few studies have focused on "what exactly happened" while physical touching was taking place through an analysis of behavioral sequences of both child victims and adult offenders.

Although previous literature on interpersonal child abuse used child victims of sexual abuse as their data source, those studies focused on effective victim treatment plans to deal with victims' post-trauma as a result of sexual abuse. Also, detailed instructions on when and how to resist unwanted sexual advances have not been delivered to children, especially who participate in youth-oriented institutions as extra curricular activities. Few have examined the dynamics of child molestation in terms of physical and verbal interactions between the two parties that were related by child victims. The purpose of this study was, therefore, to fill this void by analyzing previously kept confidential files within the Boy Scouts of America (1960 through 1990). 
This dissertation examined victim narratives to identify how scoutmaster perpetrators carried out their sexual advances against young boys under their supervision, and how boy victims responded to unwanted sexual advances made by persons of authority within the BSA. Detailed descriptions of physical contact stage in the course of same-sex child molestation were experienced, recalled, and related by boy victims themselves.

The analytical framework of the Routine Activity Theories was implemented to the qualitative analysis of victim narratives. In same-sex child molestation, scoutmasters and boy members were found to play three roles - motivated offender, suitable target, and capable guardians, to initiate and terminate physical contacts. Victim narratives exhibited behavioral sequences between boy victims and scoutmaster perpetrators while physical touching was ongoing. Scoutmaster perpetrators' initiation patterns were captured and analyzed by using a fishing metaphor-angling, spearfishing, and handpicking methods. Significant resisting actions of boy victims at each initiation case were also examined and analyzed for practical and effective preventions of child molestation within youth-centric institutions. 
TABLE OF CONTENTS

PAGE

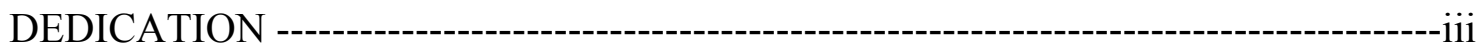

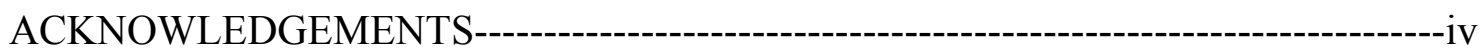

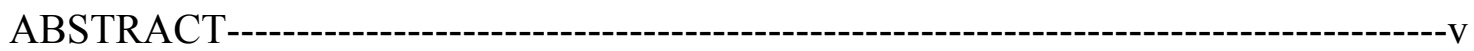

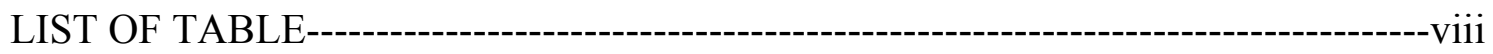

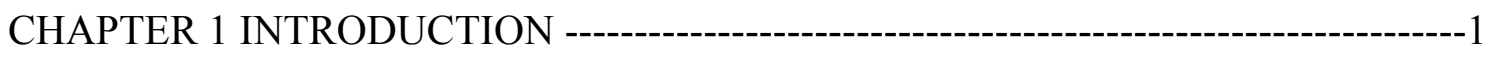

CHAPTER 2 REVIEW OF LITERATURE---------------------------------------------------18

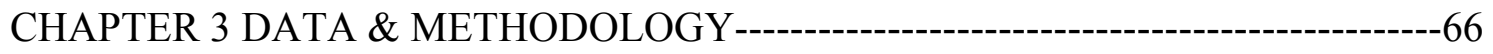

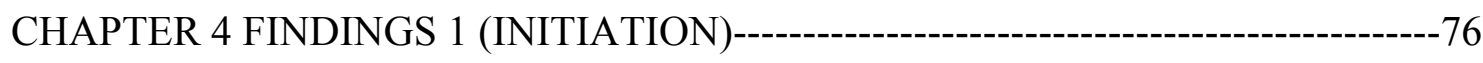

Angling contact ----------------------------------------------------------82

Spearfishing contact-------------------------------------------------------107

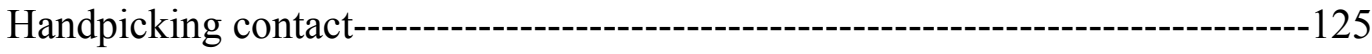

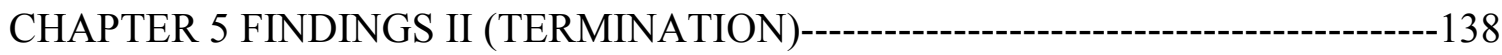

Resistance in Angling-------------------------------------------------------------141

Resistance in Spearfishing---------------------------------------164

Resistance in Handpicking-------------------------------------------------171

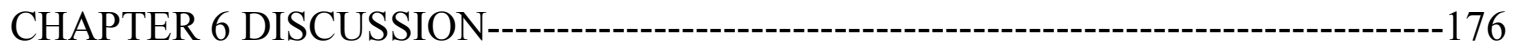

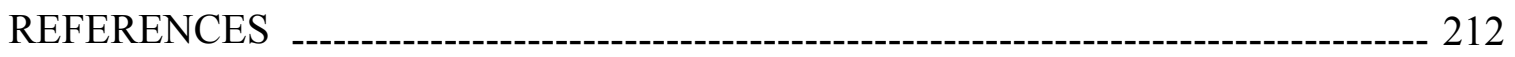

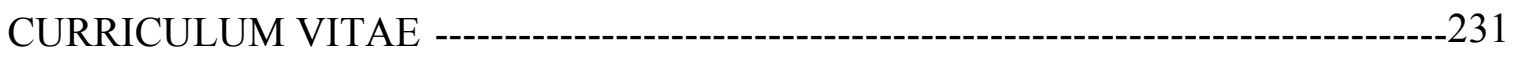




\section{LIST OF TABLE}

TABLE

PAGE

1. Typology of Perpetrator's Physical Contacts at Initiation Stage-------------------------136

2. Effectiveness of Victim Resistance at Termination Stage--------------------------------174 


\section{CHAPTER 1 \\ INTRODUCTION}

One of the most significant problems that children as a group have faced is the threat of sexual abuse from family members and strangers alike, and accordingly, the problem of child sexual abuse has received a great deal of attention in current society (Finkelhor, 1994a, 1994b; Finkelhor, Asdigian, \& Dziuba-Leatherman, 1995; Lussier, 2005; Pryor, 1996; Simon, 2000). The term "child molester" largely refers to a person who has had sexual contact with children, and the involved sexual acts are interpreted and treated as a violation of criminal law (Feelgood \& Hoyer, 2008; Knight, Carter, \& Prentky, 1989; Sullivan \& Beech, 2004).

Sexual abuse in childhood has impacted the life course of victims in consequential ways, such as adverse mental and behavioral health outcomes (Fergusson, Boden, \& Horwood, 2008; Hanson, Steffy, \& Gauthier, 1993; Hunter, 2006; Spataro, Mullen, Burgess, Wells, \& Moss, 2004; Weiss, 2010). Furthermore, literature indicates that victims of sexual abuse go on to commit sexual offenses against others as well as other forms of violence against intimates; the risk of being a sexual predator is enhanced by prior victimization experiences such as incest or pedophilia and even higher for those who exposed to both types of abuse (Cox \& Holmes, 2001; Glasser, Kolvin, Campbell, Glasser, Leitch, \& Farrelly, 2001; Hepburn, 1994). On the other hand, Easton, Coohey, Rhodes, and Moorthy (2013) revealed in their study of male victims who had experienced childhood sexual abuse that better understanding of the sexual abuse (e.g., adjusted 
masculine norms) could increase the likelihood of positive changes in life, such as healthy interpersonal relationships.

A brief overview of child sexual abuse indicates that $9.3 \%$ of cases of child maltreatment in 2012 were classified as sexual abuse; of those abused, $26 \%$ were in the age group of 12 to 14 years and 34\% were younger than 9 years old; and approximately $5.1 \%$ of boys and $26.6 \%$ of girls were sexually abused before the age of 18 (Finkelhor, Shattuck, Turner, \& Hamby, 2014). Overall, offender profiles revealed that the perpetrators of sexual abuse against children were disproportionately male (Finkelhor, 1994a; Spataro et al., 2004). Furthermore, over $90 \%$ of child victims were abused by their acquaintances such as neighbors, friends, and family members (Finkelhor, 2012).

\section{Overview of Sexual Violence Studies}

Studies thus far have classified sexual violence in several ways. For instance, victim age is used to differentiate child sexual abuse from other sex crimes targeting adults (Carlstedt, Nilsson, Hofvander, Brimse, Innala, \& Anckasater, 2009; Erickson, Walbeck, \& Seely, 1988; Hamdi \& Knight, 2012; Lang, Rouget, \& Van Santen, 1988; Robertiello \& Terry, 2007). In addition, some classifications are based on the degree of force, the range of contact, and even the situational circumstances (see Harbers, Deslauriers-Varin, Beauregard, \& Van DerKamp, 2012; Mustaine \& Tewksbury, 2000; Terry, 2008; Zilney \& Zilney, 2009; Leclerc, Wortley, \& Smallbone, 2010). Due to the numerous ways in which sexual violence is defined, it is not easy to classify sexual violence in a uniform way (Finkelhor, 1994a, 1994b).

Accordingly, there is a lack of agreement about the definition and meaning about sexual violence, and offences. For instance, the definition of childhood varies from state 
to state and study to study; some states define the end of childhood at age 16,17 , and some at 18, depending on legal stipulations (See Bard et al., 1987; Finkelhor, 2009; Sullivan, Beech, Craig, \& Gannon, 2011); some studies differently viewed child molestation when accounting for the age gap between a victim and offender (see Lang, Rouget, \& Santen, 1988). Sexual experience in childhood may or may not include nonphysical contact, as well as sexual contact with peers (Finkelhor, 1994a). It involves a variety of victims and offenders with regard to their characteristics, values, and social positions. Sex crime studies thus require a multi-dimensional analysis of offences, victims, and offenders based on behavioral, psychological, situational, and contextual considerations.

A variety of sexual offences within sex crime research, such as child molestation, rape, and non-contact sexual deviances, have yielded overlapping findings, yet also at the same time, distinguishing outcomes of crime patterns from one another. Factors influencing or predicting sexual offending behaviors also vary; they include each party's age, gender, offender motivation, victim/offender relationship, and even their perceptions of victims and sexual violence (Bard et al., 1987; Buschman, Wilcox, Spreen, Marshall, \& Bogaerts, 2008; Calstedt et al., 2009; Cox \& Holmes, 2001; Erickson, et al., 1988; Sullvan et al., 2011).

Although divided into multitudes of sub-categories, the purpose of sex crime studies is fundamentally geared toward crime prevention. The majority of sex crime studies endeavor to provide answers to a question of how ultimately to prevent sexual violence. However, most of the answers disproportionately concentrate on offenderoriented treatment and rehabilitation strategies, which only concerns the convicted sex 
offender population or crime prevention models that have to be implemented at either pre-crime or post-crime stages. Sexual violence is considered not only a public issue, but also a personal problem because it causes a tremendous amount of physical and psychological damage to victims (Merrill, Guimond, Thomsen, \& Milner, 2003; Sigmon, Greene, Rohan, \& Nichols, 1996). The victims, in this context, include direct victims and indirect victims, such as family members. To prevent sex crime, regardless of its nature and manifestation, it is necessary to have in-depth understanding of offender characteristics, offending patterns, situational/ circumstantial factors, and most importantly, victim-focused intervention strategies.

Both victims and offenders play an important role in sex crime studies, especially when it involves physical contact. It is necessary for researchers to understand the extent of behavioral patterns displayed by both victims and offenders while sexual offences are occurring, meaning actually during physical contact. Having both victims' and offenders' accounts thus enables researchers to take situational/ environmental approaches to sexual violence and to verify significant factors to foster or impede the likelihood of physical injuries. Nevertheless, victim accounts have seldom been used in this regard. Rather, victims of sexual violence who have appeared in previous studies have been used to identify post-crime trauma and coping mechanisms from medical/clinical perspectives. Thus, most of the studies searching for crime patterns and strategies were not constructed with victim accounts, but on information provided by the sex offenders themselves. Some researchers recruited victims or conducted metaanalysis of victim-focused literature to identify the effectiveness of prevention programs (Finkelhor et al.,1995; Finkelhor, Ormrod, \& Turner, 2007) and the short-term or long- 
term impacts of sexual abuse against children (Lang, Rouget, Santen, 1988; Simon et al., 1996; Walsh, Fortier, \& DiLillo, 2010). Simply put, these studies focused on therapeutic aspects of victim treatment instead of rebuilding crime scenes based on victim descriptions.

Physical sexual violence usually occurs in a confined setting, away from the view of witnesses. Consequently, the chances of a third party witnessing the sexual acts at the scene of the crime are much less, and providing testimony is highly unlikely. Hence, victims of sex crimes serve as witnesses who can provide details of the offence in a highly relevant way. That is why it is important to pay attention to victims' descriptions in their own words. However, due to the private yet violent nature of sex crimes (especially those against children), having victims participate in research processes and making them recall their horrendous experiences might be difficult due to the victims' minor status Consequently, detailed descriptions of the offenses as recalled and narrated by victims themselves have not been as salient in prior research. Instead, prior studies examining offence patterns and dynamics between victims and offenders almost always relied on offenders' accounts.

Child sexual abuse is an involvement of the child in sexual activity for the purposes of sexual gratification to the perpetrator. Child sexual abuse thus constitutes physical contact for sexual purposes, molestation, statutory rape, prostitution, pornography, exposure, incest, or other sexually exploitative activities (Malchiodi, 1997). One of the widespread behavioral commissions in child sexual abuse with physical contacts include an older person touching the child's genitalia and/or the child touching the adult for purposes of sexual gratification. 
The majority of the existing literature assumes that victims of child molestation are an all-inclusive group regardless of their gender. In other words, victims' gender has been neglected in comparison to age in the study of child molestation. Among pre-school age victims (i.e., children age of seven and less), the reason for younger children being targets of sexual abuse was not because of their gender, but because of their small physical stature (Carlstedt et al., 2009; Erickson et al.,1988; Finkelhor \& Williams, 1988). It may be necessary to take a different approach to sexual offences involving older victims, when examining offending patterns and offender behaviors at the physical contact stage. As victims get older, victim gender becomes an important factor for child molesters when determining victim selection criteria.

Previous literature about victim age and gender could be misleading because there was a disproportionate emphasis on females as victims of sex crime and because the cutoff age was defined in multiple ways. For example, studies thus far have concentrated on sexual violence against female adults (see Beauregard, Rossmo, \& Proulx, 2007; Beauregard, 2010; Canter, Bennel, Alison, \& Reddy, 2003; Deslauriers-Varin \& beauregard, 2010; Warren et al.,1998; Hewitt, Beauregard, \& Davies, 2012; Hewitt \& Beauregard, 2014; Weinrott \& Saylor, 1991), which might be explained by the availability of data and frequency of crime occurrence (see Smallbone \& Wortley, 2004). However, underage victim groups (e.g., children and juveniles) make it complicated for researchers to follow up with the crime events due to the sensitive nature of the behaviors as well as the lack of victim availability for child protection reasons.

The efforts to understand the dynamics of male-on-male child abuse largely focused on victims' coping mechanisms to such traumatic events and collateral damages, 
such as posttraumatic stresses among survivors (see Easton et al., 2013; Easton, 2012;

Fater \& Mullaney, 2000; Weiss, 2010). Few studies have treated ongoing same-sex child molestation and child victims as a topic of study in its own right. Consequently, little is known about the in-depth dynamics as to how child molesters carry out their offenses against under-age male victims.

Same-sex child molestation victims have escaped attention due to the scarcity of data and the stigma inflicted on victims and their family members. Same-sex child molestation has been less frequently reported, and therefore, less studied. Several studies briefly mentioned the issue itself as to male child victims of sexual abuse in youth centric organizational settings, yet provide few details of the physical contact stage (see Abel, Lawry, Karlstrom, Osborn, \& Gillespie, 1994; Sample \& Bray, 2006; Terry, 2008, 2015). Simply stated, male victims of child molestation have not received as much attention as female victim cases (Terry, 2014). The sample population in the majority of sex crime studies is convicted offenders (e.g., rapists) who are incarcerated in correctional facilities or provided medical treatment. Although it may be convenient for researchers to gain access to those captive audiences, there may be reason to go beyond the offenders' accounts given the honesty of respondents' accounts (Beauregard \& Mieczkowski, 2011; Kaufman, Hilliker, Lathrop, \& Daleiden 1993). It may be necessary to look to victims themselves for a much more honest account of the details of offenses.

Data obtained from incarcerated/ institutionalized sex offenders are oftentimes in the form of self-report survey, and less often, direct interviews. Weinrott \& Saylor (1991) found that sex offenders' self-reports were a useful measure of their previous criminal history. It was because the majority of them had been involved in non-sexual 
offences, and they were more likely to disclose such facts. However, some researchers have raised concerns regarding the reliability of offenders' self-reported data, especially when the offenders were sex offenders against children (Beauregard \& Mieczkowski, 2011; Stermac, Hall, \& Henskns, 1989). The discrepancy may exist between stories from offenders' side and objective information because they tend to minimize and even deny their offending behaviors due to a fear of revealing more criminal involvement and deviant sexual preferences (Banse, Schmidt, \& Clarbour, 2010; Beauregard \& Mieczkowski, 2012; Kaufman et al., 1993; Stermac et al., 1989). Therefore, it is imperative for researchers to cross-validate the offender descriptions with other sources (see Scully, 1994), such as victim statements or similar accounts from their counterparts to validate the truthfulness and accuracy of their accounts about their sexual offending behaviors (see Leclerc, Carpentier, \& Proulx, 2006). Yet, studies thus far have used official police records or prison records instead of using direct accounts from the counterparts, the victims.

Instead of analyzing the sequence of behavioral patterns at each crime phase, previous sex crime studies largely deal with sex crimes as a binary event that is divided into two phases, pre-crime and post-crime phases. In addition, these offence script analyses were conducted solely based on incarcerated offender populations with a small sample size (see Corovic, Christianson, \& Lars, 2012; Colton, Roberts, \& Vanstone, 2010; Leclerc, Proulx, \& McKibben, 2005). Despite voluminous literature on various subjects involving sex crimes, such as offenders' modus operandi and hunting patterns, few studies have been conducted focusing on "crime scenes," where actual physical contacts and interactions between victims and offenders are taking place. 
Some qualitative-oriented research on sex crime examined offenders' decisionmaking processes, victim selection, and methods of attack (see Beauregard \& Leclerc, 2007; Leclerc et al., 2006; Proulx, Perreault, \& Ouimet, 1999). Those who have examined characteristics of grooming strategies have sometimes codified their observations into numeric codes so that all qualitative and behavioral aspects of offence commissions are lost. Hence, what is missing in the literature is an in-situ explanation of offenders' actual behavior in their interactions with the victims; what is needed is a sequential and step-by-step examination of the actual behaviors involved in the sexual offences against children.

Previous studies of child molestation have taken a multitude of approaches in analyzing offenders' behavior from psychological, psychiatric, and clinical perspectives. Many studies attempt to explain offender preferences for children and motivation for child molestation according to its disciplinary assumptions. These studies thus disproportionately focus on the "why" of child molestation. Few have examined the detailed dynamics of child molestation to verify "how" offending behaviors are relayed in a sequential manner. Again, previous literature has primarily focused on the pre-stage of child molestation as to why offenders chose child victims; how they gained access to their potential victims; and the levels of organization of sex offences (see Beauregard, Lussier, \& Proulx, 2005; Leclerc et al., 2010; Terry, 2008). However, the step-by-step ways in which offenders physically carry out sexual behaviors against their victims, not only how offenders "groom" victims for sexual gratification, but also how victims manage to conform to or resist such approaches when being left alone with perpetrators, have been largely ignored in previous literature. In other words, magnifying the 
behavioral sequences of both victims and offenders at physical contact stage has been missing in previous literature.

Various theoretical frameworks have been used to explain offender behaviors and to develop effective prevention models. The frequent theoretical perspectives used thus far include rational choice theory (e.g., Leclerc et al., 2006; Leclerc, Proulx, Lussier, \& Allaire, 2009), social disorganization theory (Denny, 2015; Mustaine, Tewksbury, HuffCorzine, Corzine, \& Marshall, 2014a, b), and routine activity theory (Deslauriers-Varin \& Beauregard, 2010; Mustaine \& Tewksbury, 2000, 2009; Terry, 2013). As previously mentioned, the majority of sex crime studies have been conducted to develop effective and practical prevention models. As a part of the preventative models, increasing guardianship and/or target hardening have been suggested (McKillop, Brown, Wortley, \& Smallbone, 2015; Terry \& Freilich, 2012). By implementing such strategies, motivated offenders are supposed to be discouraged to continually carry out their sexual behaviors against children. However, it should be noted that the previous researchers framed the issue and their dependent variables as dichotomous measures, specifically whether the offense was prevented or not.

Rather than framing the research question dichotomously, it may be useful to consider an interventionist approach to prevention. For instance, educators and parents can instruct children how to recognize and avoid sexually dangerous situations. Children can be taught to say 'no' when being approached by strangers and/or caregivers as a way of preventing sexual abuse while unaccompanied by guardians. However, those preventive-based measures are not able to provide specific directions on what to do if the actual offence is in process. If a child is unwillingly touched, it is unimportant why the 
perpetrator chooses the victim and who he/she is any more; what is important is to provide a set of directions so that a step-by-step accounting of what to do to stop the behaviors and to avoid further physical and sexual injuries. In this regard, an interventionist mode of approach takes the opposite stance and instructs potential child victims what to do if abuse is in the process of occurring.

Again, the existing child molestation literature on the effectiveness of prevention programs only viewed the prevention strategies in a binary manner by asking whether the offense is prevented or not. If the prevention strategies work and prevent child molestation from happening in the first place, that is a great success and the program is considered effective. However, if the prevention does not work, then the child victims, who are only taught how to say no, have no choice but to be victimized until the offender ends the crime. An interventionist model assumes a very practical and situation-based set of directions on how to avoid becoming a victim; an interventionist approach also provides a concrete set of directions for what to do as the offense is unfolding. What is missing in the literature is how to instruct children to deal with the offenders as the offenses are occurring. That is what an interventionist approach is able to provide.

To remedy this gap, my dissertation uses accounts that were obtained from boy victims who were sexually abused by persons in positions of authority, specifically, male authority figures, the scoutmasters within the Boy Scouts of America. Therefore, this study provides a unique contribution to the literature on sex offending by examining adult-male-on-underage-male sex crimes. This study is designed to explore the behavioral sequence between boy victims and their perpetrators in terms of how adults use their power and authority over the boys who were under their supervision and how 
they, as scout leaders, carry out sexual offences against boys under their care. The behavioral patterns of both victims and offenders in the commission of sexual offences will be thoroughly examined and analyzed through content analysis of victims' accounts.

The private nature of the data has hindered thorough public scrutiny of the samesex sexual assaults against children that occurred within the auspices of the Boy Scouts of America. In other words, their confidential records have yet to be extensively investigated and examined by external researchers. These records have not been accessible to researchers for public scrutiny for numerous reasons, such as their explosive character, involvement of minors, and their confidential nature. Therefore, this dissertation is expected to serve as a groundbreaking work in examining how adults within the Boy Scouts of America exploited their position in the organization to carry out sex crimes against the boys. It does so in a qualitative manner.

This dissertation is significant in terms of its use of a rarely scrutinized group of people to determine the distinctive patterns of same-sex sexual assault against children, especially the boys who were members of the Boy Scouts of America. Furthermore, this project attempts to develop effective intervention strategies that can be implemented at the physical contact stage while child sexual violence is occurring. To demonstrate the efficacy of an on-site interventionist mode, this work employs the basic premise of a Routine Activity Approach (Cohen \& Felson, 1979). The Routine Activity theory has most commonly been used in property crime cases that involved static conditions and immobile objects as suitable targets. Some researchers extend the application of Routine Activity theory to interpersonal crimes, such as sexual and/or physical assaults assuming social actors as suitable targets (see Mustaine \& Tewksbury, 2000, 2009). 
Within this framework of Routine Activity theory, this dissertation will shed light on the effective intervention model by switching the role of the three elements for the requirement of criminal act, motivated offender, suitable target, and capable guardians at crime-scene phase. To be specific, crime occurs when a motivated offender finds a suitable target, along with the absence of capable guardians in the same spatial and temporal space (Cohen \& Felson, 1979). To discourage motivated offenders from continuing their offending behaviors at the crime scene, it is necessary to transform suitable targets into unsuitable ones or transform bystanders/witnesses into guardians capable of protecting the target. Again, the routine activity framework can thus be applied not only at grooming stages, but also at physical contact stages.

Applying this framework to the Boy Scouts' same-sex child molestation cases, scout masters are considered already motivated offenders; young scout members are suitable targets; and lastly, the majority of scout activities that take place far from the reach of the boys' parents provide a lack of capable guardianship in that no one can intervene in offenders' criminal behaviors. Given these criminal opportunities, it is not too difficult to predict that sexual offences, regardless of their nature, are going to happen. Child molestation studies conducted thus far, however, have focused on components involving pre-crime phase, such as victim selection and grooming patterns (see Erickson et al., 1988; Finkelhor \& Williams, 1988), as well as post-offence phase behaviors including reoffending patterns and victim's resistance (Balemba, Beauregard, \& Mieczkowski , 2012; Durkin \& Digianantonio, 2007; Leclerc et al., 2010). Little work has been conducted to magnify the scope of the physical contact stage. 
Knowing the sequence of on-site behaviors carried out by both offenders and victims is important to estimate the timing and degree of "cessations points" on the continuum of resistance. In other words, the Routine Activity theory framework can account for the micro-level activities that are carried out by both offenders and victims. By switching the roles of a suitable target and an incapable guardianship at the physical contact stage, this interventionist mode is expected to help keep the motivated offender from continuing sexual behaviors against the victim, most importantly, and to lead to the least amount of physical harm.

Intervention strategies for on-going sexual violence may sound similar to what previous researchers have covered in sex crime prevention works. To distinguish prevention from an interventional mode, this study will examine both offenders' behaviors and victims' reactions at the physical contact stage. For this analysis, victim accounts from boy victims will be used. The boy victims were the members of the Boy Scouts of America at the time of offence, and the offenders, who committed same-sex child molestation, were mainly the scout masters/ leaders who had voluntarily joined the Boy Scouts of America and had been in charge of one or more scout troops.

Keeping those in mind, this dissertation can fill the void found in existing literature in three ways. First, the BSA files provide a unique and rich opportunity to study sex crimes against children in distinct ways. By equally focusing on child victims and their perpetrators, this dissertation will examine victim narratives directly provided by the victims of same-sex child molestation. It should be noted that the same-sex child molesters in this study do not count as an offender population. Instead, they will be addressed as perpetrators. This is simply because of the subtle difference in the 
definition of offenders and perpetrators. The former has been used in a more narrow sense that was referred to as perpetrators who are brought to the attention of the criminal justice system. However, the majority of scoutmasters in this dissertation were not externally investigated by law enforcement agencies, but were referenced in documents filed as internal complaints within the Boy Scouts of America.

The vast majority of previous studies involved offender populations who had been brought to the attention of the criminal justice system. In other words, they were all convicted offenders. For instance, as respondents of interview and self-reported surveys, the sample populations in former studies were incarcerated or released from prison (e.g., Beauregard \& Leclercm 2007; Calstedt et al., 2009; Corovic et al., 2012; Leclerc et al., 2006; Leclerc et al., 2009; Scully, 1994) and/or institutionalized in mental health treatment facilities (e.g., Bard et al., 1987; Leclerc et al., 2009; Stermac et al., 1989). Also, it is known that a large portion of child sexual violence is not reported, especially when the perpetrator is in a position of authority (Colton et al., 2010; Finkelhor \& Williams, 1988; Sullivan \& Beech, 2002, 2004). And, therefore, analyzing the sexual behaviors of the scoutmaster molesters, as unreported perpetrators, will help reveal a dark side of child molestation that has been undiscovered in previous literature. This study is thus expected to bring the secretive yet prevalent issues of same-sex child molestation within the BSA to the forefront by investigating the details of interactions between boy victims and the scout leader perpetrators from initiation to termination of sexual/physical contacts.

To be specific, the archival data I have collected from publicly available sources are unique in that they include a variety of perspectives, from both victims and offenders. 
One of the significant points of this research involves the use of narratives that were directly provided by victims. Analyses of these data are expected to remedy the issues of data reliability and validity found in previous studies that have relied too much on offender-oriented data. In this research, however, victim narratives will be analyzed to determine how offenders carried out their offenses, as experienced, recalled, and related by the victims themselves. The victim accounts, therefore, provide a unique and rich insight into same-sex sexual assaults against children from a victim's perspective.

The second rationale for this dissertation involves its focus of analysis. Assuming that a commission of sex crime constitutes three steps, pre-crime phase, criminal event phase, and post-offence phase (see Clarke \& Cornish, 1985), previous researchers have examined macro-level variables related to sex offenders and offence characteristics. Few have paid attention to the sequential flow of offences themselves as warrantable objects of analysis within the actual criminal event phase. This project therefore delves into the details of sex offenders and sex offences, not just correlates of those offenders and offences.

The aforementioned context of both initiation and termination do not refer merely to grooming patterns that only subsume victim selection patterns, attack methods, and exit patterns posed largely by offenders. This study will explicitly analyze the crime scenes where the sexual offending behaviors are taking place, thus magnifying the stage of "during-crime." Qualitative analysis of the actual criminal event has been largely omitted in many studies. Even though most of the literature on child sexual abuse mentioned the types of offence, attack, and victim reactions with a varying degree, few 
studies have examined the sequences of on-scene offending behavior and analyzed them in a qualitative way.

Lastly, this dissertation attempts to design intervention measures. Most of the child molestation cases take place in a solitary way between perpetrator and victim in a one-on-one setting. With regard to child sexual abuse within youth organizations, studies thus far have largely focused on a dichotomous nature of criminal events, such as crime prevention at pre- and post-crime phases, from the macro-level perspective. If the existing prevention techniques are not able to prevent victimization, it may be necessary for children to know the alternatives, such as how to stop on-going sexual abuse. Such intervention strategies should be designed with caution because reckless victim resistance may double the risks of sexual and physical injuries inflicted on child victims (see Balemba et al., 2012; Stermac et al., 1989). Therefore, through the analysis of victim accounts, this dissertation is expected to identify detailed patterns of offending and defending behaviors delivered by both child victims and perpetrators, and to suggest the effective intervention strategies for the victims to safely walk out of sex crime events. 


\section{CHAPTER 2}

\section{REVIEW OF LITERATURE}

Sexual violence leaves victims with life-long trauma. Victims across diverse ages and gender sustain both long and short-term physical and psychological injuries such as depression, anxiety, interpersonal, and sexual problems (Fergusson et al., 2008; Hanson et al., 1993; Sigmon et al., 1997; Spataro et al., 2004). When children are victims of sexual violence, the impact of victimization is recognized as a significant individual and social problem (Hanson et al., 1993). In the case of male victims of sexual abuse, they frequently displayed aggressive and disruptive behaviors in an effort to overcome the powerlessness and shame they had sustained as a result of their unwanted victimization and subsequent trauma (Hepburn, 1995; Scarce, 2001; Tewksbury, 2007; Weiss, 2010).

The majority of reported sex crimes involve adult female victims and one out of ten reported rape cases were committed by acquaintances (Fisher, Cullen, \& Turner, 2000; Krebs, Lindquist, Warner, Fisher, \& Martinn, 2007; Sample \& Bray, 2006; Scully, 1994). At the same time, sexual violence against males has been known as the most underreported and unaddressed violent crime (Scarce, 2001). Sexual abuse against children involves a high incidence of non-stranger abuse (Conte, Wolf, \& Smith, 1989). The relationship between victims and offenders thus affects the likelihood of victims' disclosing sexual abuse. Since most sexually abused children knew their offenders (e.g., family members), child victims have been less likely to report their victimization to the authorities (USACF, 2012; Fater \& Mullney, 2000). Hence, the prevalence of child 
sexual abuse, especially against male children, continues to be understated and understudied (Violato \& Genuis, 1993).

\section{Impact of Child Molestation}

Previous research has revealed that the quality and length of relationship between victim and offender could affect the aftermaths of childhood sexual abuse. That is, the longer and closer the relationships are, the greater impact the child victims are to experience (Fater \& Mullney, 2000; Pryor, 1996). The majority of child molesters were reported as victims' family members or acquaintances; they comprised approximately 80 to 90 percent of sex crimes against children (Finkelhor, 1994a; Zilney \& Zilney, 2009). That said, closer attention should be paid to the issues revolving around child molestation committed by known perpetrators with regard to the dynamics and impacts in the relationships between the two parties. For instance, child victims were less likely to report because the offenders were usually perceived as a peer, a trustable figure or a rescuer by their child victims (Colton et al., 1996; Leclerc et al., 2005).

In a similar vein, female adult victims of sexual abuse by acquaintance perpetrators were less likely than stranger victims to report their victimization or to seek medical or legal attention (Brecklin \& Ullman, 2010; Konradi, 2007). Thus, acknowledging the nature and quality of the relationship between offenders and victims is important when analyzing child molestation cases (Groth \& Burgess, 1977). Nevertheless, it is not easy to capture the exact prevalence of child molestation due to the variations in definitions of child molestation (e.g., age difference), methodological discrepancies including sample populations, and most importantly, prevalence rates and 
underreporting (Beitchman et al., 1992; Finkelhor, 1994b; Knight et al., 1989a;

Schechory \& Ben-David, 2005; Violato \& Genuis, 1993).

\section{Victim Vulnerability}

Children are limited in their daily routines, largely restricted to home and schools. Most of the social activities involving children are monitored and supervised by adult caregivers such as parents and teachers. Hence, child molesters can take advantage of opportunities arising in the context of daily activities while performing caregiver duties (McKillop et al., 2015), and they often intentionally place themselves in a position where they can meet children and have opportunity to interact with children in an unsupervised way (Bagley, Wood, \& Young, 1994; Finkelhor \& Williams, 1988; Quayle \& Taylor, 2001).

Tewksbury and Mustaine (2003) revealed that lifestyle behaviors and characteristics could serve better as predictors of crime-commission and target selection processes than the demographics of the involved in sex crimes among college students. Denny (2015) also suggested that sexual offenses against children in a religious setting were more likely to be attributed to the power and control vested on youth educators (e.g., ministers and volunteers) through interactions with victims regardless of the characteristics of the surrounding community (Fater \& Mullaney, 2000).

Expanding to sexual abuse in cyberspace, such opportunistic advantages (e.g., lack of supervision) also enabled Internet child molesters to develop grooming strategies with a certain group of children (Martellozzo, 2012; Williams, Elliott, \& Beech, 2013). For instance, vulnerable children with little social support and acceptance in their lives were more susceptible to perpetrators' grooming strategies, such as acceptance, 
understanding, and compliments, and tended to conform to sexually-motivated offers out of loyalty or guilty feelings (Williams et al., 2013). Similarly, Prentky, Knight, and Lee (1997b) revealed that child molesters often used psychological coercion rather than physical force to have potential victims involved in sexual activities.

In this sense, routine-based settings of children in each age group provide offenders more frequent access to victims by presenting the most suitable environment with the least amount of effort and risk to obtain their goals (McKillop et al., 2015). For instance, children between age nine and eleven and their lifestyle activities create greater opportunities than other age group children of being a target of child molestation during daytime (McKillop et al., 2015). Furthermore, children are more likely to be sexually victimized by those who can easily gain access to and interact with children on a regular basis (Sullivan \& Beech, 2002; Sullivan, Beech, Craig, \& Gannon, 2011). So, these studies suggested that children between nine and eleven years old might be most vulnerable because they were accessible to adult perpetrators on a regular basis in their lives.

\section{Approaches to Child Molestation}

There have been ample studies of sex offences in general, and child molestation in particular. Researchers have analyzed the extent of child molestation and molesters in various manners and from different perspectives with the hope of better understanding the scope of sexual violence against children. For instance, researchers examined child molesters with regard to their modus operandi, psychological/ biological patterns in their preference for children (Banse, Schmidt, \& Clarbour, 2010; Beggs \& Grace, 2008), and most importantly, situations preferred by certain groups of child molesters (Leclerc et al., 
2010; Leclerc, Feakes, \& Cale, 2015; Terry \& Freilich, 2012). At the same time, victims have been studied in terms of their coping mechanisms to deal with their victimization and effective prevention strategies. Such efforts have yielded four general classifications of previous child molestation research: 1) Who the child molesters are; 2) why they target children; 3) what factors influence offending behaviors, and 4) how to prevent child molestation. The four areas in previous studies will be reviewed and critiqued in the following. It is also noted that several studies on sexual violence involving victims other than children (e.g., female adult rape) will also be included intermittently to compare and contrast significant behaviors carried out in the course of child molestation.

\section{Classifications of Child Molesters}

Child molesters have been identified as adult males in most publicly known cases (Finkelhor, 1994a; NSVRC, 2011). For instance, male babysitters constituted 77\% of reported child sexual molesters (Finkelhor \& Ormrod, 2001). Previous literature has shown that child molesters were largely comprised of persons who have maintained relationships with child victims and their family members in various social contexts (Franzel \& Lang, 1989; Leclerc et al., 2005). The extent of children's lifestyles is much more limited than that of adults, which involve a variety of interactions with outsiders in various social/ occupational situations (see Beauregard et al, 2007). In a similar vein, McKillop et al. (2015) found that child victims aged twelve and older were more likely than younger child victims to be sexually victimized by extra-familial perpetrators and in the later hours of the day.

Classification on sexual preference. Another classification of child molesters is based on the origins of their sexual preference for children (see Franzel \& Lang, 1989). 
For instance, Terry and Ackerman (2008) examined the difference between fixated and regressed offenders and their preference of sexual relationship with children. Fixated child molesters had primary tendency for children (Calkins-Mercado, Tallon, \& Terry, 2008; Terry \& Tallon, 2004), and regressed molesters had sexual interest in children in adulthood, which was precipitated by external stressors (Bickley \& Beech, 2001). To be specific, Groth, Hobson, and Gary (1982) classified fixated offenders as being more persistent in their offending behaviors and their deviant sexual interest had started in their earlier ages, which was also found among offenders who sexually abuse the children with whom they work, in other words, child molesters in educational professions (Sullivan $\&$ Beech, 2002, 2004).

Meanwhile, regressed offenders were described as less persistent and largely being influenced by situational or external stressors in their offending behaviors (Groth et al., 1982; Terry \& Tallon, 2004). Despite the two separate sets of interests in children, when it came to an overall characteristic of child molesters, both fixated and regressed child molesters were reported to have a late onset of deviant sexual behavior compared to sex offenders against adult victims (Terry \& Akerman, 2008), and to be more likely to choose male victims (Abel \& Rouleau, 1990; Simon, Sales, Kaszniak, \& Kahn, 1992).

Other studies have found that victim gender and the number of victims could predict offenders' onset of sexual offending behaviors against children (Groth et al., 1982; Calkins-Mercado et al., 2008). For instance, clergy and fixated offenders have earlier onset of deviant sexual interest and are more likely to target multiple male victims (Groth et al., 1982; Simon, et al., 1992). Also, child molesters in educational professions overall showed similar preference with fixated offenders in that offenders' emotional and 
sexual intentions for children manifested through planned sexual activities (Colton et al., 2010; Leclerc et al., 2006).

In this regard, Calkins-Mercado et al. (2008) argued that such a unique yet superior position of child molesters in educational professions also affected their victim selection patterns being rather circumstantial rather than fixated. However, another study saw child molesters' preferences as more fixated based on the fact that they tended to reoffend against children except for those who targeted pubertal victims age 13-15 years (Guay, Proulx, Cusson, \& Ouimet, 2001; Hanson, Scott, \& Steffy, 1995). Furthermore, Prentky, Knight, and Lee (1997b) revealed that child molesters with opposite sex victims showed the lowest recidivism rates, while those who abused same-sex victims had the highest recidivism rates.

Classification by family ties. One of the general classifications of child molesters builds upon the types of relationship between offenders and victims focusing on whether offenders are family members or not (see Allen \& Lee, 1993; Franzel \& Lang, 1989). The former is largely known as intra-familial, and the latter as extrafamilial offenders. One of the studies revealing the risk factors in both intra and extra familial environments indicated that children from a rigid family structure faced a higher risk of intra familial sexual abuse and lesser risk of extra familial abuse (Allen \& Lee, 1993). Conversely, children from a family of weak structure and control had higher risk of sexual abuse by perpetrators other than family members (Allen \& Lee, 1993). Nevertheless, a study revealed that the two groups of child molesters did not differ from each other when it came to sexual experiences, attitudes, and orientations (Pawlak, 
Boulet, \& Bradford, 1991). Hence, Allen and Lee (1993) argued that they should be considered under a single common theoretical framework.

Classification by career. Child molesters in educational professions who were frequently discussed in previous studies include teachers, childcare workers, and clergies (see Sullivan et al., 2011; Pryor, 1996). This child molester group is largely made up of persons who work in either youth-oriented institutions or organizations (e.g., schools) to target and abuse children; they are provisionally categorized as the child molesters in educational professions (Sullivan \& Beech, 2002, 2004; Sullivan et al., 2011). Child molesters in educational professions are frequently placed in a grey area between the intra and extra familial child molester groups in terms of their positions and relationship to victims (see Leclerc et al., 2015). For instance, the dynamics of child sexual abuse by acquaintances in educational settings are largely established on a hierarchical, and in most cases, trust-based relationship between perpetrator and victim. In other words, both child molesters in educational professions and intra-familial offenders are likely to abuse their either naturally or socially vested positions of authority to obtain victim's conformity to their sexual abuse behaviors.

Child molesters in educational professions may also be categorized as extrafamilial offenders (see Finkelhor, 1994a) because child molesters in educational professions are not related to victims by family/ kinship-ties, but related to victims through social interactions. However, the level of relationship (e.g., length and frequency) that child molesters in educational professions have with child victims is much greater than that of mere acquaintances under extra-familial offenders. Furthermore, child molesters in educational professions share certain characteristics with 
the intra-familial offenders with regard to the nature of their unique positions; both groups closely interact with potential child victims; and they pose less risk of physical injury (Balemba, 2010; Sullivan et al., 2011).

At the same time, similarities between professional and extra familial child molesters include the number of victims (more than one victim), a lack of social/ interpersonal skills, and low self-esteem (Cox \& Holmes, 2001; Stermac et al., 1989). Child molesters in educational professions are distinguished from intra-familial sex offenders (e.g., incest) in terms of offence patterns and overall personal characteristics. Nevertheless, these "very close" acquaintance perpetrators share some similarities with the intra-familial perpetrators; both groups of offenders played superiority or entitlement and tried to take advantage of their position of authority over child victims and victim vulnerability (Ward \& Keenan, 1999).

\section{Overview of Child Molesters in Educational Professions}

Similar characteristics between child molesters in educational settings and extrafamilial offenders were found in the level of sexual pre-occupations and emotional identification with children (Gilgun, 1994; Sullivan et al., 2011). Also, child molesters in educational professions were found to be distinguished from other sex offenders (see Simon, 2000) because they were less likely to have previous sexual convictions, more likely to prefer male children in their victim selection (male only and/or both male and female children), and prefer children aged eleven years or less (Leclerc et al., 2015; Sullivan et al., 2011). For instance, Sullivan and Beech (2004) found that the majority of child molesters in educational professions were accused of sexually abusing male children. 
Regarding the within-group differences among child molesters in educational professions, however, suggests that these are largely a heterogeneous group (Bard et al., 1989; Bickley \& Beech, 2001; Knight et al., 1989; Wortley \& Smallbone, 2006). They show a variety of offending patterns, victim selections, and even motives to join youthcentric organizations. Similar to the finding from Bickley and Beech's (2001) study, sexual offending patterns of child molesters were not consistent, and even though they had a high incidence of previous convictions, the majority of the charges were not related to sexual crimes (Banse et al., 2010; Zinley \& Zinley, 2009).

Offending patterns. Previous studies argued that the majority of child molesters were deliberate offenders (see Shoop, 2004; van Dam, 2001). For instance, Sullivan and Beech (2004) found that more than half of offenders in their study chose to work in youth-centric organizations in order to gain access to children to sexually exploit, however, this study did not specify the orientation of organizations such as religion, education, and leisure-oriented communities. Nonetheless, child molesters in educational professions plan ahead, even in a victim selection process, and therefore, they carry out offending behaviors in an articulated way so that the sexual activities are less likely to result in tangible physical injury against child victims (Erickson et al., 1988). Without the plan, offenders were more likely to follow coercive pathways to molest child victims and such a pattern stood out when molesters already had known the victims (Proulx, Perreault, \& Ouimet, 1999; Leclerc et al., 2005). Furthermore, Proulx et al. (1999) argued that those offenders who abused "known" victims were more likely to engage in sexual intercourse with their victims. 
Use of physical force. If a victim is injured from sexual abuse by a molester in an educational profession, the injury inflicted on child victims is likely to be a result of impulsive violence rather than planned violence. For instance, Balemba (2010) revealed that offenders who sexually abused children were likely to calculate their modus operandi, such as the use of force, before the crime took place. The offenders well acknowledged that child victims had no choice but to comply with their offending plans and to conform to sexual demands. Thus, child molesters usually know how much physical force they need if unforeseen factors, such as victim resistance, intervene in their criminal plots. When it comes to adult victims, however, the degree of victim resistance is an important determinant of the level of physical violence used by the offenders (Erickson et al., 1988).

The number of victims (e.g., single or multiple) also dictated the manner of sexual violence in general. For instance, sex offenders with one adult female victim tended to take manipulative approaches to their victims, while serial sex offenders set out to their crime with verbal threats (Corovic, et al., 2012). Single-victim rapists were more likely to consume alcohol before the act of rape than the serial rapist group. As a whole, single victim rapists tended to approach their victims in more intimate ways, while multiple victim offenders treated their victims as simply tools to reach to their sexual gratification, which led to additional crime, such as burglary and/or robbery (Scully, 1994). As will be discussed later, this pattern of using victims as an object was seen among child molesters who abused younger children (Lang et al., 1988).

\section{Grooming Strategies of Child Molesters}


Grooming is a premeditated and intentional behavior to manipulate the potential victim into complying with the sexual abuse, from gaining access to potential victims to achieving sexual gratification (John Jay College, 2004; Terry, 2013). Pryor (1996) indicated that child molesters' grooming behaviors included verbal and/or physical coercion, seduction, games, and enticements, and the most common grooming patterns are made through emotional and verbal coercion. Finkelhor and Williams (1988) revealed that child molesters in day-care profession positions used childcare curriculum, such as games and physical activities, as a part of their grooming strategies. By doing so, child molesters attempted to desensitize children to sexual behaviors, such as touching one's penis, and to normalize such activities. Such a wide spectrum of coercion using their position of authority is also commonly found among offenders who target child victims whom they already had known prior to sexual offence (Sullivan \& Beech, 2004).

Groth and Burgess (1977) revealed that child molesters' motivational intent underlying their grooming strategies was influenced by the nature and quality of the relationship to their victims. Oftentimes, child molesters who regarded their victims as a love-object employed enticement or entrapment to recruit potential child victims; the former employed persuasion or flattery to invite child victims to sexual relationships, and the latter involved bribing or rewarding the child with affection. By doing so, the victim's feeling of being indebted could overpower feelings of guilt regarding their cooperation with the offender. Similarly, Leclerc et al. (2005) also found a significant modus operandi of child molesters who had been involved in volunteer positions in youth-centric organizations; they gradually developed their grooming strategies to gain trust from victims and their families. Oftentimes, interacting with victims through 
positions of authority was regarded as an effortless activity among child molesters in educational professions.

\section{Offence Scripts of Sex Offenders}

As a part of offence script, physical environment was also found to affect sex offenders' decision-making in target selection processes (see Canter \& Larkin, 1993). For instance, Canter and Larkin (1993) revealed that the majority of sex offenders with more than one count of assault were more likely to display a marauder's pattern; they traveled from their home base to the surrounding region to find potential victims and to commit sexual offences. Similarly, Beauregard et al. (2007b) revealed that about $41 \%$ of their participants (i.e., incarcerated sex offenders against adult female victims) did not move their victims between the attack and the crime, and tended to choose an isolated area or victim's residence to carry out sexual offences.

Beauregard et al. (2007b) used a script approach in the analysis of the hunting process of serial sex offenders against adult female victims. In this analysis, Beauregard et al. (2007b) employed the hunting patterns of serial murderers that Rossmo (1997) presented in light of the methods of searching and attacking victims. The descriptive models of the offense processes for serial sex offenders suggested three different scripts with a couple of sub-ordinate tracks. The three scripts included the coercive script, the manipulative script, and the non-persuasive script based on searching/ approaching behaviors made to rape victims. Among those, family-infiltrator rape track was categorized under the manipulative script, and demonstrated offenders' efforts to not only gain trust from potential victims, but also to provide a favorable context for sexual activities once opportunities allowed. 
A study investigating crime-switching patterns by Leclerc, Lussier, and Deslauriers-Varin (2015) revealed that sex offenders who committed more than one sexual offence would not switch their offending behaviors from violent to seductive when interacting with their victims. To be specific, if an offender has used physical force against one victim, then it is less likely that the offender uses a different manner (e.g., seduction strategies) to commit another crime against another victim. This finding is consistent with the behaviors of serial sex offenders in stranger rape cases that they exhibited stable behavioral patterns across all victims (Hewitt \& Beauregard, 2014). Nevertheless, child molesters tended to use different strategies during the crime event from offenders with adult female victims. Especially, those who had male child victims showed little fluctuation in the degree of their violent behaviors to engage in sexual contact with their victims (Hewitt \& Beauregard, 2014).

\section{Typology of Child molesters in Educational Professions}

Although a large number of previous studies consolidate child molesters in youthoriented organizations in one category, child molesters in educational professions, it is necessary to recognize child molesters in educational professions differently by the nature of their professions. In other words, child molesters in educational professions should be further disaggregated based on the orientations of their positions to interact with children, such as vocational, voluntary, and clergy positions. The child-focused occupation benefits the vocational child molesters with easy access to child victims and trust and credibility from the victims. Different orientations of vocation can help explain the initial motives of child molesters whether they deliberately choose a certain 
profession for the purpose of molesting children or their criminality has developed and grown according to work environment surrounding the offenders.

To be specific, child molesters who are engaged with children through vocational positions will be referred to as "vocational child molesters" in this study. At the same time, child molesters who are from religious orders will be addressed as "clergy child molesters." While ample studies of child molesters in educational professions have been conducted, few studies have sufficiently examined volunteer child molesters as an independent subject by analyzing their behavioral patterns and offending strategies. For instance, Denny (2015) identified offender roles within Protestant Churches, and the least frequent offender roles were church camp workers and volunteers. This study also indicated other types of volunteer positions, such as Youth volunteers, however, did not define them as an independent offender group, but did examine them as an all-inclusive subject for child abuse cases within religious settings.

Furthermore, studies on voluntary workers who molested children in their charge largely classified offenders' behaviors in quantified measures by using subtle distinctions between volunteer and vocational molesters (see Leclerc et al., 2005). In the following, details of existing studies regarding vocational, clergy, and volunteer child molesters will be delineated based on the unique characteristics of their positions.

Vocational child molesters. Child-focused organizations (e.g., daycare facilities) have become increasingly concerned about the threat posed by some of their employees to the children under their care (Finkelhor \& Williams, 1988; Finkelhor \& Ormrod, 2001; Sullivan et al., 2011). Various studies examined the characteristics of vocational child molesters, offending patterns, and unique situational dynamics the vocational child 
molester have encountered while holding dual positions, one as caregiver and the other as motivated child molester.

Vocational child molesters, in this context, are referred to as perpetrators who worked in childcare and/or educational facilities. Although the majority of vocational child molesters prefer solo work, some also carry out sexual abuse offences as a group. The combinations include childcare workers with their family members, with outsiders, and with other staff members (Finkelhor \& Williams, 1988). As for their gender, the majority of vocational child molesters were made up of male offenders (Moulden et al., 2007), which is not different from global child molester characteristics. In addition, similar to other child molesters, the vocational child molesters are usually known as a well-planned group of sex offenders (Shoop, 2004).

Characteristics of vocational child molesters. Finkelhor and Williams (1988) argued that the majority of the sexual abuse cases committed by vocational child molesters were opportunistic in nature rather than premeditated. It was because victim selection was largely determined by victim availability and vulnerability instead of preference (Guay et al., 2001). In other words, vocational child molesters' preference for victim gender or age is general rather than specific. Terry (2015) also emphasized the importance of situational influence on victim selection patterns of vocational molesters. Along similar lines, it was not the pre-existing relationship to the victim and victim gender, but the contingent situation/ environment that affects the level of physical violence adopted by vocational child molesters in the course of sexual abuse (Moulden et al., 2007). 
Research indicated that the reason for victimization of younger children (age seven or younger) was not based on their gender, but based on their small and immature physical figure (Finkelhor \& Williams, 1988; Lang et al., 1988). Thus, the gender of victim was found to be less important for child molesters until the child victims became old enough to develop distinctive gender-based characteristics (Carlstedt et al., 2009). In most cases, older victims were more often subjected to offenders' actual orgasmic sexual acts (Lang et al., 1988). Another classification that places child molesters into an extrafamilial group is the number of victims. Similar to the career criminals among extrafamilial offenders, vocational child molesters rarely stay with one victim; some vocational child molesters had at least 20 and more victims (Finkelhor \& Williams, 1988; Sullivan et al., 2011; Terry, 2015).

Little difference was found in reported personal experience, such as experiences of sexual abuse in childhood, between vocational child molesters and other sexual offenders. This finding resonates with Scully's (1994) study that indicates little differences in childhood experiences between convicted rapists and other felons. However, other studies identified the impact of childhood sexual abuse on male child molesters' offending behaviors; sexual victimization was greatly stigmatizing to males, and child victim were likely to develop confused sense of physical and sexual space with others as they grew up (Finkelhor, 1994a; Pryor, 1996; Scully, 1994; Weiss, 2010).

Overall, researchers acknowledged that child molesters were a diverse group in various aspects, such as personal characteristics, life experiences, and criminal histories (Bickley \& Beech, 2001; Finkelhor, 2009; Terry, 2013). Adding to this heterogeneity in the characteristics of child molesters, vocational child molesters were less likely to have 
previous sexual convictions or reported criminal history than other sex offender groups (Sullivan et al., 2011). A lack of official criminal records serves as one of the obstacles for youth organizations to effectively screen their potential employees and/or volunteers. Furthermore, combinations of shared between-group variances among child molesters (e.g., vocational child molesters and other offenders) and unshared within-group characteristics among vocational child molesters (e.g., a lack of previous convictions) make it more difficult for youth-centric organizations to acknowledge employees' criminal propensity to victimize children through recruiting processes.

Advantages of vocation. The unique nature of their social positions as caregivers also made it difficult for child molestation to be recognized and reported to higher authorities. For instance, an initial yet integral grooming pattern displayed by vocational child molesters was to familiarize themselves with victims rather than threaten them. For instance, vocational child molesters tended to employ manipulating approaches rather than assertive ones when they found potential victims by using their position of trust (Leclerc et al., 2005). Such a friendly way of grooming eventually yields victims' compliance to offenders' criminal plan.

Through repeated desensitization and manipulation processes, vocational offenders are able get their victims involved in sexual activities with little risk of being told on because the victims become reluctant to disappoint or hurt their perpetrators (Leclerc et al., 2005; Young, 1997). Sometimes, child victims might think that no one was going to believe their victimization, or they were simply incapable of distinguishing the underlying intentions in vocational child molesters' behaviors (Pryor, 1996; Terry \& Ackerman, 2008). Consequently, as one of the unique casualties of child molestation 
committed by acquaintances, trust-based pre-existing relationships between victim and offender could double the victim trauma due to the feelings of betrayal and being manipulated (Fater \& Mullney, 2000; Pryor, 1996).

Vocational child molesters can gain a great degree of trust from their young victims. Prentky et al. (1997b) discussed that the amount of contact with children that were made by vocational child molesters could serve as a risk assessment tool. However, it is also noted that the majority of the vocational child molesters can take advantage of their position of authority to freely be alone with young victims (Shoop, 2004). Similar to the reasons for underreporting of female rape cases committed by acquaintances, such as self-blame, fear of stigma, and retaliation (Scully, 1994), the trust vested in their molesters kept child victims from reporting their victimization. Equally importantly, offenders who hold positions of authority are easily able to gain the trust of victims and their family members (Terry, 2008). Such factors allow the vocational child molesters to continuously abuse children under their charge.

Effort to prevent vocational child molestation. Abel et al. (1994) suggested that a major proactive step to reduce the risk of child molestation within youth organizations is to exclude child molesters from being in positions of power over children. However, the caregiver offender groups also made it hard for not only the institutions, but also law enforcement agencies to detect their abnormal interest in children under their care. It was because of the nature of their career that granted unlimited and unguarded access to victims (Colton et al., 2010). For instance, one of the benefits of youth organizations for sex offenders is that they can be continuously provided with child victims with the least risk of being caught (Leclerc et al., 2015). Furthermore, vocational molesters (e.g., 
caregivers), who usually employed manipulative approaches, easily discarded their victims after they lost their interest in the victims, and moved onto another target because the abundance of resources (Shoop, 2004).

Clergy child molesters. This group of child molesters is different from the other two offender varieties in terms of the purpose of joining priesthood, grooming strategy, and victim types. White and Terry (2008) argued that the intention of the Catholic clergy child molesters to join the priesthood was different from that of vocational child molesters in most educational institutions (e.g., childcare and schools). Sexually abusing children does not serve as a primary reason for the clergy child molesters to enter priesthood in the first place, which helped categorize clergy child molesters as regressed sex offenders rather than fixated ones. In other words, it might not be the persistent tendency that the clergy child molesters had carried prior to priesthood, but the situational factors that may have shaped and influenced their interest in sexually abusing children under their care. Similar to the vocational child molesters, however, the clergy child molesters were found to be generalists rather than specialists for their indiscriminate preferences on victim age and gender (Terry, 2015).

Nevertheless, it was also argued that the clergy molesters with multiple victims and fixated offenders still shared some similarities with regard to preference for male victims and an early onset of sexual behaviors (Groth et al., 1982). The clergy offenders with the most number of victims were found to have an earlier onset of sexual offending behaviors (Calkins-Mercado et al., 2008). At the same time, however, overall clergy child molesters were reported to have a late onset of deviant sexual behaviors; they also had a low incidence of chronic sexual offending. They were less likely to commit 
stranger abuse and to maintain networking among themselves; clergy child molesters rarely used pornography or displayed paraphilic behaviors (Terry \& Akerman, 2008).

Child molesters as a whole utilized grooming techniques when initiating sexual behaviors with child victims. The grooming patterns include verbal and/or physical coercion, emotional manipulation, seduction, games, and enticements (Proulx et al., 1999; Pryor, 1996). Clergy child molesters, however, used spiritual manipulation in addition to the aforementioned general grooming techniques (Farrell \& Taylor, 2000; Father \& Mullaney, 2000). They prefer isolated locations when carrying out sexual abuse behaviors against children, such as residence of the clergy, church (John Jay College, 2004), off-site such as victim's home, vacation home, school, and car, and offsite church-sponsored activity (Denny, 2015; Terry \& Ackerman, 2008), which reflected the secretive nature of child molestation (e.g., low risk of being reported) among the clergy child molesters. In most cases, the victims are usually alone with offenders during the sexual events. Such crimes committed by authorities are rarely detected due to their unique characteristics (e.g., solitary offender, isolated place, and spiritual manipulation) that hinder victims from seeking external assistance.

Similarly, the difference in offending behaviors between clergy molesters and non-clergy offenders was determined by victim gender (Terry, 2015). It should also be noted that the majority of clergy molesters only had a single sexual offence allegation (Calkins-Mercado et al., 2008), which was consistent with the majority of intra-familial child abusers (Erickson et al., 1988). However, clergy offenders who had molested multiple victims tended to target male children when compared to the priest molesters with a single victim (Calkins-Mercado et al., 2008). Such characteristics of clergy child 
molesters were consistent with those of fixated offenders who were more persistent in their sex offending behaviors throughout their criminal careers. In addition, Denny (2015) argued in his typology of child molesters in Protestant churches that the groomers, similar to opportunists, were likely to choose female adolescents as their potential victims; and child molesters with multiple victims overall displayed preference for both female and male victims. However, even this group of molesters preferred female adolescent church members as their victims if opportunity allowed.

Due to the profession of clergy molesters, their crimes largely remain unreported or underreported, and therefore, this group of molesters is rarely detected by the criminal justice system (Terry, 2013). Unique aspects of child molesters who hold a position of authority in their capacity have been measured and analyzed in various ways.

Accordingly, some previous findings were not agreeable with one another (e.g., onset of sex offences), while the majority of them were congruent (e.g., absence of sex-related criminal history). Furthermore, it is essential to divide child molesters according to one criterion: whether the molesters come into contact with their victims through their paidwork, or through volunteer work. Doing so is expected to help design more situationalbased and behavior-focused prevention and interventions strategies to fight sexual molestation against children in youth-centric institutions and organizations.

Volunteer child molesters. As previously mentioned, child molesters in educational professions have been examined as a whole, instead of being specified and separately examined by the nature of their positions, whether voluntary or vocational. Volunteer child molesters, such as the Boy Scout leaders and Big Brothers Big Sisters mentors, are different from vocational molesters in certain ways. Since their position in 
youth organizations was not vocation-driven, their intention to join youth organizations, their social positions outside voluntary organizations, and even victim gender preference can explain their unique criminal patterns. For instance, unlike vocational and clergy molesters whose work environment may have shaped their interest in sexually abusing children, the intention of voluntary child molesters to join youth organization may have been due to their criminal plans and they may have participated in volunteer work in youth-centric organization to seek out the opportunities. Such unique characteristics of volunteer molesters will be closely examined and analyzed in this dissertation by focusing on the behaviors at the physical contact stages.

Taken together, the intention of child molesters who voluntarily join youth/ childcentric organizations should be closely yet distinctively examined from those molesters who are involved in vocational and/or religious youth organizations. It is noted that child molesters studied in previous literature came into contact with their victims primarily through their vocation such as childcare services and schools. However, the scout leader molesters came into contact with their Boy Scout victims through their avocation. That is, this slice of their life represented extra curricular activities from their normal duties/ life obligations, which indicated that one of their primary purposes of joining the Boy Scouts of America was access to boys, the most suitable targets.

\section{Reasons for Child Molestation}

Researchers have used behavioral, cognitive, psychological, and social approaches in an attempt to understand the reasons for child molestation (Terry, 2013). Furthermore, researchers from a variety of disciplines have examined motivation and intent of child molesters as to why they aim at under-age victims for their sexual 
gratification (Bickley \& Beech, 2001; Groth \& Burgess, 1977). In the meantime, offenders' behaviors were at the center of attention for analysis to determine their potential risk factors and effective offender treatment strategies (Abel et al., 1994). A primary reason for child molestation identified in the previous studies is some sense of personal vulnerability, such as social incompetence and low self-esteem (Gilgun, 1994; Marshall, Marshall, Sachdev, \& Kruger, 2003; Milner \& Webster, 2005; Marshall, Champagne, Brown, \& Miller, 1997; Terry, 2013).

Social incompetence. The overall profiles of child molesters indicate that they are most often males who have never been married and with previous criminal convictions (Guay et al., 2001; Hanson et al., 1993; Moulden et al., 2007). When it comes to the details of offending characteristics, such as victim selection patterns, a large portion of their offences was attributed to their perceptions of children and difficulties in maintaining healthy relationships with same-aged partners.

For instance, Gilgun (1994) identified different types of relationships with child victims from the perpetrators' point of view. The result indicated that not all child molesters intended to harm children. Rather, some actually believed their behaviors were out of love, while some used child victims as an object of vengeance, control, and conquest, which indicated that emotional starvation and socialization practices might be factors leading to sexual perpetration against children. A study also revealed that offenders' personal vulnerabilities increased the risk of abuse in conjunction with situational stressors and opportunities to abuse among clergy molesters (Terry et al., 2011 in Terry, 2015). Bard et al. (1987) revealed that child molesters had significantly lower verbal and performance IQ scores than rapists. Milner and Webster (2005) saw a sense 
of worthlessness as the most prevalent feelings among child molesters when compared with rapists or violent offenders. Similarly, Marshall et al. (2003) also argued that child molesters had significantly lower self-esteem than nonsexual offenders.

Low self-esteem. Pryor (1996) discovered that child molesters were experiencing transition in their roles when they started making sexual contact with victims. That is, they were dissatisfied in their roles as spouses, parents, and employees, which diminished their sexual satisfaction with their partners and increased obsessions with unconventional sexual activities as a way of compensating for their low self-esteem (Pryor, 1996). Gilgun (1994) also argued that not all child molesters had a primary or sole sexual interest in children, and many would be expected to be primarily interested in adult women. Findings from previous studies largely discussed offenders' unstable social status or relationships with other people as one of the major reasons for child molestation. Such feelings of low self-esteem shaped offenders' perceptions of children to be displayed in the form of emotional congruence or abusive behaviors over vulnerable targets (Finkelhor, 1984; Terry, 2015; Wilson, 1999).

Emotional congruence, as a reason for sex offenders' preference for children, was found to be an exaggerated emotional affiliation with childhood (Finkelhor, 1984); and usually resulted from a lack of maturity and social skills affecting offenders' ability to relate to children better than to their age-mates (Terry, 2015). Similarly, Stermac et al. (1989) stated that child molesters were predominantly unskilled and poorly educated. However, Wilson (1999) revealed that such a tendency displayed differently between homosexual and heterosexual child molesters; the former was more likely to interact with 
children on the child's level, while the latter tended to bring child victims' status to an adult level.

\section{Factors that Influence Offending Patterns}

Previous studies have shown that personal vulnerability led child molesters to the sexual offending behaviors against children through various channels. Such findings then raise a question of how the child molesters carry out their crimes, such as modus operandi, and what factors are there to affect child molesters' offending behaviors including victim selection. As a review of previous literature discussing offending patterns employed by child molesters, this section will introduce factors found to be significant in determining offenders' modus operandi. The factors include sexual fantasy, situational factors, the use of substances, and victim characteristics.

Sexual fantasy. Child molesters are known to be heterogeneous (Finkelhor, 2009; Terry, 2013) and seemingly to carry out premeditated offences (Shoop, 2004). These characteristics label child molesters as an offender group that is fixated and preoccupied with a great extent of sexual fantasy of children (Guay et al., 2001). For instance, sex offenders who were obsessed with sexual fantasy were more apt to be premeditated and repetitive in performing their offending behaviors. Such organized and elaborated manners enabled them to successfully convert their sexual fantasy to real behaviors (Deu \& Edelmann, 1997).

However, sexual fantasy obtained from exposure to pornographic materials prior to the offence did not affect the offenders' modus operandi, such as the level of the use of physical force against and the level of injury inflicted on victims. Similarly, Proulx et al. (1999) found that those who did not use coercion against child victims had been exposed 
to pornography and had deviant sexual fantasies prior to the crime-commission stage. However, these non-coercive offenders usually selected stranger victims who had been unknown to them (Proulx et al., 1999). When it comes to victim selection, offenders' desire for victims as a result of their fantasies and the unavailability of preferred victims may push child molesters to choose children who are conveniently situated (Guay et al., 2001). While the use of sexual fantasy tools, such as pornography, was found to be less associated with the aforementioned coercive modus operandi, exposure to such sexualoriented materials before setting out to sexual violence influenced the offenders' goal of sexual abuse (i.e., sexual gratification) that often led to the involvement of genital penetration (Beauregard et al., 2005).

As for the severity of injury, genital penetration is considered the most severe level of sexual abuse against children (Leclerc, 2009). The level of injury inflicted on the victims is also affected by an offender's approach patterns to child victims. For instance, if manipulated approach was used at pre-crime stages (grooming), penetration is less likely to occur even though there was a certain degree of resistance employed by the victim (Leclerc, 2009). However, if an offender is occupied with deviant sexual fantasies related to the very victim within 48 hours prior to the offense, the offender is more likely to make the victim participate in the sexual behaviors and perform penetration (Leclerc et al., 2009).

Situational factors. Situational variations were found to be influential to sexual offending patterns including victim selection of child molesters in educational professions. Situational factors identified in previous research varied. For instance, one study revealed that situational factors played fundamental roles in the perpetration of 
sexual crime (Terry, 2008). Simply put, almost all child molesters tend to employ certain grooming patterns to entice children to comply with their sexual offending plans (Terry, 2008).

Researchers have examined offender mobility and locations associated with offending patterns. For instance, one study found that some child sex offenders used multiple locations to maintain repetitive sexual contact with the same victim (Leclerc et al., 2010). When examining the distance between the offender residence and the offence location distance, about $70 \%$ of sexual re-offence took place within one-mile proximity of an offender's home or at victims' homes (Duwe, Donnay, \& Tewksbury, 2008). However, the offenders' contacts with victims less than 18 years old often occurred in the locations more than one mile away from the offenders' residence. Furthermore, the reoffence locations were not found to be near child-concentrated areas, such as school, playground, and park (Duwe et al., 2008). Similarly, Warren (1998) argued that distance travel to offend of serial rapists varied by offender demographics, crime scene behaviors, and aspects of prior criminal histories.

A study of 69 serial sex offenders and their crime locations revealed that the use of residential areas for the encounter and the crime appeared to be relatively consistent while the use of commercial areas were not (Harbers et al., 2012). This finding suggests that even though such surroundings served as good supplies of potential victims, those locations presented potentially more unforeseen situational factors (e.g., witnesses) that could interfere with the crime (Harbers et al., 2012). The risks of sexual victimization decreased when victims were more involved in activities with strangers or casual acquaintances, and when greater proportions of time were spent alone by victims 
(Mustaine \& Tewksbury, 2000), which is consistent with the previous findings on the danger of vocational child molesters that they are vested in being alone with children, and the amount of time spent together was associated with the increasing risk of victimization.

Sex offenders who frequently move locations are likely to isolate their victims, to use violence against them, and to spend time with them; all these patterns increase the likelihood of multiple sexual offences with one victim and victims' performing sexual behaviors on the offenders regardless of victim's willingness (Leclerc et al., 2010). Meanwhile, child molesters as a whole tended to use a single location in order to minimize the risk of interruption or the intrusion of capable guardians who might detect them in transit across locations. Consequently, sex offenders in a single location are better able to control their victims and to continue the abuse with little concern for interruption (Leclerc et al., 2010).

The modus operandi of child molesters who voluntarily participated in youth services was influenced by their position of authority/trust (Leclerc et al, 2005). Although Leclerc et al.'s study utilized a small sample (i.e., 23 incarcerated sex offenders), these offenders in a position of trust adopted manipulative rather than assertive and/or aggressive manners to elicit child victims' submission such as gaining their trust and having them participate in sexual activities (Leclerc et al., 2005). Such a modus operandi was found to have a strong effect on the outcome of the sex crime (Leclerc et al., 2009). The older the child victim was, the more likely the molester was to make his victim participate in sexual activities during the crime (Leclerc \& Tremblay, 2007; Leclerc et al., 2009). However, when combining both victim gender and age, child 
molesters were less likely to apply such strategies to boys than girls; the offenders were more likely to succeed in making male victims participate as the victims get older, and an opposite trend was found in female victims (Leclerc et al., 2009).

While child molesters were known for their preference for isolated locations to avoid unforeseen interruption, McKillop et al.'s (2015) findings indicated that the majority of sexual offences occurred in another person's presence. This third party, however, does not perform a guardian's role to stop the crime because their presence was not close enough to directly witness the crime. It was also found that child molesters within familial contexts were less concerned about the risk of being witnessed when they were situated with witnesses in the same location (McKillop et al., 2015). Furthermore, simple bystanders nearby the crime scene did not entirely affect perpetrators' decisionmaking processes to crime.

Offenders' behaviors and strategies also differ by situational factors prior to and during criminal episodes (Balemba, 2010). Factors related to pre-crime phase include offenders' emotional state, the use of substances, and external stressors; crime-event phase factors are victim resistance, unanticipated events, and a lack of offender's experience dealing with contingent situations (Douglas, Burgess, Burgess, \& Ressler, 1992). For instance, since manipulative strategies adopted for pre and during crime events require a certain level of premeditation, motivated sex offenders are less likely to stop from achieving their gratification (e.g., penetration) regardless of the level of victims' resistance or cooperation (Leclerc et al., 2009). Furthermore, situational circumstances were found to have a significant impact on victim selection criteria, such as victim gender in child molestation cases (Terry, 2015). 
By examining 118 incarcerated sex offenders who victimized females aged 16 or over, Beauregard et al. (2005) investigated the role of sexual interest and situational factors to offenders' modus operandi such as the level of organization of the offence, the level of force used by the offender, and the level of injury inflicted on the victim during the sexual assault. Likewise, this study revealed that the situational factors had a greater influence on offenders' modus operandi, such as sexual aggression during the rape; a combination of situational and contextual factors (e.g., substance and anger) could affect the degree of sexual assault (Beauregard et al., 2005). Leclerc et al. (2009) emphasized that situational factors should be taken into consideration in sex crime studies and accordingly focus on microenvironment where such offending behavior was taking place (see also McKillop et al., 2015).

Other studies examined rapists' behaviors over time and distinguished the preferential sex offenders whose motivations were originally influenced by abnormal sexual desires from the opportunistic situational sex offenders (Bickley \& Beech, 2001; Hazelwood, Reboussin, \& Warren, 1989). Also, sex offenders who rarely move their crime locations are largely made up of acquaintances including victim's immediate family because they have opportunities for contact with a vulnerable person (Leclerc et al., 2010).

Similarly, Finkelhor and Williams (1988) argued that much of the abuse within the aforementioned social settings were more likely to be opportunistic in nature than premeditated as far as victim availability and vulnerability allows. Therefore, if those opportunistic molesters had not placed in the setting where they could maintain close proximity to and constant interaction with children, child sexual abuse within child- 
oriented facilities is much less likely to occur. Thus, findings from previous studies regarding the associations between sexual violence and environment provide an idea that opportunistic child abuse can be mediated by situational and environmental factors (Finkelhor \& Williams, 1988).

Use of substances. Some researchers regarded the use of substances as an integral factor to determine overall sexual offending patterns. For instance, sex offenders' alcohol consumption prior to crime could predict an increase in the level of offenders' physical aggressiveness during the commission of the crime, and eventually increase the risks of victim injury and penetration (Abbey, Clinton-Sherrod, McAuslan, Zawacki, \& Buck, 2003; Chene, 2000 cited in Beauregard et al., 2005; Ullman \& Brecklin, 2000). Hamdi and Knight (2012) also argued that child molesters' use of alcohol was found to be positively associated with the level of aggression. However, by analyzing official reports from 305 Canadian sex offenders who had served as childcare providers at the time of offense, Moulden et al. (2007) revealed that the sexual violence by the caregiver offender group was hardly influenced by the use of substance.

Brecklin and Ullman (2010) conducted a study on the influences of substances on sexual assault outcomes against adult female victims when both offenders and victims were under influence of substances. Even though the data was limited to self-reported survey, this study was significant in its inclusion of adult female victims of sexual assault to examine the dynamics in crime scenes. The findings suggested that victims who had consumed substances were likely to be assaulted by offenders who were also using substances. However, victims rarely used substances if offenders did not use them (Brecklin \& Ullman, 2010), which could explain that both parties were usually situated in 
the same social settings or involved in the similar activities when sexual offences occurred.

Victim injury more often occurred in the assaults carried out by offenders under the influence of substances (Brecklin \& Ullman, 2010). From serial sex offenders on stranger rape, Beauregard et al., (2007a) argued that offenders used drugs and alcohols to avoid victim resistance. However, Hamdi and Knight (2012) showed that victim's use of substances and offender's use of drugs were more likely to result in the aggressive rape cases. However, in the cases of child molestation within educational settings or youthoriented organization, there is a slim chance of involving substances because offenders may be less likely to be intoxicated at work (Moulden et al., 2007).

Victims' reaction. Victim physical resistance during the commission of a sexual offence increased the risk of sexual and physical injuries (Brecklin \& Ulliman, 2010; Balemba et al., 2012). Offenders' modus operandi in sex crime is referred to as their collective behavioral patterns to secure a victim's compliance for easy operation of sexual offending behaviors (Leclerc et al., 2009; Sjostedt, Langstrom, Sturidsson, \& Grann, 2004). To do so, sex offenders need to employ certain behaviors, such as manipulation and/or seduction, not only to have their victim participate in the criminal events, but also to minimize the risk of victim resistance (Leclerc et al., 2009). In relation to victim resistance, Hazelwood et al. (1989) found that assertive rapists against adult females were more easily aroused by aggressive manners of victim resistance, such as physical fighting, while the tentative rapists would be more aroused by the opposite fashion of victim behaviors such as submission and confusion (Hazelwood et al., 1989). 
Some studies supported that forceful resistance strategies were effective not only in avoiding sexual abuse (e.g., rape), but also in decreasing physical violence (Ullman, 1998). For instance, Ullman and Knight (1993) examined the interactions between the characteristics of offence (i.e., the use of weapon and locations) and specific resistance behaviors posed by victims (i.e., fighting and screaming) in adult female stranger rape cases. If a victim resists forcefully (e.g., physical fighting) against violent physical attack, it is likely that the risk of both sexual assault and physical injury decreases, regardless of presence of a weapon. In contrast, Leclerc et al. (2009) indicated that aggressive behaviors employed by the victim were likely to increase offender's physical force, which also resulted in more severe injury on victims. In a similar vein, Hewitt and Beauregard (2014) found that victim resistance made offenders employ physical force greater than necessary to subdue their victims.

Non-physical resistance employed by victims may enable the victim to avoid sexual abuse, however, may not prevent the chance of physical injury. For instance, Ulliman and Knight (1992) revealed that passive ways of resistance (e.g., pleading, crying, or reasoning) during rape increased the likelihood of physical injury. In child molestation cases, older child victims more willingly participate in sexual contact with the offenders in exchange for monetary rewards and/or for substances without causing any physical resistance (Leclerc et al., 2010). Interestingly, non-physical resistances in adult rape cases were found to be ineffective in both isolated and public locations (Ulliman \& Knight, 1993). However, according to Leclerc, Wortley, and Smallbone (2011), both physical and non-physical resistance strategies were more likely to be practiced by younger girls (age 11 or younger) and their verbal and emotional resistance 
(e.g., crying, saying they were scared) were more effective than when practiced by older girls.

When weapons were involved, screaming might be helpful to avoid severe sexual abuse, however, fleeing might exacerbate the situation resulting in more physical injury. However, overall, offenders' use of weapons resulted in less resistance from victims, hence, less use of physical force (Hewitt \& Beauregard, 2014). By and large, forceful resistance strategies were successful in lessening the risk of rape. Nevertheless, the majority of previous studies failed to identify the detailed degree of resistance techniques, such as the appropriate level of force, and to suggest the exact timing to carry out such strategies to effectively reduce the risk of severe injury from both sexual and physical assault.

Balemba (2010) revealed that a violent way of persuasion employed by the offender increases physical resistance by adult victims, which in turn increases the risk of offenders' using physical violence. Similarly, when a weapon was involved, victim's resistance can increase the likelihood of violence by the offender. At the same time, offenders without weapons reported that they were less likely to anticipate victim resistance, which reflect the finding that sex offenders commit their crimes based on rational choice (Balemba, 2010).

Overall, it was noted that situational factors were found to have more impact than offenders' original modus operandi to the level of intrusiveness of sexual offending behaviors (Hewitt \& Beauregard, 2014). Even though aggressive resistance by the victim increased the likelihood of the offender's intrusive sexual abuse (Leclerc et al., 2009), victims were less likely to be incapacitated at the time of offence due to the offender's 
fear of incompletion of sexual gratification (Leclerc et al., 2009). However, it is also noted that if a potential victim confronted a child molester in an educational profession, the molester was less likely to continue the grooming. Rather, s/he tended to move and search for another victim, who was less assertive and more submissive (Shoop, 2004).

Victims' gender and age. In addition to the situational factors that influenced offending patterns at crime scenes, some researchers also argued that victims' characteristics could affect sexual offending patterns of child molesters. Victim characteristics refer to victim age and gender in this section. These were found to affect offenders' grooming patterns, the use of physical aggressiveness, and sometimes, victim selection.

Victim gender and age were found to have strong effects on the outcomes of sexual offences, such as penetration. Victim age is largely used to distinguish rapists (adult victims) and child molesters (Robertiello \& Terry, 2007) as well as to identify offenders' mental state. For instance, child molesters who attack victims less than six years old were more likely to have emotional problems, substance abuse problems, and psychiatric disorders when compared to offenders who targeted victims aged between 1216 years old (Firestone, Dixon, Nunes, \& Bradford, 2005). Also, offenders with older child victims were more intrusive in making sexual contacts with their victims than those with younger victims, and as mentioned previously, older child victims were more likely to be treated as sexual partners than younger victims (Erickson et al., 1988).

Penetration is regarded as the most severe outcome of sexual offence (Carlstedt et al., 2009). As for victim gender, Leclerc et al. (2009) argued that if an offender targeted a male child as victim, it was less likely that the offender's ultimate goal was genital 
penetration, while adult male victims were more likely to sustain physical injuries, such as rectal trauma (Erickson et al., 1988). However, the prevalence of penetration was found to be common in both children aged between 0-5 years old (both boys and girls) and the older victims (higher proportion of boys than the other groups; Carlstedt et al., 2009), which indicated the indiscriminating characteristic of small children with regard to their gender.

The physical-sexual immaturity of child victims may be a primary focus for child molesters, which made the offenders employ a variety of seduction strategies to draw immature child victims' compliance (Lang \& Rouget, 1988). A study found that an offender with a male victim was more likely to be consistent in the victim's gender (Harbers et al., 2012). However, when the victim was a male child in an older age group, the offender was more likely to use manipulation/persuasion techniques to foster his victim's participation in the course of sexual abuse (Leclerc et al., 2009). Erickson et al., (1988) revealed that child molesters tended to use younger victims as impersonal masturbatory aids. Meanwhile, older male victims were seen more gender-focused and expected to perform sexual partner roles regardless of the victims' reluctance (Erickson et al., 1988).

Vocational child molesters were found to be significantly more likely to choose male, or both male and female children for their targets compared to intra-familial offenders (Sullivan et al., 2011), which was inconsistent with some other studies indicating that vocational molesters showed little preference on victim gender (see Erickson et al., 1988; Finkelhor \& Williams, 1988; Sullivan et al., 2011). According to Finkelhor and Williams' study (1988), of more than 2,500 children of sexual abuse cases 
that had occurred in daycare facilities, male child victims constituted about $38 \%$ of the entire cases, which was higher than the $20 \%$ of male child victim population among general abuse victims.

A previous study further examined the unique social circumstance of child molestation in youth-centric facilities by using preschool aged children who were under seven years old (Finkelhor \& Williams, 1988). Some studies revealed that the most vulnerable age of child victims was between 7 and 13 regardless of their gender (Finkelhor, 1994a; Topping \& Barron, 2009). Also, Erickson et al.’s (1988) study examined 568 child molestation cases committed by 229 male child molesters who had targeted children under 14 years old between 1975 and 1984. Of those, $70 \%$ of the offenders had female child victims and about $26 \%$ molested male children. Among the male victims, about half of them were aged between eleven and thirteen, while a quarter of them were less than 6 years of age. Finkelhor and Williams (1988) discussed that more male children in daycare were sexually abused regardless of gender-based characteristics, and this finding is consistent with the aforementioned prevalence of male victims in vocational child molestation. Hence, it can be inferred that sexual abuse against small children was more or less opportunistic rather than preference based and spontaneous rather than premeditated. Furthermore, it might not be the victim's gender that attracts child molesters to sexually abuse boys, but the victim's unique physical characteristics (e.g., small and portable) that appealed as more suitable target to motivated child molesters (Finkelhor \& Williams, 1988).

\section{Prevention of Child Molestation}


As researchers have paid a great amount of attention to the characteristics of child molestation (e.g., offender characteristics and modus operandi), many also have attempted to identify factors that could effectively prevent molesters' offenses against children. Studies thus far have suggested various preventative strategies based on those recognized factors. In most incidences, prevention of child sexual abuse is mostly delivered to children through school-based child sexual abuse prevention programs; such programs have taught children how to protect themselves (Finkelhor et al., 1995; Leclerc et al., 2011). This section will mainly discuss the overview of child victims' selfprotection/ prevention strategies. Such victim reactions are assessed by victim age and gender (Finkelhor, 2009). In addition, different theoretical channels to approach sexual violence will be addressed. Those studies were conducted in an attempt to create the best conditions to design and implement sexual violence prevention strategies (programs).

Self-protection by victim age. The efficacy of self-protection strategies used by child victims was one of the main focuses in child sexual abuse studies (Leclerc et al., 2011). As offenders' grooming strategies receive different reactions from child victims, regardless of the nature of the actions, victim resistance also affects offenders' behavior while sexual violence is occurring. For instance, Balemba (2010) revealed that victims who were sixteen and over faced more violent reactions to their resistance when compared to victims who were twelve years old and younger.

When it comes to the effective implementation of prevention strategies, younger girls were found to be more capable of effectively applying particular strategies than older girls. In other words, younger girls who were taught self-protection strategies tended to use the techniques and be more protective of themselves than older girls 
(Leclerc et al., 2011). However, it should be noted that the majority of studies did not specify where and how children learned such resistance strategies.

Younger girls were more vulnerable than older girls to manipulative approaches carried out by child molesters, which suggested child victims' vulnerability by their age and gender. In stranger-involved child abuse cases, older girls were susceptible to manipulative offenders who offered them money, alcohol, drugs, and other favors in return for sexual contact with them, which rarely involved physical violence from the offenders (Leclerc et al., 2010).

Theoretical approaches. To develop prevention programs, researchers have attempted to understand the strategies used by child molesters (Repucci \& Hauggard, 1989). Previous studies employed several different theoretical frameworks; and the different approaches were largely taken from Routine Activity theory, rational choice theory, and social disorganization theory. For instance, Finkelhor and Williams (1988) revealed that child molesters chose suitable victims based on availability and visibility to the perpetrators themselves. Vocational molesters in particular were fully aware that their work place served as a continuing source of victims; they were less likely to plan ahead but act according to the opportunity available to them (Finkelhor \& Williams, 1988). However, most of the youth-centric organizations only conducted a one-time screening process based on official reports (e.g., criminal background check) for deterrence purposes, rather than identifying potential offenders in various manners such as in-depth interview (Sullivan et al., 2011).

A study by McKillop et al. (2015) revealed that child victims' age and their activities created victimization opportunities; offenders also tended to take advantage of 
such opportunities arising in the context of everyday lives in their capacities of caregivers. However, all those opportunities can also be regarded as a part of offenders' plans for crime within youth-centric facilities. It is because child molesters in educational professions are able to predict certain activities for children under their care. Accordingly, such opportunities do not arise as surprises. Rather, child molesters in educational professions can make efforts to be situated in such opportunity-driven situations and take an advantage of predicted opportunities in their capacity.

By using the Situational Crime Prevention (SCP), Terry (2008) identified the patterns of child molestation by persons of authority (e.g., vocational child molesters) within youth-centric institutional settings. This study assumed that environment played an integral role for child molestation to be perpetrated. Consistent with the findings of Moulden et al. (2007), the majority of child sexual molestations were delivered in the manipulative manner, and therefore, injuries inflicted on child victims, if any, might be due to impulsive violence precipitated by situations rather than premeditated plan. Along the same line, Beauregard, Robocho, \& Rossomo (2010) also emphasized the significance of the physical environment of crime scenes because it largely determined rapists' decision-making scheme in victim selection and grooming processes.

Within the framework of rational choice theory, one of the most important findings from the SCP perspective is the emphasis of target hardening to effectively prevent child sexual abuse (Terry, 2008) by educating potential victims about proactive strategies. Similarly, Leclerc et al. (2015) also employed the SCP approaches to identify potential offenders, policy implementation, and parents' role to prevent sexual abuse within youth-centric organizations. It is necessary to develop advanced techniques to 
educate children about protective strategies to prevent child sexual abuse. However, such preventative strategies have omitted the detailed instructions as to "how" and "when" the child victims should carry out such protective techniques to most safely rescue themselves from the threats of not only sexual assaults, but also subsequent physical assaults that may result from their resistance.

Furthermore, verifying employees' past criminal records prior to recruitment can be considered as one of the ways of target hardening (Leclerc et al., 2015). Increasing guardianship, such as educating parents and guardians, is also important in terms of effective supervision and recognizing dangerous behaviors indicative of abuse (Terry, 2008). Since child molesters' criminality is hardly aging-out (Terry, 2014), the appropriate strategies reflecting long-term risk posed by child molesters should be addressed and intervention strategies should be developed (Hanson et al., 1993).

Increasing capable guardianship was also an option for the SCP model in child molestation. Studies suggested two primary strategies. First was to raise awareness of child molestation for parents and guardians in charge; second was to educate them on how to provide effective supervision and to recognize dangerous behaviors that can further develop into sexual abuse against children (Finkelhor, 2009). Finkelhor et al. (1995) revealed that children who were frequently and regularly instructed by their parents about effective prevention strategies of sexual abuse showed better understanding of such circumstances and accordingly became capable of applying appropriate selfprotection techniques based on costs and benefits.

Child sexual abuse was also interpreted within the framework of social disorganization theory (Mustaine et al., 2014). Although the social disorganization 
perspective was unsuccessful to explain the differences in the locations of single and multiple victim cases, this study was significant in that it attempted to identify locations where child sexual abuse was more prominent and to develop environmental adjustments to reduce the risks of child molestation in certain areas.

In the line of extending guardianship, a combination of measurements in both routine activity theory (i.e., individual victim's lifestyle activities) and social disorganization theory (i.e., neighborhood structures) can better serve as predictors of physical/ sexual violence than offenders' individual characteristics (Mustaine \& Tewksbury, 2000). Furthermore, a combination with the presence of community temptations and potential offenders could also result in significant differences in sexual victimization rates (Mustaine \& Tewksbury, 2009).

The concept of extending guardianship was also discussed in other studies (Deslauriers-Varin \& Beauregard, 2010; Smallbone \& Wortley, 2004). For instance, since a large number of child molestation cases are regarded as a crime of opportunity, reducing temptations may be effective in preventing the commissions of a sex crime, with minimal danger of displacement to other targets (Wortley \& Smallbone, 2006). Based upon crime script analyses on different victim activities prior to crime, Deslauriers-Varin and Beauregard (2010) suggested increasing the level of guardianship might help reduce the risk of sexual victimization especially in the outdoor scripts. This finding is congruent with the finding of Harbers et al., (2012) in analyzing offenders' preference for isolated locations to carry out their crime. Public settings often offer the greatest potential for control over the environment as authorities can design or reconstruct these public places accordingly. 


\section{Effectiveness of Crime Prevention Programs}

The primary objective of prevention programs is to increase children's understanding of child sexual abuse, including definitions, prevalence, and knowledge about potential perpetrators (Daro \& Donnelly, 2002). These programs provide parents and children with guidelines as to how to teach/ identify dangerous situations, refuse an abuser's approach, break off an interaction, and summon help (Finkelhor, 2009; Kenny, Thakkar-Kolar, Ryan, \& Runyun, 2008). However, previous studies were inconclusive about whether such programs actually helped reduce child victimization (Finkelhor, 2009).

Furthermore, among parents who have discussed sexual abuse with their preschool children, most did not use any supplementary materials such as books or videos (Tutty, 1997). One study showed that regardless of sexual abuse experience, children were not fully able to distinguish potential risk for sexually abusive situations as well as the danger of such activities (Miller-Perrin, 1990). Studies thus far, however, largely focused on pre- and post-crime phases of prevention strategies such as distinguishing 'okay and not okay touching,' and teaching correct terms of genitals for effective communications in disclosure reporting, discussing about blame, and sharing misconceptions about perpetrators (Kenny et al., 2008).

Some prevention programs were found to be atheoretical and were only offered for a short period of time to children (Topping \& Barron, 2009). Furthermore, previous studies have lacked consistency in terms of definitions, populations, and research methods used to examine the effectiveness of school-based child sexual abuse prevention programs. Child sexual violence prevention programs should be designed differently for 
younger and older children because children's reaction and cognitive levels are different from each other by age. Furthermore, the most commonly reported positive effects by children are an increase in a sense of control and feeling of safety, which were attributed to active parental involvement, repeated practice, customized program levels based on child development, and vocabulary skills (Kenny et al., 2008).

\section{Critique of Existing Literature}

This chapter began its review of previous studies on child molestation in particular and sexual violence in general, highlighting the unique characteristics of victims, offenders, and offences. Following the overview and impacts of child molestation, child molester classifications were specified focusing on the social relationships to victims, the origin of interest in children, and their professional distinctions. Such classifications then centered on the unique group of offenders, child molesters in educational professions, which later were divided into three groups based on their motivation/ intent to join certain professions: vocational child molesters, clergy child molesters, and volunteer child molesters.

This chapter also examined the reason for targeting under-age victims in light of social incompetence and low self-esteem that child molesters sustained. Overall modus operandi of child molesters was also discussed; different factors were found to affect offending patterns in various situations. Lastly, child abuse prevention strategies that have been mainly implemented and practiced within educational settings were examined. Additionally, different theoretical approaches to child molestation were also present, and the key frameworks included rational choice, routine activity, and social disorganization theories. 
The aforementioned contributions have been made through various studies on sexual violence against children. However, there are several aspects that have been neglected in previous literature on sex offenses and child molestation, especially as it relates to the subject population, methodology, and most importantly, the focus of study. The details of critiques will be delineated in the following.

First, the majority of the studies used a sample of either incarcerated sex offenders in correctional service or convicted sex offenders who were ordered to participate in sex offender treatment programs when examining the patterns of, and reasons for, offences. Regardless of victims' gender and age, those studies revealed offenders' grooming patterns and modus operandi in the course of sexual assault based on self-reported data or semi-structured interviews provided by sex offenders who had been brought to the attention of the criminal justice system.

Studies that rely too much on an incarcerated offender population, however, suffer from a lack of generalizability and a biased sample. It is because such groups of people only represent a fraction of the universe of the sex offender population. Therefore, previous studies only provided a limited amount of knowledge about criminal patterns and offender behaviors as previous studies are based on biased samples of convicted offenders. Convicted and incarcerated offenders represent incompetent offenders who have been caught and sent to prison. Thus, they are not representative of the overall sex offender population.

Only a few studies have focused on "what exactly happened" at the physical contact stages by analyzing behavioral sequences of both victims and offenders. Even though an ample amount of previous literature on interpersonal child abuse used child 
victims of sexual abuse as their data source, those studies were largely conducted in a search for effective victim treatment plans to deal with victims' trauma as a result of sexual abuse. In other words, studies focused on the degrees of victims' traumatization as a result of sexual victimization, such as depression, anxiety, and posttraumatic stress disorder, or the coping mechanisms that victims employed to deal with their victimization, instead of reconstructing the crime scene to understand the dynamics of behaviors of both victims and offenders in a qualitative manner. A handful of qualitative studies investigated criminal behaviors, however, their focus was on the factors that affected offenders' decision-making during sexual offences, instead of the dynamics in the behavioral/ verbal exchanges between the both parties.

Second, previous studies failed to provide substantial analyses regarding how each physical contact was initiated and continued at the very crime scene. The majority of existing studies heavily focused on pre- or post-crime stages, instead of magnifying the sequences of crime-scene behaviors exchanged between victims and offenders. Furthermore, previous literature largely looked for the underlying factors of "why" offenders committed sex crimes based on offenders' accounts or official records accessed through criminal justice agencies. Those narratives were then transcribed and quantified into numeric codes for quantitative analysis. However, a quantitative-oriented analysis is unable to capture the details of behavioral (and verbal) sequences of both victims and perpetrators. Analyzing rich narratives can help understand the unique dynamics of each child molestation case when especially child victims are left alone with their perpetrators, who are oftentimes their educators and caregivers. 
Lastly, regarding prevention strategies that the children should consider, previous studies have failed to specify the desirable timing and specific behaviors for children to adopt in order to stop an offender's sexual advances and to safely get out of the crime scene. In other words, effective intervention strategies in child sex crime have been relatively less focused than the effective prevention programs, which largely instruct victims in preventative behaviors up to the point where the actual sexual contacts were just about to begin. Few alternative solutions were suggested once preventative efforts failed to rescue the potential victims from the risks of actual offences.

Taking the above components into consideration, this dissertation attempts to shed light on one of the most under-recognized sexual offender populations, same-sex child molestation, especially within the nations' most conventional youth-centric organizations, the Boy Scouts of America. The majority of the BSA cases used in this dissertation was only investigated internally, and then was placed in confidential files to prevent the same scoutmasters from future registrations in the BSA. Unless otherwise indicated in the BSA files (e.g., presence of arrest reports, newspaper clippings of arrests/ indictment), the sample used for this dissertation consists of "active" offenders rather than convicted offenders. Using boy victims' and/ or their family members' direct descriptions about their victimization at the crime scene, this dissertation will analyze the "how" of behavioral and verbal sequences exchanged between boy victims and their scoutmaster perpetrators from initiation to termination of sexual contacts. By doing so, this dissertation is expected to bring insight into the sex offence literature and to assist in the design of the most effective and safe intervention models. 


\section{CHAPTER 3}

\section{DATA AND METHODOLOGY}

As was stated in the previous chapter, this dissertation presents qualitativeoriented research focusing on same-sex child molestation cases within the Boy Scouts of America. Conventional content analysis was conducted for this study; this methodology involves unmotivated reading, coding categories by emerging themes, and identifying thematic patterns (Berg \& Lune, 2012). Behaviors displayed throughout the interactions between victims and perpetrators were coded and grouped into thematic patterns (also subgroups). Each thematic pattern was then analyzed to find the most appropriate means of intervention that child victims could perform while sexual offending behaviors were undertaking.

The thematic categories have been derived directly and inductively from the raw data, which are victim accounts as a main source of data for this dissertation. The victim accounts were provided by boy victims and/or their caregivers in the form of complaints/ accusation letters that had been internally kept within the Boy Scouts of America. The victims narrated their experiences of sexual abuse perpetrated by their troop or unit leaders, the scoutmasters. The adult scoutmaster positions were volunteer positions, and the volunteers were in charge of each troop or unit, in other words, the scoutmasters had been considered as persons of authority by boy victims within the Boy Scouts of America. 


\section{The Nature of Data}

To conduct conventional content analysis of same-sex child sexual assault cases, secondary archival data was collected and sorted for this research design. The data used for this dissertation are records of allegations that came to the attention of the Boy Scouts of America; each case involved sexual abuse activities, with a varying degree, between male children as victims and adult males as perpetrators. Both parties had known each other through the youth organization the Boy Scouts of America. Each allegation was reported, collected, and kept confidential under the title of "Ineligible Volunteer (IV)" file by the Boy Scouts of America for years, and the data released to the public contains cases filed from the early 1960s to the early 1990s (The Los Angeles Times, October 18, 2012). Dates mark when the Boy Scouts created each file upon completing internal investigations, not when the incidents were alleged to have occurred (The Los Angeles Times, October 18, 2012).

The ineligible volunteers are referred to as those who had been brought to the attention of the Boy Scouts of America officials for the allegations of child molestation. When complaints were received, the local Boy Scouts of America offices usually conducted an internal investigation and, in most cases, recommended suspects to voluntarily resign from the current scoutmaster position. The officials then consulted internal legal advisors and decided whether to place the records of given scoutmasters in their confidential files. The local office informed the headquarters of the Boy Scouts of America, which was located in Texas, of their decisions, and shared all the relevant documentation to substantiate each scoutmaster's ineligibility with the main office. The 
original intent of the "Ineligible Volunteer" files was to prevent the perpetrators from registering within the BSA again in the future.

As a result of a long legal battle between victims, who used to be the youth members, and the Boy Scouts of America over the same-sex sexual assault cases committed by scoutmasters, the Oregon Supreme Court ruled to make the "Ineligible Volunteer" files publicly available in 2012 (The Los Angeles Times, October 19, 2012). The first wave of data was released immediately after the court order. The Los Angeles Times posted the first batch of the confidential files that were derived from confidential Scouting files submitted as evidence in court cases on The Times' database under the title of an article 'Inside the 'perversion files,' Tracking decades of allegations in the Boy Scouts" (The Los Angeles Times, October 18, 2012). The second wave followed about a month later; The Los Angeles Times uploaded the rest of the "perversion files." Accordingly, the entire retrieval was completed right after the second wave of data upload made by the Los Angeles Times. As a publicly available and open source, the rules regarding the protection of human subjects are not applicable. It should also be noted that the database also included basic information (e.g., name of the accused and location) of several thousand cases between 1947 and January 2005. However, the detailed case files were only available for the years between 1960 and 1990, and the rest of them simply revealed year of suspension, perpetrators' name, and location of allegation (The Los Angeles Times, October 19, 2012).

Data sorting processes. Data sorting focused on three criteria. The initial 2,931 case files were retrieved and stored in a PDF format. Each case file was listed by the last name of the accused. There were two major data cleaning processes before the data were 
analyzed. The first step of data sorting began with elimination of duplicates. All case files were carefully read, and if the same documentation were found under the same perpetrator's name, only one file was counted. Through a first data cleaning process, 587 files appeared to be duplicates. The reason for duplication can be explained if the same person is associated with more than one troop or unit, that name or number is repeated (The Los Angeles Times, October 18, 2012). Also, it might be due to the Boy Scouts' recruiting system for volunteer scoutmaster positions in earlier years. Deleting duplicates resulted in the elimination of 587 files; a total of 2,344 case files were kept.

A second data cleaning involved an elimination of files that did not fit the topic of same-sex child molestation: sexual abuse behaviors by male adults against male children. The details of exclusion criteria are presented in the following. Considering the nature of same-sex child molestation within the Boy Scouts of America, this dissertation did not count female perpetrators in a position of scout leader and/or an accomplice of male perpetrator (e.g., wife), and for this reason, seven cases were eliminated. Victim gender was considered in the process of data cleaning as well. Any perpetrator who was reported for sex abuse against females, both children and adults, were also excluded because they did meet the inclusion criteria. Through this process, a total of 208 cases concerning female victims were deleted. Lastly, if a scoutmaster was placed in an "Ineligible Volunteer" file for reasons other than same-sex molestation, such a case is not included in the final data set. The reasons include, but are not limited to, possession of pornography, different sexual orientation, religious cult, alcoholism, adult male victims, mistrial, incest, and physical abuse only. This process led to an elimination of 98 cases from the final set of data. As secondary archival data, a total of 2,031 case files were 
cleaned, sorted and kept in a data set. All the case files involved allegations of same-sex child molestation, with a varying degree, committed by scoutmasters against young boys and/or members of boy scouts between the early 1960s and the early 1990s.

Contents of case files. The documents contained in each file were not identical. Since the files were not collected by criminal justice agencies (e.g., police, prosecutors, and court), the depth of information in each case file varied. The page numbers in each file range from three to 221 pages including cover pages. Common information found on the first page in the file was each perpetrator's demographics, which were filled out by the BSA officials when they decided to place the accused scoutmaster in "Ineligible Volunteer" file. This front page lists basic information including the perpetrator's full name, age, occupation, education, marital status, and whether a perpetrator had a child or not. However, not all items were filled out; the majority of demographics remained unanswered. Furthermore, since those forms were filled out before computers, the vast majority of answers were handwritten including the "Ineligible Volunteer" form, victim accounts, and perpetrators' resignation letters.

In addition to this "Ineligible Volunteer" form, each case file contained various sources of information such as victim's accounts, accused scoutmaster's resignation letter, registration application, newspaper clippings, and sometimes, police and court records. Of those various types of documents, this dissertation explicitly focused on victims' accounts. Victims' accounts are the handwritten (or a few typed) letters that victims wrote to the Boy Scouts officials as a description of crimes that were committed against them. Since the victims were underage boys, this dissertation also counts the narratives from victims' caregivers as victim accounts. It should be noted that the victim 
accounts in the "Ineligible Volunteer" files were different from victim statements in the "official" sense of a word because they are not official statements that victims provided to the court or police as part of a criminal investigation. Sometimes these narratives included the statement given to police, but most of the time, they were letters that the boy victims and their parents had sent to the Boy Scouts of America describing their experiences. They are therefore internal records within the BSA. These letters also serve as an invaluable source of data about the sex crimes perpetrated from a victim's perspective.

Among 2,031 case files collected through data cleaning, the selected source for this dissertation is accounts from both boy victims and/or their caregivers. As noted, the information contained in each case file varied. After data cleaning, a total of 331 case files contained victim accounts. These 331 cases that include a victim's own description of the offense will be used for analysis in this dissertation. The primary reason for using victim accounts for this dissertation is that their narratives are expected to provide indepth understanding of detailed behavioral interactions between boy victims and scoutmaster perpetrators. Perhaps with the exception of a few exceptional studies (e.g., Beauregard \& Leclerc, 2007; Leclerc et al., 2009), qualitative approaches to such narratives have not been made in previous studies, especially when it comes to identifying sequential patterns of behaviors carried out at crime scenes. However, the BSA confidential files, fortuitously, contained this unique and rich source of information about victimization from a victim's perspective. Thus, the victims' accounts provide a unique opportunity to study the offence behaviors of perpetrators from the perspective of underage victims, told from their direct experiences. 
It is important to note that these letters were akin to letters of complaint that victims wrote, probably at the behest of their parents. They are personal letters describing their victimization to the leadership within the Boy Scouts of America, with an intended purpose of preventing the perpetrator from being affiliated with the organization. They are not the official victim statements that were usually collected for investigation/ prosecution purposes nor are they similar to victim impact statements to be read at sentencing. Some case files included more than one victim account. This duplication can be interpreted in two ways: The perpetrator had committed sexual molestation of more than one victim; or a victim and his caregiver both submitted narratives. However, regardless of the number of victims, if victim accounts were regarding the molestation committed by one perpetrator, then that was counted as a single victim account. The length of each account varied; most of them were handwritten and the raw documents were scanned and uploaded via a PDF format. Some narratives were simply illegible. In this case, the unrecognizable words, sentences, and/or paragraphs were left blank during the transcribing processes to prevent the facts from being misinterpreted.

Data analysis. Grounded theory serves as a foundation of qualitative analysis in this dissertation to identify the dimensions or themes that seem meaningful from the text through "inductive content analysis" (Berg \& Lune, 2012; Elliott \& Lazenbatt, 2005; Elo \& Kynga $\dddot{s}, 2007$, p. 111). This process usually involves open coding, creating categories, and interpretations of the contextual meaning of specific terms or contents (Berg \& Lune, 2012). Having this in mind, the primary process of this dissertation involved analyzing the victim narratives $(\mathrm{N}=331)$ that were directly obtained from 
victims and/ or their family members at the time of reporting sexual molestation incidents to the Boy Scouts of America between the early1960s and the early 1990s.

Details of the qualitative analysis for this dissertation are presented in the following. I conducted a content analysis of victims' accounts in order to investigate the significant patterns in the relationships between perpetrators and victims. Focus included the ways in which scoutmasters initiated sexually-oriented advances on boy victims and the patterns of termination of such behaviors. The spatial and temporal frame between initiation and execution does not refer to the stage of victim selection, hunting and grooming behaviors; these behaviors fit better in a "pre-crime" phase. Rather, this dissertation exclusively focuses on the physical contact stage where the actual physical contacts between a Scoutmaster perpetrator and boy victim are taking place. By conducting content analysis of victim accounts, therefore, this dissertation will identify behavioral patterns carried out by the both parties at the crime scene.

To do so, I first performed several unmotivated readings of all victim accounts. Throughout the readings, recurring thematic categories were captured based on the behavioral sequence between boy victims and scoutmaster perpetrators, for instance, how they initiated, developed and terminated sexual behaviors. This process is important because numerous unmotivated readings allow researchers to capture the essential features of data scripts (Elo \& Kynga s, 2007). Emerged themes from content analysis have been grouped together based on a similarity of behavioral patterns displayed by both victims and perpetrators. The grouped patterns will then serve as foundations of analysis in search of safe and effective ways of establishing intervention techniques. 
The main theme of this dissertation was derived from the processes and development of sexual offending behaviors by actors, and then was divided into two categories. Simply put, scoutmaster perpetrators played a major role in initiating sexual advances, and boy victims could play an important role in terminating such behaviors. To be specific, the first thematic category was thus focused on scoutmaster perpetrators who usually initiated sexual advances in various situations. Their behavioral patterns at initiation stages were indicative of how child molesters actually begin their physical contacts with boy victims. Behaviors of the scoutmaster molesters were then grouped into three sub-categories depending on the situations and/or opportunities.

The second theme emerged from victims' reactions to sexual advances made by scoutmaster perpetrators. The boy victims were able to play dual roles in the course of sexual molestation. That is, the victims' reactions served as termination signals to perpetrators to withdraw from further sexual advances or continuation signals to the perpetrators to continue the sexual advances on the boys until they achieved sexual gratification. Victims' reactions were coded into three sub-categories based on their descriptions of how they felt about and reacted to the sexual abuse at the crime scene. On the continuum of resistance, boy victims' behaviors are analyzed based upon the level of assertiveness of victim resistance that especially brought perpetrators' sexual behaviors to a full stop.

In sum, this dissertation will examine the behavioral patterns of both boy victims and their sexual perpetrators (scoutmasters) in the course of sexual molestation. To do so, victims' direct narratives about their victimization will be used; the accounts were obtained from the (previously) confidential Ineligible-Volunteer files that have been kept 
within the Boy Scouts of America. This dissertation will present a qualitative analysis of rich narratives from victims of same-sex child molestation, and doing so is expected to contribute to the development of safe intervention techniques that children can easily perform against their sexual perpetrators. 


\section{CHAPTER 4}

\section{FINDINGS I}

\section{Overview of the Analysis}

This chapter presents findings from analyses of victims' narratives. The analyses are divided into two areas based on significant patterns that emerged from the continuum of physical contacts between boy victims and scoutmaster perpetrators. The two specific areas of focus in this analysis are initiation and termination of physical contacts in samesex child molestation.

This study employs micro-level qualitative analysis in an attempt to magnify specific stages where physical contacts between the two actors actually occur from the beginning to the end. Thus, the specific focus at both initiation and termination points in this dissertation is physical interactions between the two parties from initiation to termination, and the presentation of analysis is based on the behavioral patterns of perpetrators and boy victims.

Under initiation and termination of child molestation, thematic patterns are analyzed using behavioral and verbal exchanges between boy victims and scoutmaster perpetrators. To identify the patterns of sexual contacts, a total of 331 case files were examined; each selected file contains victim narratives. It should be noted that the data were not collected as a part of official investigation, but kept as a part of internal classifications (notifications) within the Boy Scouts of America (BSA). In this regard, there were several different channels for each case to be brought to the BSA officials' 
attention, such as boys'/ parents' complaints, witnesses, previous criminal history, etc. Nevertheless, this analysis simply has to rely on data availability.

It should be thus mindful that the 331 narratives used for this study do not represent the entire population of child molestation cases. Second, some scoutmasters molested multiple victims at a time or over the course of their tenure in the BSA. Not all victims came forward with their victimization. For instance, in some cases, one victim revealed that there were multiple boys being molested by the perpetrator. In other cases, several victims wrote the letters or testified about their victimization committed by one perpetrator. Lastly, about $48 \%$ of victims' accounts did not provide thorough descriptions of "physical contact" stages, and therefore, those narratives were classified as unknown cases for the current analysis.

Sexual advances towards boy victims were mainly made during the Boy Scouts activities, such as campouts and conferences. Oftentimes, perpetrators' residences (e.g., house or apartment) were used to make sexually motivated advances against boy victims. Other locations used for same-sex child molestation included perpetrators' cars, hotels/ motels on the way to the BSA conferences/ campsites, and victims' residences. Not many variations were found in the location. Routine activities of young children are highly restricted to their home, schools, and known places, under supervision of trusted adults. However, the ways in which each perpetrator carries out his sexual behaviors against boy victims show certain patterns regardless of the locations. These behavioral patterns will be the main focus of this analysis.

The timeframe that the incidents occurred (1960-1990) may help to elaborate on the routine activity perspective (see Cohen $\&$ Felson, 1979). It was not unusual that 
underage boys spent a night or two at a scoutmaster's residence because of a lack of resources to entertain young kids at home and the emphasis of outdoor activities that could be learned through interaction with respected figures, such as scoutmasters. The locations used for this type of sexual offences can also suggest that the scoutmaster perpetrators were able to build a sound rapport with victims' families, and the scout leaders were in a position of respect and trust among the boys and their parents.

When multiple victims were reported, the victims were usually friends who were part of the same units/ troops. The ways in which each victim knew about the existence of other victims came about when boys shared their experiences or rumors going on within their scout units about certain scoutmasters' unusual behaviors with boys. Sometimes the victims were found to be from the same family; due to the unique nature of the BSA, underage brothers were the members of the same units, in this case, either one of the brothers or both of them were found to be the victims of same-sex molestations by the same perpetrators.

Since the victim narratives were not written in a structured format, information between and within narratives greatly varied. The depth of narratives completely relied on victims themselves because all the narratives were written voluntarily. In a very few cases, victim narratives were collected through interviews conducted for investigative purposes. In this case, victims provided their answers to the questions that investigators were asking at the interview. However, due to the sensitive nature of such crimes and victim characteristics, the interviews were also voluntary. Therefore, the analyses for this study were based on data availability. Details of behavioral sequences from initiation to termination of sexual contacts will be delineated in the following section. The two 
sections will explicitly present 1) initiation and 2) termination patterns in the course of same-sex child molestation.

First, to identify the initiation patterns, it was essential to verify sexually motivated behaviors that made up same-sex child molestation from the data. The initiation patterns are then divided into three sub-categories based on the starting point where the actual touching begins. The behavioral sequences are made up of the following components: hugging, kissing, holding hands, touching legs, spanking, laying down, touching boys' genital area, making boys touch perpetrators' genital areas, undressing boys, undressing perpetrators themselves, fondling boys' penis, oral sex to boys, making boys give oral sex to perpetrators, masturbating boys, masturbating themselves, making boys masturbate perpetrators, and lastly penetration of boys. Scoutmaster perpetrators initiate their sexual contacts on boy victims; boys and the perpetrators developed their physical interactions on the continuum of the aforementioned behaviors.

Implementing the framework of the Routine Activity theory (see Cohen \& Felson, 1979), when granted to a position within the Boy Scouts of America, scoutmasters are expected to perform the role of capable guardians during the scouts' activities. However, in the course of sexual abuse, they actually switch their role to motivated offenders by removing their masks of caring guardians. In the meantime, young boy members are placed in the position of suitable targets. According to the Routine Activity theory, for a certain crime to occur, three components, motivated offender, suitable target, and a lack of guardians, should converge in the same time and space (Cohen \& Felson, 1979). However, only two actors, boys and scoutmasters, are involved in the actions of sexual 
molestation within the BSA. The two actors are able to play other roles by making contingent changes in their roles. Scoutmasters are at the center of focus in the beginning of sexual molestation.

The initial role of scoutmasters is to provide guardianship to young boy members. However, by initiating sexual advance against the boys, the position of suitable guardian is switched to a motivated offender. At the same time, the initial sexual touch solidifies the young boy members as suitable targets. In the process of role changing, it is apparent that the once-filled capable guardian position is now vacant. The findings in this analysis extensively focus on the patterns of such behaviors by looking into the role switching between the two actors.

Second, termination of the sexual contacts is done in two ways: Either boy victims resisted, or scoutmasters finished the act, or in other words, they completed their crime. It is noted that the point where perpetrators stop their sexual behavior-where they achieve sexual gratification - is largely shown as a point when they touch the boys' penises at a minimum. Some are able to develop such behaviors to the point that they ejaculate or make boys ejaculate — but very few perpetrators had sexual intercourse with boy victims.

Similar to the perpetrators' role switching pattern from capable guardians to motivated offenders at an initiation stage, victims' reactions while being molested can also serve as a significant point to determine the likelihood of escalation of sexual advances. Furthermore, the level of boy victims' resistance can predict the likelihood of termination of sexual molestation. To be specific, this section will present when and how 
boy victims are capable of switching their roles from captive targets into capable guardians.

Role switching enables boy victims to rescue themselves from further victimization made by their motivated offenders (e.g. scoutmasters). Once a position of capable guardian is absent, it is inevitable for the boy victims to fill this position to protect themselves. Otherwise, they are likely to remain in a victim's role. Furthermore, this study examines the degree of resisting actions and appropriate timing that effectively help the boy victims to stop the perpetrators' sexual behaviors from further development.

The resistance behaviors made by boy victims are then divided into two subcategories, either passive resistance or active resistance. Passive resistance is made up of rolling over to the other side, leaving the scene, and doing nothing. The active resistance includes verbal assertiveness and physical assertiveness. Contrary to the initiation, it is noted that the initiators of termination are usually boy victims, and depending on the types of resistance, the sexual contacts are either discontinued or continued until the perpetrators make a full stop. In the following sections, significant themes on both initiation and termination patterns from the qualitative analysis will be discussed. Excerpts that best illustrate the analytical category being discussed are presented as examples.

\section{Initiation Patterns}

Scoutmaster perpetrators demonstrated three significant behavioral patterns at initiation. The initiation is used as a pivotal point to determine the escalation or cessation of sexual advances. The three themes (patterns) employ different "starting points" of physical contacts. Thus, it is essential to understand how scoutmaster perpetrators 
employ different strategies to begin their actual physical contact with the boy victims. The analogy applied to these themes comes from the perpetrators' perception of the Boy Scouts of America that the environment is like a fish farm to them where there are plenty of resources readily available which they can use for their sexual gratifications

To be specific, what is perceived as cultivated fish to fishermen in a fish farm is the same as young boy scouters are to the sexually motivated scoutmasters in the Boy Scouts of America. Thus, the ways that offenders achieve their goals involve different types of fishing techniques. They are angling (baiting), spearfishing, and handpicking.

Before proceeding to the detailed analysis in initiation patterns, it is essential to know what exactly is defined as the "catching" moment, in other words, the perpetrators' initial goal to make sexual advances against boy victims. Rather, in most cases, the cessation point was found to be the moment when perpetrators touched and fondled a boy's penis. Some perpetrators were able to develop such activities into further advances, such as performing oral sex, ejaculation, and penetration. However, in this analysis, the actual "catching" point is when perpetrators actually touch boys' sexual organs.

Angling contact. It is found that about $29 \%$ of scoutmaster perpetrators employ an angling-type method when initiating their sexual contact with their boy victims. Angling fishing usually involves placing an angle (fish hook) in the water. The hook is usually dressed with baits attached to a fishing line to attract fish into the target zone. First, fish usually approach the bait with caution. Several trials are made until the fish bites the bait or gives it up and leaves the site. 
The same-sex child molestation cases employing the angling method are found to be the most sophisticated, premeditated, and time-consuming of the initiation methods. This technique requires at least 2-3 steps for the perpetrators to perform until they accomplish a minimum of their goals, touching a boy's penis. In this analysis, the angling method used in same-sex child molestation within the Boy Scouts of America will be thoroughly discussed in terms of the significances in contextual factors that affect perpetrators' initiation patterns. To do so, the following excerpt represents the components of sexual behaviors that scoutmaster perpetrators use when approaching their boy victims.

Behavioral sequences in angling method. The following narratives are simple and precise, yet well demonstrate how each behavioral component is relayed and portrayed in the picture of same-sex child molestation using an angling method. Excerpt 1.

On July 18, while members of our troop were distributing advertisements in Mr. Collins' area, he invited me into the basement of his home and expressed excessive affection toward me by hugging and kissing me and opening my zipper and fondling the area inside. This lasted for one-half hour. I thought about running away but was too nervous and upset. On one previous occasion on a fishing trip several months previous to my last experience, I had a similar experience. His affection toward me started at Camp Myron Kahn in the summer of 1963, when he kept me up late at night in his tent helping me to pass advancement tests and hugging me. I didn't realize at the time that this would lead into anything more serious. 
In this narrative, the boy victim describes that he is invited to Mr. Collins' basement while other scouters are working on their assignment. Then, Mr. Collins starts to feel him in a sexual manner, but the boy is not able to distinguish it until it gets serious. For instance, Mr. Collins begins his molestation with hugging and kissing. Applying the angling method in fishing, such behaviors can be considered as "testing out" the boy victim. As a fisherman plays a game with his target fish over the bait, Mr. Collins also examines the boy's reaction to his "pre-game" touches, such as hugging and kissing. Until Mr. Collins actually grabs the boy's penis after he has observed the boy's reaction, two previous steps have been taken. In most cases, behaviors found to be done before touching a sexual organ (inside a boy's pants) include hugging, kissing, touching arms and legs, lying down, and in some cases, undressing boys.

In the angling method, these behaviors are delivered very naturally so that the boy cannot realize the hidden implications of the perpetrator's touches. Most importantly, such behaviors can be interpreted in multiple ways by his potential victim, and thus, minimize the risk of resistance on the victim's side. These actions contain an element of deniable plausibility. They allow offenders to impute another motive besides a sexual one. Since the boy victim's age is very young, subtle behaviors like casual hugging made by a person of authority may not exactly come across as sexually-motivated actions. Rather, as is described in the boy's narrative, he may view those actions as a sincere expression of affection. Then, such trivial yet ambiguous behaviors are developed into more obvious sexual advances, such as touching the boy's penis, which eventually turns into fondling. 
In most victim narratives, the ultimate "destination" of perpetrator's sexual advance is touching/ fondling the boy's penis. This behavior serves as a turning point in the course of the angling method of child molestation. To be specific, by the time a perpetrator touches a boy victim's penis, the victim becomes capable of performing dual roles: It serves as either termination of the "pregame" actions, or predictor of further sexual advances, such as oral sex and masturbation. Therefore, the action of biting the bait in angling fishing is transformed into the action of "fondling" boys' penises. Once it happens, the perpetrator nearly succeeds in prolonging his sexual performances to the point of oral sex, masturbation, and in a few cases, sexual intercourse with boys.

Furthermore, it is noted that boy victims are always awake in the course of angling type of sexual molestation. The angling method is mainly used to test the boy victims to see how much they can take at a time. By doing so, scoutmaster perpetrators can cultivate more precise yet intense actions to achieve their ultimate goals.

\section{Excerpt 2.}

On Tuesday, August 2, 1966, Mr. Collier and myself went to the rifle range to work on a marksmanship merit badge. After firing a few rounds, Mr. Collier said that I was too tense and needed to relax. He told me to roll over (I was in a prone position). When I rolled over, he had his arm underneath me. He said he was going to relax me and he unbuttoned my pants. He placed his hand underneath my underwear and played with my penis. I was too scared to do anything. This lasted about 5 minutes. Then he told me to put my legs together and he layed on top of me for a while. Then he rolled off of me and told me to resume shooting. After shooting a while, he did the same thing again. 
The angling method requires a perpetrator to have a certain amount of preparation time and thorough plans. Yet, this method yields a good success for the perpetrator to achieve what he wants once his target steps into the perpetrator's radar. For instance, there are only two people, a perpetrator and a victim, at the rifle range, and the purpose of going there is to for the boy to fulfill his merit badge requirement. Owing to the position of trust that Mr. Collier holds within the BSA, his invitation to this activity in a remote location is unlikely to raise any suspicion not only from the boy victim, but also his primary caregivers. Mr. Collier deliberately makes a chance for the two of them to be alone and undisturbed at an isolated place. Furthermore, he makes up a plausible reason to initiate his first sexual advance on the boy, helping him to relax.

There is a very subtle distinction between the actions involving a body massage and sexual molestation in terms of the area over which the perpetrator can touch. The boy victim, albeit scared, may not be able to discern the specific intention of his perpetrator's taking him to the rifle range. Also, the boy is not sure about his body parts and where the perpetrator is and is not supposed to touch because the boy is still confused about the entire situation resulting from sexual contact. Most importantly, he does not want to misinterpret his scoutmaster's actions because he is confused.

\section{Excerpt 3.}

Chuck started rubbing really low down my back. Then he started rubbing my chest muscles and started rubbing my stomache[sic] then the upper part of my legs. While he was rubbing my legs he started moving his hand over and sort of rubbing my private spot. He quit and asked me which felt better this spot, this spot, or this spot. I shrugged my shoulders because I was scared he might do 
something if I told him I didn't want him to rub me... Before (A) faked his wakeup, Chuck had started rubbing my private spot and said "do you like that" and I said "yes" because I was so scared. Then he said "I know why you like this place for me too rub because of this" and put his finger down on my private spot and then said "youre horney," and sort of chuckled.

As scoutmaster perpetrators aim to test boy victims through angling-type initiation, they engage simple verbal conversations in an effort to estimate the level of victims' comfort and willingness for further sexual behaviors. As illustrated in Excerpt 3, Chuck keeps on asking the boy about his feeling every time Chuck attempts to move onto next actions. By convincing the boy of his physical response to Chuck's touch, Chuck tries to justify his sexual advance with the boy, as well as the nature of male-onmale sexual behaviors. Such behaviors may be further implemented to instill the boy with the feeling of guilt and embarrassment. By doing so, the perpetrator can reduce the risk of being rejected or blamed, and therefore, they are able to avoid the legal and moral liability in the future.

Escalation of sexual advances. Most importantly, the narratives involving an angling method exhibit an escalation of sexual behaviors. In other words, sexual molestation is repeated on the same victims with a gradual escalation in the degree of sexual contact. In other words, while this method of initiation allows a scoutmaster perpetrator a better chance of success in the long run, such as repeating molestation on the same victim, it takes time, preparation, and most importantly, the risk of failure if the potential victims refuse to take the bait. The following two excerpts are derived from the repeated incidents involving the same boy victim and perpetrator. 


\section{Excerpt 4.}

I don't remember the exact day or month but I think it was in July 1967 that I was over at Mr. Silva's house one day and no one was at home there but Mr. Silva and Mr. Silva was helping me with my scout work and he told me to come into the bedroom with him so he could show me some of his merit badges and after we got into the bedroom Mr. Silva un-zipped my pant and started playing with my peter. I am not for sure whether he played with his own peter this time or not. He didn't put his mouth on my peter this time. I don't know the days or months but since the first time that he played with my peter he has had me over at his house and about three different times he would put his mouth down on my peter and suck on it. While he would be sucking on my peter we would be in the bedroom at his house all except one time and that was in his car and he was taking me home and he drove up behind the salt mine and stopped the car and he told me to get in the back seat with him and he sucked on my peter. One time when I was over at his house he took me into his bathroom and he pulled my pants down and he told me to bend over and he took his peter and stuck it in my but hole[sic]. It hurt me and after he got through some white stuff run down out of my but[sic]. The above excerpt well illustrates the processes of sexual behaviors in the context

of how they are escalated from initiation to termination within a case. This particular boy victim states that he has been involved in the BSA for about six months when the first sexual molestation starts to occur. His assistant scoutmaster, Mr. Silva, has known that this boy needs special instruction as to how to pass his tenderfoot test, and has proceeded 
to build rapport with the boys and family members (mother and stepfather) until Mr. Silva is actually able to bring the boy into his residence.

Furthermore, although the boy does not provide the breakdowns of each behavior in a thorough manner, it is found that the perpetrator makes some efforts to identify the boy's needs (e.g., passing the test), and once he brings the boy in his house, which is equivalent with proximity to the bait in angling technique, the perpetrator gradually develops his sexual advances towards the boy as assessing the likelihood of the boy's cooperative response to his sexual movement.

Going back to the continuum of physical contacts, the first touch began with unzipping the boy's pants followed by fondling. It can be due to the lack of ability for a young boy victim to describe what exactly happens at the moment, or most possibly, the feeling of shame or embarrassment that affected the boy's inability to resist. There was no indication of the boy victim's resistance towards the perpetrator's sexual advances. Once the perpetrator had an idea of what kind of behaviors were effective to make sexual touches on this boy at his first attempt, the perpetrator became confident about carrying out more advanced sexual behaviors on the boy, such as performing oral sex and penetration.

Private locations. The boy victim described in this excerpt that the actions of sexual molestation take place at the perpetrator's residence. It can thus be inferred that those who use the angling method for same-sex child molestation within the BSA prefer some places isolated and familiar to themselves so that they can take the time to develop their sexual behaviors on the boy victim. However, it should also be noted that once the 
perpetrator feels comfortable with the boy victim in terms of delivering sexual behaviors, his selection of location is expanded.

Excerpt 5.

Last Wednesday, October 4, 1967, I called Mr. Silva that afternoon and told him that he could come over to my house and look at them and see if he wanted any of them. He told me that he couldn't bring any cats home because his wife couldn't be around them for some reason and that he would come over to my house though and look at them. My three sister and one brother was[sic] at home with me. Mr. Silva and myself went and looked at the kittens and then we went in the house. He told my sisters to go and look for my scout books and they did. This left Mr. Silva and myself alone in the bedroom. Mr. Silva then closed the bedroom door and he un-zipped my pants and took my peter out and started playing with it. Mr. Silva then un-zipped his own pants and started playing with his own peter and he then took my hand and made me play with his peter. He then got down on his knees and started sucking my peter. By this I mean that he put my peter in his mouth. While he was sucking my peter he was jacking off himself. One time while he was playing with my peter my nine year old sister started into the bedroom and Mr. Silva held the door and acted like he was playing with her by holding the door and I zipped my pants up before she got in the room and he let her in the room he sat down on the bed and crossed his legs so my sister couldn't see that his pants were un-zipped and that his peter was sticking out. As is described in the Excerpt 4, the boy victim does not exactly know what the perpetrator's behaviors mean and the consequences of such sexual activities. He 
describes semen coming from his perpetrator in plain and innocent words, "white stuff." His expression can be translated that boys at his age (age of the boy) may have not been explained or exposed to sexual activities, especially in male-on-male situations. Similar reactions are frequently found from other cases, and this will be discussed in the next section.

Most importantly, this young boy seems very loyal to his scoutmaster regardless of the sexual nuances in the behaviors that the perpetrator has delivered to the boy. The sense of trust then leads the boy to invite the perpetrator to his house to watch newborn kittens. However, the perpetrator, who has built confidence and comfort with his victim, takes advantage of the boy's innocence, and interprets the invitation as a sign of consent to another sexual molestation. Consequently, Mr. Silva blatantly carries out sexual activities while other family members are present in the same house.

As mentioned previously, the majority of the angling cases take place while a boy victim is left alone with his scoutmaster. If this is the case, the location is most likely to be either the perpetrator's residence or some other isolated places. It should be noted that several angling cases are also found to take place during outdoor activities; other boys or staff members are present while the scoutmaster perpetrator sexually assaults the victim. However, in outdoor locations, angling scoutmaster perpetrators can still find an isolated place, such as their tent, in order to remain undisturbed while initiating sexual advances against a target victim.

The following excerpt illustrates how a scoutmaster perpetrator molested a boy victim at a location while other boys were around.

Excerpt 6. 
The first nite when we were in the tent, we were about to go to sleep but we didn't for about an hour. When Mr. Harkeness was coming to bed I wanted to talk about the awards with him. Most of the scouts in the tent unrolled their sleeping bags and I was talking to Mr. Harkness. I was in my sleeping bag. Mr. Harkeness unrolled his bag right next to mine. Then he got into his sleeping bag. He scooted my bag next to his. He put his left arm around my shoulder and as he talked to me he moved his hand downward. He touched my legs, privates, chest, and arm. He was holding me close to him. Then he stopped a little bit later. The second nite the troop and another troop played a game. The game finished and we were all very tired-we did a lot of running. I wanted to go to sleep but Mr. Harkeness didn't want me to. He wanted me to go out and listen at the campfire....I was tired but Mr. Harkeness kept me awake by talking about awards. I asked him about awards but I didn't expect him to talk that long. Again he scooted my sleeping bag next to his. He put his arm around me and did things like he did the nite before. He touched me a little longer this time.

In this narrative, the overall behavioral processes are the same, such as beginning with touching other parts of the boy's body. However, this incident took place during the campout, and specifically, in the victim's tent. Contrary to the previous excerpt (see Mr. Silva) that both victim and perpetrator were isolated from other people, even though they all were in the same house, Excerpt 6 shows that Mr. Harkeness did not mind carrying out sexual activities on the boy victim while other boys were sleeping in the same tent.

One of the differences that the two locations, perpetrator's residence and campsite, suggests is the degree of "obsession and preparation" that each perpetrator has for his 
victim. For instance, a perpetrator may need to invest more time and effort to build trust with a victim and family so that he can eventually bring the victim into his residence. Also, as Mr. Silva's case indicates, a perpetrator needs to acknowledge his victim's interest and need so that, at a minimum, the perpetrator can have something to lure the victim to his residence. However, in Excerpt 5, it does not require for Mr. Harkeness to conduct "research" on his potential victim. Rather, he is able to cease the self-provided opportunity that the boy presents (e.g., wants to talk about the awards and promotions within the BSA), and is able to usurp the boy's needs into the opportunity to achieve his sexual goals.

According to the boy victim's narratives, Mr. Harkeness molested him multiple times, and as the excerpt indicated, the sexual behaviors' duration or intensity escalated as the number of contacts increased. Most importantly, perpetrators who use an angling technique tend to repeat their molestation against the same victims because each time they learn how to advance their sexual behavior based on the victim's reactions and behavioral responses. As previously mentioned, most boy victims had built a great amount of respect and trust for their scoutmasters.

Repeated actions. One of the significances of the angling technique is that perpetrators begin with seemingly unsuspicious actions, such as casual hugging, and gradually develop into obvious behaviors, such as fondling. Thus, boy victims are not able to distinguish the intent of such touches until it gets really serious, usually defined as the point of erection or masturbation. Also, young boys are simply not aware of/ exposed to male-on-male touching. Consequently, while boys were in an indecisive state or simply ignorant of what to do, their perpetrators are able to take advantage of such a 
sense of ambiguity and/or anxiety being interpreted as "yes" to their sexual behaviors, and continuously carry out their molestation. The following excerpt also illustrates the patterns of repeated molestation on one boy. As the number of molestation incidents increases, the level of sexual molesting behaviors that the perpetrator makes against the boy victim also escalates.

\section{Excerpt 7.}

I am 13 years old. I joined Troop 5 about a year and a half ago. The Scoutmaster was Max Dubois. On one Saturday morning last winter, Max asked me to go to his apartment to help him move some stuff in the attic. He picked me up at my house on his motorcycle and took me to his apartment. After we got there he sat down in a big chair that hits back and has a foot piece and asked me to sit on it with him. He started feeling me, and after a while he put his hand inside my pants and played with my dick. About two Saturday later the same thing happened when I went to his apartment. Over the next four or five months I went to his apartment sometimes 2 or 3 times Saturday in a row and sometimes I skipped a week or two. Each time he would pick me up on his motorcycle late morning or about noon, and bring me home about an hour later. The third time I went to his apartment he got in bed and asked me to get in bed with him. He was wearing his underpants, and I was in my clothes. He told me to take off my clothes, and I did except my underpants. We stayed on top of the covers and he played with my dick, and kept doing it for about 30 minutes. Thus we got dressed and he took me home. The same thing happened on my next visit. On about my $5^{\text {th }}$ visit to Max's apartment, after he played with my dick for a while he took my underpants off, 
and he kept playing with my dick. A little later he took off his underpants and put his finger in my rear end and felt around. After a while he put his mouth around my dick and sucked. After about 15 minutes we got dressed and he took me home. The same thing happened on several other Saturdays, but about 3 Saturdays later he made me put his dick in my mouth....About a month after the first time I went to his apartment, the whole Troop went camping at Richmond Hill. On Sunday afternoon, we were playing in the Ogeechee River, and Max asked me to come to his tent. We took off our clothes and laid on his air cushion under a silk blanket and he played with my dick. The same thing happened on three other camping trips.

As is seen in other excerpts, the boy in Excerpt 7 is also a targeted victim chosen by his scoutmaster, Max. The boy narrates that he is asked to help Max with his chores. This invitation can be considered as an action of throwing a fishing line into the water, which the fisherman thinks is a good spot to catch fish, by using two things: his position as scoutmaster and the boy's altruistic character. Then, Max starts to take an action on the boy by making all the behaviors look accidental yet natural, such as sitting in a recliner chair together.

As gradually developing his sexual advance against the boy (e.g., sitting on his lap and touching boy's body), Max observes the boy's reactions and acquires an idea that his target is likely to be non-resistant and submissive. Confidence is built based on the boy's reaction, which is doing nothing. Max keeps moving forward by putting his hand inside the boy's pants and fondling the boy's penis. Max's sexual advances become more frequent and serious as time passes. 
As was shown in previous excerpts, perpetrators who utilize angling techniques for child molestation tend to seek isolated and undisturbed spaces, such as their residence. However, in some cases, they are able to continue sexual molestation while other people are around, especially during scout campouts. Such a location demonstrates the perpetrators' confidence and comfortableness about their victims and in their abilities. .

In the later part of Excerpt 7, Max expands his location of molestation to more open spaces, the Boy Scout campsite. Max invites the same boy into his tent, which is equivalent to his own room at a campsite, and proceeds to molest the boy as he usually does at his residence. One of the significant points in perpetrators' behaviors in this strategy is that they usually try to bring the boys into their safety zone, instead of the perpetrators themselves entering into the boys' spaces. Even during the campout, where there is not enough room for privacy, Max molests the boy in his tent. To secure their privacy while public events are going on, some perpetrators frequently come up with excuses that can justify the separation of their target victims from others. As a result, the potential victims usually end up being placed in either perpetrator's tents or some other isolated places. The following excerpt illustrates how a perpetrator is able to isolate a victim while other people are around at campsite.

\section{Excerpt 8 .}

In the morning I went down to the lake and there I saw Mel again. Then we meditated and went to breakfast. During "Breakfast" by use of sighn[sic] language he asked me what name was and when my birthday was. During this time he had been periodically hugging me. After I finished Breakfast we had some spare time....Then we went to our work crews and then after working came 
back for "lunch" and periodically he hugged me and squeezed my hand. After lunch we went back to work until we were called for a meeting at the (blank). At the meeting he asked me to sit with him and the other boy joining this time he playfully tickled me. After the meeting we went to change for dinner. During dinner I stayed away from him. Then when dinner was over I went over to see if I could sleep with Mr. Thompsons Troop because I have a few friends in that troop. I could not find their camp, so I went to the nature lodge where Mel and (A) were. Mel asked me if I wanted to sleep with him and I said OK. After putting my ground cloth and sleeping bag down, he asked me if I wanted to walk with him and I said I was tired and was going to bed. He said he wished I could walk with him. I consented and we walked across the stream to some rocks where he asked me about merit badges and whether I held a troop office or not. Then someone came by and asked what we were doing and he said talking about troop offices. Then we moved under a tree and he told me to lie down and relackse[sic] then he told me to picture a balloon in my mind then he asked me what color it was. Then he told me to watch it rise but it will never fade. Then told me my body felt like lead. During this time he had been caressing me on the legs and (blank). He then told me to pull down my pants and he then started to fondle my penis. While he was doing this he asked me if it bothered me. Then he asked me what I was thinking about and I said I was thinking about why he was doing this and that I thought it was stupid. He said that he was trying to help me and I said with what? He said what ever[sic] I needed help with. 
According to the boy victim, it is his first time he meets Mel during a scout camp. The camp runs for several days, and since an introduction is made between Mel and the boy, Mel starts to show interest in the boy by asking his address and attempts to make an initiation movement by hugging the boy and holding his hand. The boy seems cautious enough to stay away from Mel after several unexpected physical contacts, such as hugging.

However, at night, the boy cannot find his friend and ends up entering Mel's tent where there are $\mathrm{Mel}$ and another person. To find an undisturbed and isolated place, Mel attempts to take the boy to outside the tent by asking the boy to walk with him. Again, the boy does not want to, but Mel is eventually able to take advantage of the goodness of a young boy. Even though Mel encounters another obstacle, someone comes by, even in a safety zone, Mel is able to be free of suspicion by using his position as a scoutmaster.

As this excerpt shows, in order to carry out sexual behaviors, Mel has repeatedly tested the boy regarding how far he can make sexual advances with the boy. Although it is their first time meeting each other, over the course of camp activities (e.g., during/ between meals) Mel has gradually tried to narrow the distance between the boy and him. Mel eventually succeeds in taking the boy to an isolated place where Mel can achieve his goal, fondling the boy's penis. In the course of the interaction, Mel disguises sexual activities as some type of meditation processes.

\section{Excerpt 9.}

At the age of about 14 in April of 1964 I was approached by Jim as to going on a trip with him to the mountains for snowshoeing. I was told that he was going to take a couple of other guys along and that I would be welcome. As it turned out it 
was only Jim and I that went, he told me that other wouldn't be able to come because of certain changes in plans. We went up near Idaho Springs and on the way up he treated me to a dinner. It was about 5:30 or 6:00 when we arrived at our destination on a desolate mountain road off the main highway. I tried the snowshoes while Jim remained in the car, an International with large open areas in back, and then came back. We talked about different things such as Order of the Arrow, the existence of God, and the universe. Then he began talking with me about friendship and society's view of same. As time proceeded he made various physical contact with me, saying, "Let's wrestle," or just pretending to bend my arm....Later I told him as the conversation proceeded that I had been feeling very nervous lately so he offered to give me a massage. During this time he made the first contact with my penis. Then we went to bed and had mutual masturbation.

The above excerpt also demonstrates a premeditated plan of the perpetrator, Jim, in his selection of location and separating the two of them in an isolated place. Jim knows that his potential victim, a 14-year old boy, is interested in an out-door activity. He comes up with a plan to be left alone with the victim by telling the victim a lie about the number of people who would be there together.

As was mentioned in the previous excerpt, most of the perpetrators using angling methods prefer isolated places, such as their residences. If not available, they make great efforts to find excuses to isolate their victims, and then proceed to their sexual advances from the beginning, such as natural touching of other body parts. In this excerpt, Jim also 
tried to justify his behaviors with his victim by discussing the issues of friendship and conventional views of same-sex relationships.

It is also noted that, in most of the angling method cases, perpetrators are more likely to treat their victims as intimate partners, as is seen in the narrative that Jim treats the boy to dinner, while expecting submissive yet reciprocal behaviors from the victims. It is unknown from the narratives whether each perpetrator has only one victim or multiple victims during their tenure of scoutmaster. Therefore, it is too soon to conclude that all perpetrators using angling techniques are obsessed with their boy victims to the point where they express the sense of jealousy.

Contextual factors. Before getting to the details about contextual factors that affect the processes of sexual advances that scoutmaster perpetrators make against boy victims, it should be reminded that the outcomes of the angling method are results from carefully calculated and planned behaviors. Scoutmaster perpetrators manipulate young boys under their care in several ways in an effort to bring them into the perfect timing and spaces to initiate sexual advances. In other words, it is certain that the choice of victim, location, and most importantly, ambience in angling method are not spontaneously made.

Those who use this technique are more premeditated, organized, and most importantly, responsive to circumstantial factors like contingent environmental conditions. As their sexual advances against boys escalate, the victims are more likely to build the sense of shame, guilt, and embarrassment. Consequently, once the victims lose their momentum to resist or report their victimization, sexual molestation is more likely to repeat. The angling perpetrators are able to manipulate not only the victims' internal 
feelings, but also their external needs and interests. In the following excerpts, the narratives show the specific ways in which scoutmasters recruit the boys as their permanent victims by constructing the emotional and circumstantial traps.

Excerpt 10.

I first met Michael Ross at the beginning of summer 76, during school summer vacation, at Santa Monica Pier. Ross took me and others to a lot of places during that summer. Ross took me to Magic mountain a couple of times in July of 76, after the fourth.... At Ross's house, (A) and I sat down on the sofa and Ross sat on a chair, we all watched color TV for about 10 mins. Ross came over to where I was sitting and grabbed (blank). I had no shoes on at that time. I then saw Ross, (blank) and suck on (A) toes. Ross then took (A) into the bedroom and closed the door, they were in there together for a few mins. Ross and (A) came out, I saw some (blank) (A)'s hand. Ross told me he would give me forty dollars, if I would let him suck my dick. I said ok. I went into the bedroom with him. (A) stayed in the livingroom. Once inside the bedroom, Ross closed the door, told me to pull my pants down and sit on the bed. Ross sat on the bed, next to me, leaned over and began sucking my dick. Ross sucked my dick for a couple of mins. When Ross finish, I pulled my pants up and Ross got twenty dollars (two tens) from his pocket and gave it to me.

To give a little bit of background story, Ross has repeatedly molested the boy, and the sexual interaction has reached the point of oral sex. As was seen in other excerpts, Ross has gradually developed his sexual touches with the boy victims. Sometimes, he invites multiple boys and molests each boy at a time in an isolated place, which happens 
in his room. Ross seems to treat his victims not as underage boys, but as sexual partners (prostitutes) by way of offering money for sexual interactions. Similarly, some scoutmaster perpetrators offer not only money, but also valuable gifts to their victims before/after they molest them. It can be inferred that child molesters who utilize angling methods prefer to be safe in performing and continuing the molestation against boy victims. To do so, many perpetrators employ various channels to safely enter and exit the stage of physical interactions with young boys under their charge.

Overall, the angling method requires perpetrators to have accomplished certain levels of preparation to create a suitable environment for them to initiate sexual advances against their targets. In this case, it is found that the unique interest of boys at scouting ages are taken into account when scoutmaster perpetrators create a desirable environment for baiting in the course of preparation, such as adult movies or magazines. Sometimes alcohol is involved in angling-type initiations. Scoutmaster perpetrators deliberately use such contextual factors because the environment helps the perpetrators to justify their behaviors to the victims, and most importantly, to increase the likelihood of victims' conformity to reciprocal sexual behaviors.

Excerpt 11.

It started back in 1973-1974. I was a scouter looking for a future in wrangling. My scoutmaster, Mr. Crooks was the head wrangler at D-A Scout Ranch on the weekends in the winter season. My objectives were to become a winter wrangler. Mr. Crooks had an interest in me because he was pushing me through the ranks so I could have enough experience in scouting to ride for him. Some of my duties to him were to receive the "Beard". The beard is an initiation or something like one 
where Mr. Crooks would rub his unshaved face on my chest until I gave up...Drinking was not a usual practice for me while I was at home. But the night I got to the ranch for the first time I was offered a beer. At the time I was offered, (A) already had a beer but (B) was not drinking. I took the beer and was requested to give Mr. Crooks a special. A special was a backrub to be given to Mr. Crooks on request. If someone did not want to give him a special they were threatened with their job. I was threatened many times. The first couple specials I was required to give were done in the presents of other wranglers. So I got the feeling they were harmless. Eventually Crooks worked his way up to making me give them to him on Sunday afternoon when nobody was around. After a couple of week of that, I was required to sleep in the same room as Crooks and give him a special while he was getting to sleep. If I resisted my job was threatened. I wanted to be a wrangler pretty bad so I always gave in. Usually after the special Crooks would turn around and pull me down off his back. I would have to lay on my back on his bed while he layed on top of me. If I was wearing a tee-shirt he would take it off of me...Eventually I was catching on to why Crooks was pulling me down after the beard, I felt Crooks masturbating on either my leg or the corner of the bed. I knew it was happening but didn't know what to do. As far as I knew he didn't continue until ejaculation but there was the possibility. While this was happening he usually fondled the upper half of my body (breast section). Many times he would swipe over my penis with his hand after pulling my leg closer. Many times he excited me until I had an erection. (Boy 15 years) 
The above narrative is one of the cases involving alcohol before a perpetrator makes sexual advances against a boy victim. Crooks tries to engage the boy victim into physical contacts in a deceptive way. Crooks orders that the boy receive the "Beard" as a means of promotion. To justify such behaviors, Crooks attempts to convince the boy that the process is a part of initiation process to promotion. It can be inferred that Crooks uses his position of authority to make the victim feel obligated to conform to Crooks' command.

At the same time, Crooks blatantly provides alcohol to the boys and the consumption of alcohol is used as a medium to desensitize the boys about what they are asked to do to Crooks, such as the "Beard" and the special. Crooks begins his crime with broader targets (several boys) by providing them alcohol and exchanging some physical contacts. Then, he eventually narrows down to one boy (according to his narrative) and is able to engage his victim into further sexual behaviors, such as laying on top of the boy and masturbating. The following excerpts illustrate another way of creating sexually charged atmosphere by scoutmaster perpetrators. In these cases, the perpetrators again try to take advantage of young boys' proclivity to sexually explicit materials. By doing so, it becomes much easier for the perpetrators to initiate sexual advances against the boys.

Excerpt 12 (1).

Roy picked up at my house at approximately 6:00 p.m. and we went over to his house. Upon arrival at the Case home, Roy gave me some magazines to look at. The magazines varied from "pin-up" to "hard-core" pornography showing men and women engaged in sexual intercourse...I read some more of the magazines 
given by Roy and then we went to bed at about 11:30 pm. Roy had a double bed and during the hour it took me to go to sleep, Roy made three or four homosexual advances towards me.

Excerpt 12 (2).

He (boy) further stated that upon entering the room, Mr. Backes accompanied him to the bed and at this time produced magazines with nude women in them and showed them to him. (Boy) stated at this time Mr. Backes reached over and grabbed ahold of (boy) pants and unzipped them and pulled them down to his knee. He stated at this point Mr. Backes began fondling (boy) penis. After manipulating (boy) penis for a short period of time, Mr. Backes pulled his pants down to his knees and began masturbating himself. He stated that then Mr. Backes put his head down and took (boy) penis in his mouth and commenced to lick it. After this there was some conversations between Mr. Backes and (boy) and in this conversation Mr. Backes was explaining to (boy) various things related to the facts of life. Mr. Backes then lay back on the bed and masturbated until he ejaculated. (Boy) related that he observed a white liquid coming from Mr. Backes' penis. After this Mr. Backes showed the sperm to (boy).

As is shown in the two excerpts, angling initiation is made up of different types of preparations. It can include the use of alcohol to desensitize boy victims, and sometimes, creating a sexually-charged atmosphere to easily invite boy victims into sexual advances. From the routine activity perspective, the preparation stage can be interpreted as a transforming process having new roles assigned to or assumed by each member in this situation. 
There are always three components converging in a same time and space when a crime occurs. The three elements (actors) are motivated offender, suitable target, and an absence of capable guardian. However, only two main actors are involved in the activities involving the members of the Boy Scouts of America, scoutmasters and boy members. Therefore, in an analysis of same-sex child molestation within this youth organization, it is important to know the dynamics of role changing in terms of when and how the two actors switch to and perform their new roles.

For instance, in the course of the initiation process scoutmasters who are supposed to serve as capable guardians obviously replace the role with that of motivated offenders and young boy members serve as suitable targets in this scenario. Simply put, in the same-sex child molestation cases within the Boy Scouts of America, it is apparent that only two actors, boy members and scoutmasters, constitute the three actors in routine activity framework, and this analysis extensively focuses on the patterns of such behaviors by looking into the role switching between the two actors.

In this section, it has been discussed how scoutmaster perpetrators initiate and develop their sexual behaviors against boy victims. An angling fishing method is used to explain detailed behavioral sequences that scoutmaster perpetrators carry out to groom their boy victims into the sexual interactions. In an angling method it should be noted that boy victims are always fully awake while all the sexual advances are made. In theory, the boys are able to express instant responses to the perpetrators' sexually charged behaviors. However, in reality, it is hard for young boys to acknowledge the complexities of behaviors that their scoutmasters carry out, especially having sexual intent hidden underneath such behaviors. . 
For instance, young boys hardly have previous sexual experience, especially male-on-male interactions. Thus, boy victims are not equipped with a frame of reference to determine whether their scoutmasters' behaviors are sexually charged or not. Furthermore, angling initiation is gradually developed from very casual actions, such as hugging and holding hands; the ambiguous characteristics of such behaviors do not allow the boys to speculate that they are being treated as sexual subjects by their scoutmasters.

By the time the boys realize what has been happening to them, they have been unintentionally involved in further sexual interactions. Therefore, the boys come to feel responsible for the whole situation and the self-blame and shame hinders the boys from seeking external assistance to rescue themselves from repeated molestation. Since the victims are fully conscious and their responses are used by the perpetrators to re-calibrate their future movement against the victims, sexual molestation adopting an angling method takes the perpetrators a prolonged time and more efforts for preparation and delivery of the behaviors.

Spearfishing contact. As one of the fishing techniques, spearfishing involves a fisherman in the use of a spear or any type of sharpened tool to strike the hunted fish. Angling fishing does not require for a fisherman to venture into the water. Instead, the fisherman hangs baits at the end of fishing line to attract the hunted fish to the hook. However, spearfishing demands that a fisherman walk into the water and actively attack the fish he wants to catch. Hence, the fisherman can attack the target fish when it least expects. Furthermore, the angling method is used to catch fish alive after several rounds of the tug of war over the baits. Yet, spearfishing usually causes death or paralysis of the caught fish due to the strike with force made by the fisherman. Once striking is 
successful, it is much easier for the fisherman to carry on their next step, harvesting the fish. However, once missed, the fisherman has no choice but to seek another fish.

The most significant distinction between a spearfishing-type initiation and other methods for initiating contact is the victim's state. To be specific, in spearfishing cases, boy victims are usually unconscious or in a pre-occupied state, such as sleeping or driving. The victims are not capable of realizing what is going on until they wake up (or realize) to find the perpetrators are fondling their private parts. Touching the boys' penis underneath their clothes is usually found to be a "starting point" of sexual molestation in most spearfishing-type cases. While the angling method involves at least a couple of steps (e.g., holding hands and hugging), perpetrators who adopt the spearfishing method are able to skip all those "grooming" processes to achieve their initial goal, fondling a boy's penis.

As the title of method suggests, victims usually become too paralyzed and shocked by the sudden attack to effectively resist on-going sexual molestation. Usually, the feelings of shock and embarrassment that boy victims experience turn into a good chance for scoutmaster perpetrators to increase the level of sexual molestation. They are also able to take advantage of victims' states being dazed and drowsy resulting from sleeping. Furthermore, victims' motionless state out of shock is usually interpreted as passive consent by the perpetrators, and therefore, the same behaviors are likely to occur repeatedly.

Behavioral sequences in spearfishing method. About 15\% of scoutmaster perpetrators were found to employ a spearfishing method when initiating their sexual contact with their boy victims. Spearfishing hardly involves a preparation stages for 
perpetrators to accomplish a minimum of their goals, that being to touch a boy's penis. In this analysis, the spearfishing method used in same-sex child molestation within the Boy Scouts of America will be thoroughly discussed in terms of its effects on the boy victims' state of mind and the environment where the child molestation occurs to affect the pattern of child molestation. Before proceeding to the breakdowns of significance in spearfishing child molestation within the BSA, it is necessary to acknowledge general behavioral components that make up a spearfishing attack by scoutmaster perpetrators. The following excerpts are intended to represent the overall patterns of spearfishing behaviors that scoutmaster perpetrators exhibit against their boy victims.

\section{Excerpt 13.}

(Boy) was clothed for sleeping in his short, long johns, and a turtle neck sweater. They (boys) went to sleep about 12:15 am was awakened by (Richins) stroking his leg about 6 inches above the knee. (Boy) was lying on his back as he awoke. He was confused by this and subsequent actions and said nothing-and report that (Richins) said nothing in this or the subsequent episode. After stroking his leg for 2-3- minutes, (Richins) then reached above and pulled down his (boy's) long johns and shorts from his waist to just below his genitals. (Richins) pulled at one side, and then the other to accomplish this result. At that point, (Richins) used both of his hands, the one manipulating (boy) testicles and the other stroking (boy's) penis. He fondled (boy) this way for 5 minutes. (Richins) first produced an erection on (boy) with his hand, and then (Richins) took his thumb and forefinger and moved to a stroking action up and down the length of the penis, masturbating (boy) with this method, periodically drawing his thumb over the end 
of the penis. (Boy) tried to think what to do and realizing that (Richins) was attempting to effect an ejaculation.

The above narrative succinctly demonstrates behavioral components that constitute spearfishing initiation. Richins begins his sexual advance while the boy victim is asleep. In this regard, one of the significant points that should be taken into account in this excerpt is the victim's state. The boy has not been aware of Richins' behaviors until he wakes up to excessive force made by Richins over his body. The boy instantly becomes paralyzed out of shock and also confused of the whole situation at the moment.

In the meantime, Richins, who believes the boy is still asleep, starts to undress and masturbate the boy to the point he ejaculates. To Richins, the sleeping boy is nothing but a toy that he can sexually manipulate and from which to earn sexual gratification. Again, due to the boy's unconscious state- he has been sleeping-Richins is able to minimize the time and effort that would have taken to develop his sexual relationship with the boy from the beginning, such as hugging or holding hands. Therefore, in spearfishing behaviors, it is important to verify the specific action to which a boy victim wakes up. Usually, it is fondling or touching of the boy's penis.

\section{Excerpt 14.}

(Boy) told that Bill Fisher asked him to get in bed with him because it was cold and the heat was turned down. After he kissed him on the lips and told him good night, (boy) began to go to sleep. (Boy) said he felt his underpants being pulled down and Bill's hand began rubbing his buttocks. (Boy) felt peculiar, but did not know exactly what to do, except hoping that he would quit. After a time, he felt Bill's hand go between his legs and began to fill[sic] his genitals. (Boy) began to 
fill[sic] panic, but was afraid to move or say anything. After a time Bill pulled down his underpants and lay on top of (boy), (boy) felt terrified and just wished Bill would get off of him.

The above narrative also precisely captures the dynamics in spearfishing-type initiation and the boy victim's state of unconsciousness. The boy wakes up to Fisher's sexual touching, such as undressing and rubbing his private parts. Out of shock and drowsiness, the boy does not know how to handle this situation. Furthermore, the boy's body starts to respond to the perpetrator's constant fondling, which leads the boy to even a greater degree of fear and shame being unable to stop Fisher from continuing his behavior. By the time Fisher undresses himself and moves on top of the boy, the boy almost gives in and lets Fisher achieve what he wants. In the course of this episode, Fisher still does not know the boy is awake. In other words, Fisher is able to take advantage of the fear and shock that the boy is experiencing.

\section{Excerpt 15.}

I was on an overnight with the ranger program, and was sick so they were going to walk me in but Jim Kennedy showed up for no apparent reason except to check on us out there. So me and (A) received a ride in with him. The doctor told me not to go back so Jim Kennedy said I could sleep in his air conditioned cabin so I said all right. I went to sleep about 2:00 pm. About (2:30 approx) I woke up as Jim Kennedy had his mouth over my jenitiles[sic] sucking, it was past the point of stopping him. I did not do anything because it was just him and me up on chapel hill and did not no[sic] how to react after the climax. He went into the bathroom did something I do not know what. Then while going back to bed he kissed me 
on the shoulder and said good night. There is know[sic] way he could have know I was up it was so dark as it was I could not see the air conditioner less than 2 feet away from me. I was on the top bunk he was standing during the ordeal.

Similar to the previous two excerpts, Kennedy delivers sexual advances to the boy victim while the boy is asleep. Owing to the boy's unwitting state, Kennedy is able to reduce the amount of time and effort for gradually inviting the boy into sexually charged behaviors in a reciprocal manner. Rather, Kennedy forthrightly performs oral sex on the boy, and this is the point when the boy wakes up and becomes paralyzed out of shock. Kennedy performs several experimental-type of sexual behaviors in an attempt to stimulate the boy, and Kennedy succeeds to cause the boy's erection. Not knowing that the boy is fully awake, Kennedy also treats him like an object of sexual pleasure that does not demand Kennedy any extra reciprocity and concern of being resisted.

Public locations. In an angling method, it was found that the majority of child molesters tended to seek isolated place where they could covertly develop their sexual relationships with boy victims, such as their own residence. Even when they are out in public (e.g., camping) with others, scoutmaster perpetrators who prefer an angling-type of approach to their victims make efforts to separate their potential victims from a crowd. It is noted that boy victims approached in a spearfishing method are treated like manufactured goods that can be accessed as needed, when compared to the boys approached by the scoutmasters using angling methods. This significance will be discussed in its own right shortly, however, it is worth noting that the selection of locations for spearfishing can be a reflection of perpetrators' perceptions about their boy 
victims. Or, it may simply be a manifestation of confidence that the perpetrators have after calculating costs and benefits of molesting sleeping boys.

Excerpt 16.

Saturday afternoon at Sue Cherley Lake we fished. Mr. Leland went fishing with (A) somewhere for about one-half hour. (B) and I stayed together. Saturday night we all slept in one tent. After we were in our sleeping bags for a while Mr. Leland unzipped my sleeping bag. I didn't know what was wrong with him but he kept putting his hands on my privates. Every time I would wake up my pants would be opened and I had to keep moving around and rolling over on my stomach to keep his hands out of there.

Excerpt 17.

It happened on the night of July 13, 1971, (A), (B), Herb, and I were on our way back from the canoe trip in Herb's plane. We were spending the night in Ogden, Utah. (A) and (B) were sleeping in one bed, Herb and I were sleeping in the other. I woke up in the middle of the night and realize that Herb was holding my sexual organ. At first, I was too groggy to do anything, but finally rolled over and he let go.

\section{Excerpt 18.}

On March $14^{\text {th }}, 1982$, while on his first weekend camping trip, our son (age 11) awoke during the early morning hours with Mr. Bob Deal laying beside him. $\mathrm{He}$ was aware of his levi-shorts and underwear being pulled down and his genitals fondled. He was afraid to say anything or keep his eyes open...Two older scouts were asleep nearby in the same tent, but no other boys Todd's age. 
According to the boy's description in Excerpt 16, he is sharing his tent with two other boys and Mr. Leland at a campsite. We cannot assume what has happened to the boy (A) while gone fishing with Mr. Leland, but according to our victim, they disappeared for about one half-hour. When night arrives, believing that the boy is asleep, Mr. Leland starts to unzip the boy's pants and to fondle his penis. Such actions are repeatedly carried out every time the boy falls asleep. Above all, the point of this excerpt is that Leland does not molest the boy victims while other boys are present in the same tent. This behavior significantly illustrates scoutmaster perpetrators' different perceptions of their victims that while the boys are treated as private and secretive sexual partners by the scoutmasters performing an angling method, boy victims are more likely to be treated as public and accessible objects by the perpetrators who tend to make spearfishing-type initiation.

Similarly, the boy victim in Excerpt 17 specifies that four people share the two beds in the same room. Although we are not told how the boy ends up using the same bed with Herb, it is apparent that Herb targets the boy for sexual gratification. His plan to molest an unconscious (sleeping) victim is then successfully accomplished. Even after awakening, the boy is not able to think straight until he realizes the situation and is able to roll over to the other side. The most important point in this narrative is again that Herb is not afraid to carry out sexual acts on the boy victims while other people are around in the same hotel room. At the same time, it is also noted that, in the offender's mind, everyone including the victim is asleep.

Excerpt 19. 
A couple of weeks later we went to see another movie but this time it was at a drive-in and also we were in the van this time instead of the car. I was uncomfortable sitting in the front seat so we moved to the back seat which was folded down so we could lay on it. I had no idea about what was about to happen. Nor did I have any intention about it rather-we were both lieing[sic] on the folded down seat and watching the movie. I was so involved in watching the movie hat I dodn't know what he was doing for a couple of minutes. When I finally relized[sic] what was happning[sic], he had unsipped[sic] my pants and was feeling around...I knew it must be wrong but never having it be done to me before, I was confussed[sic] on the way home, we got to a back road and next thing I knew I was driving again I can't remember if I ask him to drive or if he has asked me. But, as I was driving, he was kneeling beside me I thought he was just there to help me drive because I needed help. But then he started playing with me again. I was so shocked that I lost control of the van for a moment but he grabbed a hold of the wheel and pulled the van back on the road. I told him to stop and started driving again. But he continued to play with me. I honestly didn’t know what to do because he just didn’t stop.

Excerpt 20.

Mr. Cooney asked for a volunteer to accompany him to his car that was parked in the lower lot near the council ring at Camp Catchalot. (Boy) and (A) volunteered. Mr. Cooney choose (boy). Mr. Cooney asked if (boy) would like to drive his car. Mr. Cooney sat behind the wheel and asked (boy) to slide over next to him. Mr. Cooney edged the car out and allowed (boy) to steer the car and use the gas to 
drive the car up to the parking lot reserved for campers staying for the week. While (boy) was steering the car, he felt Mr. Cooney's hand scratch against his genitals.

Both of the incidents in the above narratives take place inside perpetrators' vehicles: One happens while they are watching a movie at a drive-in theatre, and the other occurs while the boy victim is driving the perpetrator's car. Unlike the previous incidents that take place while boy victims are deeply asleep, in these two excerpts, victims are fully awake. Nevertheless, it should be noted that the boys in the both excerpts are occupied with their activities — watching a movie and driving respectively— and therefore resistance is fairly limited. The method of attack that the scoutmaster perpetrators adopt to begin their sexual contact on the boys is a quick and intense spearfishing behavior. By doing so, both perpetrators are able to freeze their boys and to start their sexual movement from an advanced point, fondling the boys' penis.

Most importantly, spearfishing initiations are made at more diverse locations, compared to the limited selections where angling-type of initiation occurs. In other words, perpetrators who approach their victims in a spearfishing manner are given more options in locations, while the perpetrators making angling initiation actions prefer their residence and/or tent at a campsite. Such a difference can be interpreted as a reflection of the perpetrators' viewpoint about their victims.

As is discussed in the previous excerpts, spearfishing perpetrators view their victims as the equivalents of inanimate objects. Victims in spearfishing initiation approaches are only expected to play a passive role in responding to the perpetrators' actions. Perpetrators do not expect or want their victims to reciprocate in kind. Rather, it 
is found that the perpetrators prefer their victims to remain unconscious so that they do not have to deal with any unforeseen obstructions, such as victims' resistance, in the course of sexual molestation. Therefore, the perpetrators do not feel it necessary to take into account victims' feelings (e.g., shame, embarrassment) when they are molested in public locations. In a way, spearfishing and the men who carry out these types of attacks against young boys can be viewed as a form of sexual paraphilia, for boys are simply used as sexual objects used for the purposes of the offenders' sexual gratification.

Similarly, one of the major purposes of carrying out spearfishing-type initiation is to take advantage of victims' immobility resulting from sleeping, or driving or other activities that require victims to pay utmost attention. Since the victims are pre-occupied with other activities and thus incapable of giving active feedback, the perpetrators may feel less concerned about victims' resistance and/or unforeseen factors that restrain them from accomplishing sexual gratification. Also, boys who are attacked in a spearfishing manner usually become paralyzed out of shock, and therefore, the victims are not able to respond to such sexually charged attacks in a timely and effective manner.

Frozen victims. In the previous excerpts, it is argued that scoutmaster perpetrators intentionally target boys who are unconscious or sleeping in most cases, and sometimes, they are preoccupied with other activities, such as driving or watching movies. By the time the boys are able to detect the sexual contact by their scoutmasters or their body's reactions (e.g., erection), the boys usually find themselves being undressed and fondled by the perpetrators. Boy victims state that they are not able to instantly process the situation due to the sustained drowsiness and/or abrupt fear and embarrassment. Furthermore, it is found that spearfishing initiation usually occurs in 
public locations while other people are present. Thus, due to the nature of same-sex child molestation, boy victims feel embarrassed to ask for help when they come to realize that their penises are already responding to the scoutmasters' sexual contact.

Excerpt 21.

On a Saturday night while camping with troop 55 at the River Bend campsite at Camp Arrow head Royce Adkins and I decided to tent together. I was awake[sic]n by Royce Adkins massaging my penis and pubic area. I was very deeply shocked and surprised because I had acquired an admiration and respect for him in the past.

Excerpt 22.

When I was approximately twelve or thirteen years-old, Robert took the scouts in our ward on an overnight camp. During the night, I was awakened to discover that Robert had unzipped my sleeping bag and was fondling my private parts with his hand. I pretended to remain asleep because I was frightened. After that, nearly every time that the scouts would have an overnight outing, Robert would repeat this behavior. This happened numerous times. He would foldle[sic] my genitals with his hands and sometimes also his mouth. I was both embarrassed and frightened to ever confront Robert about his actions and so I would just act like nothing had happened.

The above narratives illustrate the dreadful feelings that strike boy victims as soon as they find out their scoutmasters are touching their bodies to cause sexual arousal. The majority of the boys who are first victimized by the spearfishing-type approach indicate that their immobility at the scene arises as a result of the sense of betrayal, 
embarrassment, and shame. As intended by the scoutmasters, boys' feelings of shock then make the boy victims remain unresponsive to the actions of molestation.

Even though the boys are fully awake, the perpetrators do not have to worry about their resistance or confrontation because the boys still pretend that they are asleep. As was mentioned in the previous excerpts, most of the boy victims are at an age where they had not been exposed to sexually charged interactions either with women or men. It can also be inferred that such unique circumstances may come across the boy victims as scared and confused distress. Furthermore, the boys do not know what to do except for remaining motionless until their perpetrator finishes the sexual actions.

Excerpt 23.

I remember that we prayed out loud together. I felt very close to God. I felt secure in myself for the first time in my life. I felt that I had a friend I could trust. I awoke sometime in the early morning. I think it was about 5:00 A.M. I remember as though it was last night. I woke up and Mr. Danhauer had wrapped my left hand around his erect penis. He was moving my hand up and down to masturbate himself using myself. I distinctly remember the feeling of rubber as if he was using a condom, when he moved my hand over the tip of his penis. My first reaction was fear. I remember fearing for my life. I was afraid that he would find out that I was awake. I was thinking he might kill me if he found out I was awake.

As describing the boy's state of shock, this narrative demonstrates immediate fear that strikes the boy victim in the course of spearfishing molestation. In the discussion of angling initiation, it is found that boy victims of angling contact are usually given 
sufficient time between first general physical contact (e.g., hugging) and sexual molestation (e.g., fondling). Therefore, boys who are sexually contacted through angling initiation are accustomed to such behaviors, through the escalating nature of sexual behaviors. Most importantly, boy victims in angling initiations are all awake and in an active state. Even though their scoutmasters begin to sexually touch the boys' genital areas, the degree of shock may not be as great as the spearfishing victims may feel.

However, the boy victim in the above excerpt has not detected any sexually charged cues from his perpetrator; he has nothing but respect for his scoutmaster. Due to the sudden sexual attack, the boy instantly has to deal with both physical changes and emotional shock. While the angling perpetrators transform into sexual molesters through a protracted time span, the spearfishing perpetrators switch from good scoutmasters to sexual molesters in the blink of an eye. Consequently, the level of fear experienced by spearfishing victims can be greater, and such patterns are well illustrated in their narratives.

Perpetrators' reactions. Another significant theme in spearfishing initiation is found in perpetrators' behaviors after the molestation. That is, the majority of perpetrators still believe that their sexual contacts remain unknown to their victims. Believing that they have completed the perfect crime the night before, the perpetrators attempt to reset the incidents as if nothing has happened.

\section{Excerpt 24.}

The next morning, Robert came to me out in front of troop's camp. He asked me if I slept okay. I said yes. He made reference to if I had an erection when I work 
up. I said yes that I did. He said that I was probably dreaming about (A), a fellow scout's younger sister.

Excerpt 25.

(Boy) kept minimal contact with Richins that day, and inquired concerning going back with others, but went back with Richins as the only option. Richins acted as if nothing had happened during that day and on the way back home. Richins attempted to choose a tone of conversation that was neutral, their common interest in electronics and how he could hook up circuits in his room with his new stereo. The above excerpts show a specific behavioral pattern of perpetrators after they completed their spearfishing attacks. It should be noted that the angling perpetrators tend to gradually develop their relationships with the victims after they complete physical contact at each stage. This is consistent with the inference that the angling perpetrators are more likely to treat their boy victims as sexual partners from whom they can expect reciprocal responses and the same level of affection. Also, to groom the boy victims into further sexual contact, the angling perpetrators need to show how they care about their relationships and convince boys of the value of sexual interactions.

In contrast, the spearfishing perpetrators are found to treat their victims as motionless and emotionless objects. Hence, they do not need to express either affection or remorse to their victims in relation to their behaviors they have committed the night before. Most importantly, their boy victims are still believed to have been sleeping, although in fact the victims all acknowledge what the perpetrators did to them. Therefore, such afterwards reactions made by the perpetrators increase the degree of confusion and sense of shame on the victims' side, because the boy victims may feel that 
they are the only victims. Furthermore, the perpetrators' pretentious manner implies denial of what they have done to the victims, and therefore, the boy victims may feel it impossible for them to seek external assistance due to the unspeakable nature of such behaviors. The boy victims are more likely to sustain complex feelings about their victimization, and sometimes, feelings of helplessness discourage them from fighting their perpetrators and speaking of their victimization.

Disposable Victims. The analysis of initiation patterns is conducted largely based on the analogy that the Boy Scouts of America is like a fish farm. A fish farm provides unlimited resources to the fishermen who aim to catch fish. This analogy then expands to the fishing techniques being adopted to explain scoutmaster perpetrators' behavioral patterns of initiating physical contact to their boy victims. When it comes to a spearfishing method, a fisherman is supposed to attack one fish at a time with his tool with a certain level of risk of missing the target fish depending on the accuracy of strike and the response of the fish.

However, since the fisherman is located in and surrounded by plenty of fish in a fish farm, the fisherman does not need to worry about missing his target. There are always alternatives available in a fish farm. Once he misses one, he can immediately target the next one available, because the spearfishing method does not require any preparation period, such as reorganizing one's fishing rod and placing new baits. Therefore, as an extension of the analysis that the spearfishing perpetrators treat their victims as emotionless objects, the perpetrators also view them as disposable objects that can always be replaced by other fish.

Excerpt 26. 
On April 11, 1970, I went on an overnight camping hiking trip with five other boys and the Scout leader Mr. Paul Longway. There were two older boys from the Scout troop, Don Hershman and Redmond and a boy Malik Mobley who wanted to join. There was one younger boy (A) of the Scout troop and (B) and myself who wanted to join the scouts.

We hiked up North Mt. to tag Kun(?) when the fire tower had been. After supper we made two shelters and bedded down. The three older boys on one side of the fire and my two friends and $\mathrm{I}$ in the shelter on the other side of the fire. Mr. Longway suggested we three younger boys share our combined sleeping bags with him for warmth. Some time during the night, Mr. Longway who was sleeping between (A) and me began to get his hands inside my clothes. After fighting his off for half an hour ,finally hit him in the stomach then he stopped. The next morning (A) said Mr. Longway had done the same with him. I don't know whether he actually got his hands inside (A) pants or not. All three small boys were very mad the next morning and I told my parents when I got home. As this narrative indicates, Mr. Longway first targets one of the youngest boys in his camping troop, and begins to make a spearfishing-type contact, touching the boy. Longway does not bother making sexual advance against the boy while other boys are around. However, Longway encounters an unexpected obstruction, a boy victim's stubborn reactions. The boy victim resists to the point he hits Longway in the stomach, and finally succeeds in stopping Longway from making further physical contact. However, the scout activity, such as campouts, comes across to the perpetrator as a good source of young and vulnerable boys, and not surprisingly, it is later found that Longway 
attempted the same behaviors with other boys in the tent. It can be hence inferred that the spearfishing perpetrators hardly stay with one boy at a time. Rather, they demonstrate the exact same behavior that the fishermen adopt in spearfishing. That is, they do not spend excessive time over one target. If their attempt misses/fails, they move onto another target and repeat this behavior until they get one.

\section{Excerpt 27.}

To my knowledge it appeared we were short one tent, our tents sleep two boys. Friday evening Mr. Bill Kovatch, assistant scout master adviced (A) and me he would sleep with us in our tent Friday night. (A) and I had laid out our sleeping blankets and were lying on them when Mr. Kovatch entered with his blanket, laid it out and also laid down on it. Incidentily[sic] we were all freely clothed. $\mathrm{He}$ immediately reached over to me, (A) and proceed to seek my penis and nearly all other parts of my body. He stopped rubbing me turning to (A) and proceeded to seek his penis. Being very ashamed and embarrassed I turned away so as not to see there. I do not know if (A) body was ever exposed during this time. I can only say at no time was my body exposed to Mr. Kovatch.

In relation to the nature of a fish farm that never runs out of supplies-especially for spearfishing fishermen - the above excerpts well illustrate the situations where scoutmaster perpetrators take advantage of the abundant resources (boys) to achieve their sexual gratification during the Scouting campouts. The benefit is, as mentioned previously, that one perpetrator can try his sexual contact on several targets, and therefore, boy victims in spearfishing initiation are treated as disposable objects with the least amount of risk for the perpetrator to feel attached to a specific victim. 
In this section, spearfishing-type initiation patterns have been examined and analyzed. Each theme is discussed in relation to the perpetrators' behaviors, victims' reactions and feelings, and most importantly, perpetrators' perception about the boy victims influenced by the nature of the Boy Scouts of America, the unlimited source of victims for scoutmaster perpetrators. One of the noteworthy points in spearfishing initiation is the victims' state of unconsciousness. Boys are asleep or doing something else that demands a great amount of attention, such as driving or watching movies, from the boys. Thus, they are unable to realize perpetrators' suspicious physical contact until it gets to the point of actual fondling and/or oral sex. The moment that the boy victims realize what their perpetrators are doing with their penis is the moment of initiation in spearfishing molestation.

Simply put, in spearfishing initiation, perpetrators can skip several steps that are necessary prior to achieving their potential goal (i.e., fondling boys' penises). The spearfishing perpetrators know how to fully take advantage of the boy victims' physical and emotional signs. For instance, when the boys realize the perpetrators' sexual contact being made on their bodies, they are still sustaining the state of drowsiness as well as an additional state of shock and embarrassment. Furthermore, since plenty of potential victims are present in the course of Scouting activities, the spearfishing perpetrators are not longing for achieving sexual gratification from any particular or specific boy victims. Rather, the boys in spearfishing initiation are regarded as immobile yet disposable tools that can be replaced by new supplies with the least amount of time and efforts required from the perpetrators. 
Handpicking contact. In the initiation patterns of same-sex child molestation within the Boy Scouts of America one of the key distinctions in each initiation method is the number of steps in which scoutmaster perpetrators engage prior to achieving an initial goal of sexual contact. In this regard, angling initiation was first discussed followed by spearfishing initiation. The former involves the longest physical grooming processes for scoutmaster perpetrators to escalate sexually charged behaviors from initiation to the point they achieve their goals. The latter, spearfishing initiation, enables the perpetrators to minimize the length of time and the amount of effort until they touch a boy victim's penis.

Although the initiation behaviors are expressed in different manners, one of the major assumptions underlying the perpetrators' behaviors is identical. That is, scoutmaster perpetrators have established a great deal of confidence with their boy victims in terms of the boys' conformity and loyalty to authority. In other words, the position of authority being granted to scoutmasters within the Boy Scouts of America facilitates the perpetrators' abilities to sexually manipulate young boys under their charge. Due to the rigid structure of the organization each boy member feels obligated not only to obey commands, but also to act like a real man.

In the aforementioned two themes, angling and spearfishing initiation, however, perpetrators' misuse and abuse of authority in a forcible manner are not noticeable. Rather, it is taken for granted that the perpetrators emotionally play out their position as scoutmasters. Hence, there is little indication of ostensibly using physical or emotional force over the boy victims to conform to sexual contact. In both angling and spearfishing cases, the perpetrators do not need to convince the boys of their authority since it has 
already been mutually agreed upon and understood. In order for the perpetrators to molest the boy victims, they persuade the victims into sexual relationships, and therefore, the direction of the relationship between perpetrators and boy victims is horizontal, especially in angling initiation.

In the following analysis, the third theme found in perpetrators' initiation behaviors will be discussed using an analogy of a handpicking method in fishing. Handpicking is considered the simplest form of fishing because it only requires fishermen to gather their targets by hand. Objects that can be collected by hand include any slow moving fish like snails, mussels, and crayfish that are available in the zones within the manual reach of humans. In this regard, it should be noted that availability of targets determines the outcome of handpicking activities, and a good pool of targets become available in combination of desirable weather, water conditions, and most importantly, the right timing for fishermen to gather available targets. Simply speaking, the handpicking method is largely dependent on the opportunity that naturally emerges in the course of fishing activities. It is then the fisherman can take the opportunity to turn it into the best outcome he wants.

Applying the handpicking method to same-sex child molestation within the BSA, it is first found that scoutmaster perpetrators in handpicking initiation blatantly take advantage of their position of authority. In other words, the authoritative position as scoutmaster is found at the center of the entire dynamics of child molestation in the BSA. Furthermore, scoutmaster perpetrators do not miss the opportunities that arise in the course of the Scout activities, and the opportunities only become available for those who hold a position of authority as scoutmasters. At the same time, targeted victims have no 
choice but to conform to the commands handed upon them because all the sexually charged behaviors delivered by their scoutmasters are performed as a part of discipline or training sessions to be recognized as brave citizens of the Boy Scouts of America.

In other words, the behavioral significance among handpicking perpetrators is that they are capable of taking advantage of both their positions of authority and opportunities during the Scouts activities. This pattern differs from the aforementioned two fishing methods, angling and spearfishing, in terms of the level of expression of their authority. Unlike the previously discussed two patterns, the direction of relationship between the two actors in handpicking behaviors is thus vertical, rather than horizontal. In the two previously discussed initiation patterns the position of authority is used as a means of relaxing and persuading boy victims. However, in handpicking cases, scoutmasters attempt to use their position as a means of forcing and threatening boy victims.

Behavioral sequences in handpicking initiation. One of the outstanding distinctions between handpicking and the other two initiation methods is the starting point with which scoutmaster perpetrators begin as an indication of sexual molestation. Similar to the spearfishing initiation, handpicking saves scoutmaster perpetrators time and effort by not necessitating grooming contact with the boys. Handpicking perpetrators (about $8 \%$ from 331 victim narratives) can blatantly begin one of the major behavioral components of child molestation, which is removing boys' clothes. In other words, being naked is considered as a starting point in handpicking molestation. The perpetrators then are easily able to develop further sexual contact by reducing a lot of time and effort for "grooming" contact. Had it not been for the opportunity and authority allowed to scoutmasters, handpicking perpetrators would have not enjoy such convenience. 


\section{Excerpt 28.}

My son then recounted to me a series of (blank) that phoned me. He was the subject, as were several other boys, of "initiation" rites. My son has told me that the adult leaders participated in and encouraged the other boys to join in. One such act they called "shake n bake" which involves stripping the boy, rolling him in the sand, and placing shaving crème in their private areas. They also were repeatedly "mooned" by the adult leaders which involves lowering their trousers and underwear and posing their rear-ends at the boys. There was also the streak or jest that Bill Chiappini would use as straight razor to shave my son's pubic area. These were other things done as well, which I find distastfull[sic] and objectionable but I am most concerned about the implication of the above conduct.

The above narrative describes an overview of how handpicking initiation takes place against boy victims. As mentioned previously, handpicking perpetrators are well versed in constructing certain events, such as Scout initiations and trainings, and converting those activities into sexually charged ones. They can also transform random opportunities, such as a boy's need of medical assistance or special attention, in order to use those circumstances to make sexual advances on boys under their supervision. Such circumstantial merits serve as privilege to those who are in the position of authority within the Boy Scouts of America, because they as scoutmasters are expected to serve as not only capable guardians, but also successful educators.

For instance, Chiappini enjoys the privilege of his position as a scoutmaster by organizing "initiation" events in an unusual and inappropriate manner. That is, Chiappini 
encourages the boys under his charge to participate in the activity called "shake an bake." The alleged initiation ceremony demands the boys to be naked and seemingly molested by adult leaders. Furthermore, Chiappini deliberately makes inappropriate and sexually charged physical contact against the boys to achieve his own sexual gratification. All these activities are, however, introduced to the boys as part of Scout initiation processes. The perpetrator is thus able to hide his intention of molesting boys behind the opportunity (privilege) that he is granted as a scoutmaster.

Group victims. Handpicking is largely known as a fishing method that enables fishermen to yield a large sum of fish at one trial because the types of fish that fishermen can gather by hand are slow moving species. When environmental factors - such as weather -permit, handpicking fishermen are able to spot a pool of such fish, and gather them by hand concurrently. A similar pattern is found in child molestation perpetrated by scoutmasters within the BSA. That is, they catch an opportunity with several boys gathered together (e.g., campout) for activities, and take advantage of such activities that are constructed and directed by scoutmasters.

Excerpt 29.

I met Mr. Schell in the spring of 1982 when he took over as the scoutmaster of Troop 297. Later he chartered Troop 90. When he became our scoutmaster, he informed us that we were going to be given the opportunity to learn how to SCUBA dive. The classes were to begin that summer and he planned on teaching us in his own home. One of the first times we went to class, he had myself, my brother, (A), (B), and (C) go into this room he called the lab. There he told us to remove all of our clothing except our underwear and "assume the position". This 
position consisted of standing with our legs shoulder width apart with our hands behind our heads. He then came around to each on[sic] of us and touched our genitalia much like a doctor would during a physical. On me, he also seems to feel my testicles. We all thought this was very out of the ordinary but were too scared to say anything.

Mr. Schell, in this narrative, tries to merge his role as a scoutmaster into a new role as an educator. Throughout the entire sample of victim narratives, it is noted that every scoutmaster has served multiple roles in his troop/ unit, such as a role model, caregiver, and educator, other than the original role as a scoutmaster. From the Routine Activity perspective, scoutmaster perpetrators are deemed to switch their roles from capable guardians to motivated offenders as soon as they assume inappropriate physical contact against boy victims.

To be specific, in the previous two initiation patterns, scoutmaster perpetrators are able to separate their role as scoutmasters from child molesters. Even though the majority of abusive behaviors transpire during Scout campouts and relevant events, the specific sexual behaviors delivered to boy victims have nothing to do with the purpose of the scouting activities. Rather, sexually charged contacts are made during isolated events, such as sleeping, helping scoutmasters, and driving. Thus, it is easy to determine scoutmasters' role switching patterns from guardians to perpetrators in the two initiation themes.

However, in some handpicking cases, it is noted that the action intending sexual abuse is done as a group, usually the entire troop. Furthermore, the sexually abusive behaviors take place in the form of supposed Scouts activities, such as initiation. Thus, a 
role switching of scoutmasters in handpicking initiation emerges very subtly. It is because, as most of the handpicking narratives indicate, the perpetrators are still believed by boys to be performing their scoutmaster roles. Since the chosen scouting activity (e.g., initiation ritual) as a means of child molestation involves a number of boys, it is even harder to imagine that the perpetrator is performing an offender role, instead of a scoutmaster role.

Excerpt 30.

It is reported that Mr. Shellel informed several boys they would be initiated into the pack that evening. These boys were then taken to an adjoining room and were told to undress. Mr. Shaffel then proceeded to fondle several of the Cubs. Excerpt 31 . Initiation (blank) of me taking down my pants and off my shirt in front of the other boys who told me he also did it to them. This was about 9 or 10 months ago at Whilewatery. He placed a little cube of ice and rubbed it on my belly, thy and once in a while on my penis, while I was lying down by Tom Burke, the boy scout teacher.

As was discussed in Excerpt 29, when multiple boys are subject to sexual molestation during the Scouting activity, a scoutmaster is usually playing a role of either a leader of the Troop, or an educator to provide Scouts trainings to the boys. In a similar vein, the above two excerpts illustrate how scoutmaster perpetrators manage to camouflage their intent of molesting several boys simultaneously, and to force the boys to conform to the commands that imply sexual nuances, such as rubbing ice cubes on the boys' bodies. 
One of the most significant points in handpicking initiation is that, oftentimes, most of the so-called "initiation" activities begin with disrobing boys. In the aforementioned angling initiation, it is perpetrators who remove boys' clothes, and it takes place almost half way through the sexual abuse processes, between touching boys' penises outside the pants and fondling inside the boys' pants. Similar to the spearfishing initiation, handpicking perpetrators are also able to avoid unnecessary grooming behaviors prior to making the boy victims naked. It should also be noted that undressing of boys in spearfishing initiation is performed by perpetrators, which causes the boy victims a great shock. However, it is the boys who disrobe themselves in handpicking initiation, in response to the scoutmasters' demands. Boys are taught and forced to follow the command and order in a Scout Troop. Therefore, handpicking perpetrators are able to naturally perform child molestation in public and to take advantage of young boys' obedience to authority.

Individual victims. Some handpicking cases take place individually. In such cases, the scoutmaster perpetrators' role is oftentimes as a candid caregiver or private instructor. It should be reminded that the aforementioned handpicking scoutmasters are found to serve as a commander or educator when there are a large number of boy victims. However, such a group activity opportunity can be dissected into a small individual lesson. Also, some handpicking scoutmasters do not miss opportunities that arise from natural causes, such as weather and boys' medical condition.

Excerpt 32.

Mr. Quick took me to his home to try on a Boy Scout uniform. He told me to take off all my clothes, and gave me a uniform to try on, after that he told me to 
remove the uniform and he gave me a physical. He examined me below the waste[sic] in front and up my bottom.

Excerpt 33.

I had to do the hypothermia treatment with him and I had to take my shirt off and he had me take off his shirt. He had me stand front to front and I had to put my arms around him like he was the victim of hypothermia.

Boy victims in the above two narratives become subjects to sexual molestation while they believe they are under special attention of their scoutmasters. Mr. Quick orders the boy to undress pretending that he is trying to help the boy in selecting his Scout uniform. As previously mentioned, the way Mr. Quick proceeds to sexual contact comes out naturally so that the boy victim, although uncomfortable, does not discern the scoutmaster's intention underlying such commands.

Similarly, a boy victim in Excerpt 33 is also ordered to take off his shirt and becomes a subject of sexually charged contact while believing that he is given a special lesson from the scoutmaster. In these two narratives, the handpicking scoutmaster perpetrators target individual victims. The scoutmasters' roles in each case are more personalized and detailed according to their victims' needs compared to the aforementioned perpetrators who victimize boys as a group.

Excerpt 34.

(Boy) who suffered from chronic asthma and who was in some discomfort all week even with his medication, had told Lambert about his problem. Lambert, evidently in an effort to help the boy, suggested that (Boy) think about other things-the program features, the fun out-of-doors, etc. to take his mind off his 
pain. However, the conversation turned to mental control of pain, Lambert stating that some people can even insert pins and needles into their skin and, because of mental control, not feel any pain. (Boy) stated he didn't believe that and asked, "Will you put some pins in me to prove I won't feel any pain?" Lambert assented, took (boy) into the rear of his camper pickup which was parked nearby, removed (boy) pants and inserted needles in (boy) buttocks. (Boy) comment to his father was “He was right dad, I didn't feel any pain until he put alcohol (to prevent infection) on."

Excerpt 35.

One Sunday afternoon Edson Merlau took some boys ice skating. One of our sons was in the group. Our son broke through the ice and Mr. Merlau had him get in the car and take off his wet clothing and Mr. Merlau played with the boy's penis. After the boys had returned from skating we overheard the boys talking about this happening. We started asking and found that the same thing had happened before and with other boys.

In the individual victim cases, some handpicking perpetrators are also able to extend their role as a scoutmaster to a medical provider or personal caregiver. For instance, Lambert is in charge of a boy who sustains chronic asthma, and promises to take care of the boy during Scout activities. However, Lambert takes the opportunity of the boy's vulnerability as a result of his medical condition, and performs inappropriate "treatment" on the boy. Similarly, Mr. Merlau in Excerpt 35 misuses his position as a caregiver while the boys are away from home. A boy victim falls through the ice while skating on it, which comes as a good opportunity for Merlau to undress and molest the 
boy. This handpicker does not miss such an opportunity and achieves his goal. Most importantly, the handpicking perpetrators who molest individual boy members are later found that they have done the same to other boys. As handpicking fishermen collect a number of fish either simultaneously or at a time, the handpicking perpetrators are also able to follow the same pattern.

This chapter examined behavioral patterns in each initiation method, angling, spearfishing, and handpicking (see Table 1). The analysis was conducted based on the assumption that the Boy Scouts of America is like a fish farm to scoutmaster perpetrators. Scoutmaster perpetrators are originally motivated offenders, who have earned their position of authority as capable guardians within the BSA. Their authoritative positions among youth members enable them to freely spend time and share various scout curricular activities without accompanying the boys' primary caregivers. By doing so, the motivated offenders are able to wear a mask of caring guardians until they make their first sexual contact against boy victims. Each initiation method requires scoutmaster perpetrators different manners to develop their sexual contacts until they achieve the minimum goal of sexual molestation, touching a boy's penis. It is also found that scoutmaster perpetrators' perceptions of boy victims can also determine the specific manner of initiating sexual contacts.

\section{Table 1}

Typology of Perpetrator's Physical Contacts at Initiation Stage
Behaviors
Angling
Spearfishing
Handpicking

\begin{tabular}{llll}
\hline Behavioral & - Take a minimum & - Fondle/ touch a & - Undressing boys \\
sequences: Starting & of 2-3 steps prior to & boy's penis without & as a group or \\
point of physical & fondling a boy's & any prior physical & individually \\
\hline
\end{tabular}




\begin{tabular}{|c|c|c|c|}
\hline contacts & $\begin{array}{l}\text { penis (e.g., hugging } \\
\text { or holding hands) }\end{array}$ & contact & \\
\hline $\begin{array}{l}\text { Victim's State: } \\
\text { What victims are } \\
\text { doing upon } \\
\text { perpetrator's } \\
\text { making physical } \\
\text { initiation }\end{array}$ & $\begin{array}{l}\text { - Awake } \\
\text { (e.g., having } \\
\text { conversations with a } \\
\text { perpetrator) }\end{array}$ & $\begin{array}{l}\text { - Unconscious/ Pre- } \\
\text { occupied } \\
\text { (e.g., sleeping or } \\
\text { watching a movie) }\end{array}$ & $\begin{array}{l}\text { - Awake } \\
\text { (e.g., Scout training) }\end{array}$ \\
\hline $\begin{array}{l}\text { Perpetrator's } \\
\text { perception of boy } \\
\text { victims: How } \\
\text { perpetrators treat } \\
\text { boy victims during/ } \\
\text { after physical } \\
\text { contacts }\end{array}$ & $\begin{array}{l}\text { - Reciprocal/ } \\
\text { intimate partners } \\
\text { (e.g., increasing the } \\
\text { level of sexual } \\
\text { contacts/ repeated } \\
\text { actions) } \\
\text { - One victim at a } \\
\text { time }\end{array}$ & $\begin{array}{l}\text { - Disposable tools } \\
\text { - Multiple victims } \\
\text { simultaneously } \\
\text { while victims are } \\
\text { sleeping in a same } \\
\text { location }\end{array}$ & $\begin{array}{l}\text { - Subjects of } \\
\text { discipline/ Scout } \\
\text { training } \\
\text { - Vary by victim's } \\
\text { need (e.g., medical } \\
\text { condition) } \\
\text { - Victims as a group }\end{array}$ \\
\hline $\begin{array}{l}\text { Locations: With or } \\
\text { without other people } \\
\text { at crime scene }\end{array}$ & $\begin{array}{l}\text { - Private locations } \\
\text { (e.g., perpetrator's } \\
\text { residence or tent) }\end{array}$ & $\begin{array}{l}\text { - Public or private } \\
\text { locations (e.g., } \\
\text { sharing with others } \\
\text { while they are } \\
\text { sleeping) }\end{array}$ & $\begin{array}{l}\text { - Public or private } \\
\text { locations (e.g., } \\
\text { Scout training) }\end{array}$ \\
\hline Contextual Factors & $\begin{array}{l}\text { - Alcohol/ Adult } \\
\text { magazines } \\
\text { - Engaging verbal } \\
\text { interactions } \\
\text { (e.g., testing boy } \\
\text { victim's feeling and } \\
\text { acting by victim's } \\
\text { responses) }\end{array}$ & $\begin{array}{l}\text { - Use of boy } \\
\text { victim's state of } \\
\text { unconsciousness } \\
\text { - No verbal } \\
\text { exchanges }\end{array}$ & $\begin{array}{l}\text { - Good use of } \\
\text { opportunities } \\
\text { (e.g., weather, } \\
\text { medical conditions, } \\
\text { and position of } \\
\text { authority) } \\
\text { - Disciplinary } \\
\text { actions }\end{array}$ \\
\hline
\end{tabular}




\section{CHAPTER 5}

\section{FINDINGS II}

\section{Termination Patterns}

In the previous chapter, one of the findings in the initiation patterns indicated that scoutmaster perpetrators always play a role of initiating sexual contact against boy victims regardless of the manner of contacts. Also, boy victims do not participate in the initiation of sexual behaviors voluntarily. Such facts suggest that, during the sexual contact between scoutmasters and boy victims, scoutmasters are in charge of triggering sexual advances, and boy victims serve as passive recipients of such behaviors. In this regard, it can be inferred that the first role switching takes place in the beginning of the initiation phase: Scoutmasters finally remove their masks as capable guardians and carry out their intended roles as motivated offenders. Consequently, boy victims are inevitably placed in a position of suitable targets in the dynamics of same-sex child molestation within the BSA.

From Routine Activities perspectives, the moment for both parties to converge in the same time and space occurs when the crime is on the verge of occurring (see Cohen \& Felson, 1979). In the BSA child molestation cases, this is when a scoutmaster perpetrator, who has previously presented as a capable guardian, makes his first physical contact against suitable targets, a boy member. Now that the scoutmaster becomes a motivated offender, his original position, a capable guardian, is vacant. Until the initiation of sexual contact is carried out, the Routine Activity triangle in the picture of 
same-sex child molestation is not materialized due to the presence of capable guardians and absence of motivated offenders. However, the status of the two roles is reversed when scoutmasters initiate sexual contact, and the Routine Activity triangle is initialized to make it possible for same-sex child molestation within the BSA to occur.

Along the same lines, in order for an ongoing criminal activity to desist, at least one element, either a suitable target or motivated offender, should be removed from the equilibrium of the RAT triangle. Also, the termination of crime can be accomplished by inserting capable guardians in the Routine Activities triangle. It is found from the boy victims' narratives that as soon as physical contact is initiated, another role switching is likely to take place. That is, boy victims, who are in the purported position of suitable targets, can replace the position of capable guardians. It should be noted that capable guardians, in this context, refer to the boy victims who can exercise self-protective measures of their own. Capable guardians also include those who express their feelings of objection to the sexually charged touching. Simply speaking, all the boys in the BSA cases are victims of same-sex child molestation by their scoutmaster perpetrators. However, it is also feasible for the boys to perform the two roles at the same time in an effort to discontinue the cycle of the Routine Activity elements within the BSA.

Young boys are vulnerable without persons of authority to protect them, especially when the boys are in the middle of Boy Scout activities that are isolated from their primary caregivers. However, some boy victims are found to be capable of performing self-protective roles to terminate further molestation. This is how the second role switching takes place. It is boy victims who terminate the series of sexual advance made by their scoutmasters. Simply speaking, termination of sexual molestation is 
usually accomplished by the boy victims' role switching from suitable target to capable guardians. The term 'guardians' can be interpreted in two ways in this context. That is, boys can undertake the acts of self-protection as well as perform a witnesses' role that can actively intervene in ongoing sexual molestation of other boys within the Boy Scouts of America.

In a narrow sense, termination of sexual molestation can be said to be the moment when a perpetrator desists from the ongoing sexual contact. Hence, victims become released from unwanted physical contact at the scene. In a broad sense, however, cessation of sexual molestation can include a state of victims being free from any further unwanted contact and not becoming the subject of repeated sexual violence by the same perpetrator in the future.

This dissertation addressed micro-level behavioral sequences between boy victims and scoutmaster perpetrators. Hence, the primary analysis of termination patterns extensively focuses on the narrow sense of ending sexual contact-when boy victims are physically detached from perpetrators' sexual advance at the scene. In this case, a risk of repeated sexual molestation in the future still exists. In order for a practical use of the findings from boy victims' termination patterns, this study thus also examines the boy victims' behaviors that result in permanent termination of sexual molestation from the same perpetrator in each case. Simply speaking, to identify the victims' role switching pattern from suitable targets to capable guardians, specific manners and timing of resistance exercised by boy victims are examined.

Boy victims' resistance sometimes successfully accomplishes its genuine purpose. The acts of resistance can stop perpetrators from sexual advances against the victims. 
However, due to the nature of same-sex child molestation, in combination with the position of authority that scoutmaster perpetrators have held over their victims, the majority of victims are not able to achieve a full cessation of sexual molestation. Another reason for the victims not being able to rescue themselves is due to the level of resistance that they exhibit against the perpetrators. Scoutmaster perpetrators do not take a simple message (e.g., saying "no") as an objection.

However, it should be also noted that boy victims' actions of resistance are sometimes read in a distorted way by their perpetrators. Thus, in this analysis, detailed reasons and patterns of boy victims' resistance that are intended to lead to a full termination of sexual molestation will be delineated. During this process, excerpts that illustrate each situation will be presented. The boy victims' efforts to stop their perpetrators from committing further sexual contact will be explained on the continuum of the analogy used in initiation patterns. In the following, the patterns of boy victims' resisting behaviors in an attempt to cause termination of molestation will be discussed.

Resistance patterns during angling contact. One of the significant behavioral patterns of scoutmaster perpetrators when committing same-sex child molestation within the BSA is the rare use of physical force to subdue boy victims at initiation phase. That is, scoutmasters hardly use force, such as hitting, punching, kicking, restraints, and other weapons in order to physically control or threaten the boys. Similarly, in the course of termination, victims' resistance against the perpetrators rarely results in the use of physical assault against boy victims. Consequently, little sign of physical injury is found in boy victims. 
Some boy victims are able to physically confront their scoutmaster perpetrators. However, perpetrators rarely use physical force to overcome their victims' resistance. Such non-physical harm in response to victims' resistance within the BSA is attributed to the unique nature of the youth-oriented institution. That is, the scoutmaster position brings perpetrators advantages and disadvantages when it comes to dealing with victims' resistance and continuing sexual molestation against the victims.

First, their position of authority enables them to approach, lure, control, and sexually abuse boys under their charge without encountering any suspicion, and most importantly, resistance from the boys. However, if a boy victim is physically assertive, chances become slim for a perpetrator to physically control the boy just in case the physical force causes any injury on the victim. If so, the tenability of the perpetrator's position within the BSA will be at stake, and he is likely to be suspended from his position that has brought him a great opportunity to contact potential victims.

Boy victims, in this context, serve multiple roles, not only as a target of child molestation, but also as evidence, witness, and most importantly, guardians of themselves. If any visible injury is left on the boy's body as a result of efforts to subdue the victim, the boy's caregivers can easily notice the injuries inflicted on underage boys. Then, it is likely that the perpetrator will be caught and expelled from the Boy Scouts of America. The removal from the Scouts will then result in the removal of a means for accessing young boys. Such would be a highly undesirable outcome for scoutmaster perpetrators. In the following, boy victims' different resisting actions will be discussed in terms of the level, manner, and efficacy of them. Details of perpetrators' reactions will 
also be analyzed in an attempt to identify the most effective and safest ways to terminate sexual molestation during immediate sexual contacts.

Verbal Refusal. One of the significant patterns of angling initiation is perpetrators' perception about their victims as sexual partners from whom they usually expect reciprocal behaviors. In the course of angling initiation, perpetrators tend to use verbal cues to groom boy victims into sexual interactions, and to escalate the level of sexual touching. Perpetrators usually ask how victims feel about the ongoing touching. Sometimes, they ask their victims to show their private parts or perform masturbation in a very persuasive manner.

Excerpt 1.

I am a member of the Boy Scouts and am 12 going to be 13 in about 3 weeks...Then he passed me off an Family Living skill award. After that he was asking if I remembered when I told him that my friend (A) was acting and I said yes I do so, then we were talking about his behavior. Then he asked like has my friend ever been attracted to me sexually or if he liked boys and I said no. After that he whether he undressed in front of me in a sexual manner and I replied shacked no. Then after we kept talking about (blank) give me a lot of pleasure but I wouldn't listen. Then after (B) about sex which I don't really remember, he asked if he could have a peek at my penis or if I wouldn't mind to let him see my penis, and I said yes I would mind. So then he said to get ready to leave and then we left. On the way he said if $(\mathrm{C})$ - the person in charge of the newsletter and my friend-wouldn't come to get the newsletters, he would call me again to prepare the newsletters. So then we arrived at my house and he dropped me off. 
The above excerpt shows that verbal interactions occurred between a scoutmaster perpetrator and a boy victim. As the boy describes, the perpetrator tries to initiate sexually charged atmosphere by bringing up sexually explicit topics of conversation about the boy's friendship with another boy. At the end of each conversation, the perpetrator allegedly includes sexual implications to find an opportunity to turn their verbal interactions into a physical advance, such as exposing the boy's penis. However, as the conversation proceeds, the boy's verbal reaction becomes more assertive to say no to any of the offers made by the perpetrator.

It should be noted that there has not been any physical contact yet, and once the boy repeatedly says no, the perpetrator gives up trying to persuade him and then they both leave for home. According to the victim's accounts, even though there are only two of them at the scene, there is no sign of physical or verbal threats made against the boy, and the perpetrator's tone of voice is persuasive rather than coercive. The boy's verbal rejection does not lead to any further incident — neither physical nor verbal—however, the boy's tone of voice is not enough to permanently discourage the perpetrator. The perpetrator attempts to invite the boy into the same situation again by asking for help from the boy in delivering newsletters, which indicates that the victim's verbal refusal the night before is only a temporary solution. The following excerpt exhibits the similar pattern of a boy victim's resistance and a perpetrator's response. However, it should be noted that the perpetrator also contingently changes his manner and level of sexual contact based on the boy victim's response.

Excerpt 2. 
I was in the (blank) troop and the scoutmaster was John Treder, a member of the camp staff as (blank) week, I was sleeping in a tent with another scout on Saturday night July $6^{\text {th }}$, the other scout remained a sleep during the incident (incident). That night, I had fallen asleep in my (blank) and about midnight Mr. Treder came into my tent and wakened me and told me I should sleep in my underwear. He came back in about five minutes and laid down beside me on my back, I don't remember all his exact words but he put his hand on my leg and asked me if I liked that and I said "no." Then he told me he wanted to try an experiment and then he touched me between my legs second time and again asked me if I liked it, I said "no." Then he kissed me on the cheek, I could feel his whiskers. At first I trusted him because I liked him, then he said if he could kiss me again, he could go, so I let him. He tried to kiss me on the mouth but I would not let him. Later in the week, he asked if he could come back again but I told him I had to get some sleep, so he did not come back.

The perpetrator refuses to take "no" as an answer; he seems to retract his behavior, but still has a hope to reunite with the boy. Unlike the previous excerpt, which has not involved any physical contact yet, sexual touching has already begun in Excerpt 2, and the perpetrator tries to escalate his behaviors against the boy as he keeps talking to the boy in an intimate manner. By the time the perpetrator touches the boy's genital area twice, the boy has expressed his uneasy feeling about the perpetrator's touching by saying no to his verbal suggestion. It can be inferred that once a physical contact begins, the scoutmaster — here occupying a fisherman's position—feels confident that he can catch the fish - touching the boy's penis at a minimum. Thus, the perpetrator in Excerpt 
2 attempts to escalate his behavior from putting his hand on the boy's leg to the genital area.

In the meantime, even though the boy repeatedly says "no" to the perpetrator's further contact, he does not try the second touching, and then, he stops the behavior at the boy's third "no." Taking one notch down, the perpetrator continues to test the boy by asking if he could kiss him. This behavior suggests that the perpetrator still continues to attempt to reel the boy in. Only to make the perpetrator leave, the boy says "yes" to the offer. The perpetrator, however, immediately escalates the level of the kissing behavior, and asks if he could do it on the boy's mouth.

Even though the boy manages to resist the kiss on the mouth, the perpetrator is able to establish confidence about the boy that he is still vulnerable and scared. The perpetrator becomes confident enough to offer to come back to the boy. However, this time the boy is able to prevent the perpetrator from coming back by making an excuse, instead of expressing his distress and disgust caused by the perpetrator. In this analysis, it should be noted that merely saying "no" is not perceived as a determined rejection by the perpetrator, who comes up with other ways to prolong the contact.

Consistent with the case in Excerpt 2, the following narrative also exhibits the tricks that a perpetrator, Mr. Palmer, employs to involve the boy into sexually charged interactions by asking different formats of questions to obtain positive answers.

\section{Excerpt 3.}

He picked me up and we went to Jacomo where you shoot bows and arrows and were following the trails and shooting arrows and then we sat down on a log out there and he, Mr. Palmer, put his arm around me and he said "You want to go 
shooting some more" and I said "yeah" so he goes - well, he pulled my nuts, on the outside of my pants then he said "does it feel good" and I said "no." Then we went on with the other kids and there were about six of them. Then we went and took the other guys home and he took me back to my sister's house and this was about 2:00pm. Then we went out to the firing range the Independence Police Dept. firing range at Courtney Road and Kentucky Road and then shot some bottle rockets off and he took about three rounds of shells out of his gun. Then we went walking over to this one log. Then he put his arm around me and he was in back of me. I had on my blue jean shorts and they are real baggy and I didn't have a belt on. He kept saying for me to pull in my stomach, for about 15 minutes, and I said that I didn't want to. Then he said "see that gun over there?" and he put his hand down my pants and reached all the way down to the bottom and touched my penis and then I jumped up and said "I want to go now" and he said "OK." We picked up the stuff and left and he took me back to my sister's house.

For instance, Palmer asks the boy if he wants to go shooting, and the boy interprets the question as is. However, the boy's positive answer to the suggestion for going shooting only results in further sexual contact made by Palmer, the motivated offender. When Palmer attempts to make sexual advance against the boy, the boy finally answers "No" to Palmer's question if it (touching penis) feels good.

On another occasion, the boy's previous reactions sounded neutral and indecisive. Most importantly, he was tricked by Palmer's questions. Thus, Palmer tries the same trick again with the boy by asking the boy to undress. When the boy continues to refuse 
to participate, Palmer again changes the subject all of a sudden and distracts the boy with something that the boy is interested in, the gun. Immediately, Palmer places his hand on the boy's penis, and the boy takes a more assertive action this time: He stands up and clearly states that he wanted to go home.

The two excerpts suggest that, in angling initiations, boy victims can hardly recognize that they are being subjected to sexual molestation by their scoutmasters. Scoutmasters' verbal and behavioral modus operandi exacerbates the level of confusion that the boy victims can handle at their age. For instance, it is difficult for the young boys to comprehend the hidden meanings in the scoutmasters' questions as a prelude to initiating sexual contact. The scoutmasters use various formats/ subjects of questions based on the boys' response. Such variability in scoutmasters' questions confuses the boy victims to a great degree since the questions appear to be neutral and without sexual intent. Most importantly, young boys cannot interpret the nuances of the statement. It is noted that multiple victims provided the following narratives. They are subjects of sexual molestation by one perpetrator, Jeff. Even though each boy's name is redacted, at least two boys are called into Jeff's tent, and touched by him consecutively. Before proceeding to detailed analysis of this excerpt, it should be noted that the majority of scoutmaster perpetrators victimized at least one boy victim. The number of victims in each case is not finalized because of the unique nature of data—only known victims voluntarily submitted complaint letters. Thus, it is not feasible to verify the exact number of victims. However, since this study aims to identify victims' resistance pattern when being attacked by scoutmaster perpetrators, it is also imperative to know whether each 
perpetrator utilizes the same modus operandi on each victim, and most importantly, whether there is any variation in resistance patterns.

\section{Excerpt 4.}

Jeff came to (A), (B), and (C) told them what a virgin was. When (D) arrived Jeff left. Before (D) arrived he asked (A) and (B) to come to his tent and ask him question about being a virgin and other things. Jeff called for anyone and (A) went in and Jeff told (A) to come closer and Jeff picked him up placed you on the cot. Jeff asked (A) if had tried to get a hard-on. Jeff "asked" if he could do it for him. Jeff lifted up his shirt and tried to undo his pants, (A) said "NO" and Jeff squeezed (blank). (A) asked if he was his teddy bear. Jeff said yes. Jeff asked (A) if any of the other boys had tried any of things he had told them. (A) told (B). Not knowing he would try the same thing. (Another boy came in). (C) went in and Jeff asked him to sit on the cot. Jeff grabbed him and told him he was going to be his Teddy bear. He asked if any of the other boys had tried to get a hard-on. Jeff started to feel his leg and (C) said NO, when he touched his thigh. Jeff told him not to be afraid of him. Jeff told (C) not to tell anyone and rubbed his cheek. Jeff returned to (A) and (B) tent and asked if they were tired. The boys discussed it among themselves and went to another Pack and told the cubmaster. In this excerpt, Jeff molested two boys on separate incidents, and he undertakes the same pattern of sexually molesting the two boys, such as sitting the boy on a cot, verbally provoking the boy, and gradually touching the boy's penis. The first boy verbally turns down Jeff when he attempts to undress him, but Jeff tries some other way around by distracting the boy with another subject—-the boy's friend—but still on sexual 
matters. When the second boy comes in, Jeff proceeds to the same behaviors, but as soon as Jeff touches the boy's thigh, the boy says "no." The narrative does not specify the tone and manner of the boys' "No." However, Jeff remains, or at least pretends, calm so that the boys do not recognize the hidden intent of his behaviors. Although Jeff's attempts are all incomplete because of the boys' verbal resistance, the resistance is not enough to permanently discourage Jeff.

The following excerpt illustrates how a boy victim acts differently based on the circumstances.

\section{Excerpt 5.}

Larry Strain, a Boy Scout leader in Troop \#372, MO, has made homosexual advance towards our 13 year old son (A), and has incouraged[sic] him to participate in these actions, it was through (blank) our son's part that this was accomplished. Larry Strain asked our son to accompany him alone to his home near Betlany, MO, under the guise of helping him plant tree and work toward some of his merit badges. It was at the far, that these homosexual advances were made. Larry Strain also approached our son in his tent late one night at Boy Scout Camp this year. At this time, our son refused, knowing that he could safely do so because of the presence of the other scout and scout leaders. Larry Strain also told our son of having had similar experiences (blank) other scouts. (Blank) he gave specific names.

From this narrative, the fear and embarrassment that each boy victim may feel when sexually molested by the person whom he trusts, can be seen. The boy in this excerpt is actually a repeat victim. He has already been molested by Larry while the boy 
is helping Larry with some garden work and the boy's scout advancement. After Larry achieves his goal with the boy, Larry attempts to molest the boy again at a camp. However, the boy is able to refuse Larry's touching because he feels much safer being surrounded by other scouters at a camp. This case suggests that the Boy Scout activities (e.g., campout) are good environment for scoutmaster perpetrators to potentially access as many boys as they want—like in a fish farm. Also, the BSA environment raises a certain level of shame and embarrassment for some boy victims because of the fact that they are sexually molested by their scoutmasters. However, the presence of the crowd can still benefit the boy victims to feel safe and protected even though their primary guardians (scoutmaster) may turn into motivated offenders.

Verbal confrontation. Most of the boy victims in the BSA cases cannot think through how they should respond to the sexually motivated contact upon realizing the perpetrators' intention in their behaviors because they are simply inexperienced and scared of such sexually charged situations. Thus, many boy victims are likely to give in to the perpetrator's sexual advance out of despair while simply saying "no" to their perpetrators can save them from unwanted sexual contact.

Thus far, a frequently used method of resistance found in boy victims' narratives is a verbal rejection by saying "no" to their perpetrators' sexual advances. In other words, there is little indication of active confrontation to bring about a permanent termination of the perpetrator's sexual contact. It should be, however, noted that the boy's meek expression of saying "no" does not come across as a real threat or refusal to their perpetrators. It is also found from the previous excerpts that follow-up actions should be taken after temporary solutions, such as saying "no." Otherwise, the "no" is 
still interpreted by perpetrators as a different form of invitation to future interaction. The following excerpt demonstrates how a boy's expression of objection effectively works to discontinue a perpetrator's ongoing sexual contacts.

Excerpt 6.

I went on Camping outing for the weekend with the scouts. All my friends were there and we had fun. One of our Scout master Mr. Gooding was there too.

Friday night we had just got there and started putting up our tents and Mr.

Gooding told us to hurry up and get ready to go to bed. Mr. Gooding said to me "(A), you sleep in my bag with me and your brother can sleep with (B). He also told me not to sleep in any pajamas and he didn't sleep in any his stuff, during the night he held me tight and I felt his other hand laying his penis on my behind. I told him to stop and he said go to sleep. When I came home from the trip I told my mother and she was very upset. After this happen, we had a rap session and Mr. Gooding wanted to know what we liked and what we didn't like about him. I got up and called him a queer he wanted me to say this in front of Mr. Jason and (B) and I did, they wanted me to apologize to Mr. Gooding but I said no, so then Mr. Jayson and Mr. Gooding came home with me to find out if my mother knew and she told him yes I had told her but she was afraid to say anything about it to anyone. I want you to know that this is the truth.

In the above excerpt, the boy victim stands strong against his scoutmaster perpetrator, Mr. Gooding, after the boy identifies Gooding's true intentions when he is trying to touch the boy's penis. The boy uses a temporary solution, in a more directive manner, saying "stop it" of some sort. He is able to rescue himself from unwanted sexual 
touching for that night, and then, his follow-up action, such as telling his mother, encourages him to ultimately confront Gooding during the rap session, while Gooding is acting naturally and pretending nothing has happened in front of others. Even though the boy was once placed in a position of a suitable victim of child molestation, the boy is able to switch his role to that of a capable guardian. His new role, as a guardian, not only benefits himself via a self-protective measure (e.g., saying "stop" to Gooding), but also turn into a great safeguard for the rest of the young boys by bringing the incident to other people's attention in a public place.

The following narrative also illustrates the effectiveness of having higher authority involved in the termination of sexual molestation. Doing so can not only terminate immediate sexual touching, but also to brings in preventative actions against a perpetrators at an institutional level in the long run.

\section{Excerpt 7.}

Bob Dixon, our scoutmaster, left to go see another Scoutmaster. He left David of Troop 209 in charge of us. After awhile we started talking around the campfire.

David told us a story about the time his friends bet that he couldn't go around the house nude the whole weekend. The boys told his mother about it and said the winner would spend the night with her and the loser does the same with the father. He then asked us what we would do if someone offered to give us a blow-job. After I went to bed David started to rub my back and then he began rubbing my legs up to my crotch. When Bob Dixon came back, David stopped, zipped up my sleeping bag. After David thought everybody was asleep he started the rubbing again. I think he may have sucked on my fingers because I felt his beard and 
mustache on my hands and my fingers were wet when I came fully awake. David put his hand on my penis and started squeezing it which woke me up completely because it scared me. I yelled for Bob Dixon and told him what happened. David acted like nothing had happened. However, as David left I heard him say "I'm so sorry (A)" very softly.

As is commonly seen in the angling initiation, David begins with touching the boy victim's legs while attempting to continue sexually charged conversations. David's sexual contacts is first intervened by another scoutmaster, Bob Dixon. However, the boy woke up to the David touching his penis. Although scared, the boy immediately yells for help. By doing so, he is able to have an authoritative figure, Bob Dixon, take care of David. Apparently, David does not want Bob Dixon to know what he is doing to the boy - he immediately retracts from touching the boy. The boy victim is capable of manipulating the fear and vulnerability that David had about other people (adults) knowing his behaviors. So, the boy loudly called Bob Dixon to rescue himself from David' sexual contact.

The scoutmaster position within the Boy Scouts of America provided numerous opportunities for scoutmaster perpetrators to achieve their sexual goals by freely accessing and legitimately spending overnights with young boys. The BSA is like a fish farm to the scoutmaster perpetrators because it provides nearly unlimited resources for the perpetrators to do what they do within the BSA. Thus, while boy victims are placed in the position of suitable targets in the beginning of the initiation, it is also possible that the boys can successfully perform a self-protective guardian role by using the perpetrator's vulnerability, a fear of losing their reputation within the BSA. The 
following excerpts are written by three different boy victims, all of whom are molested by the same scoutmaster whose name is Frank. The excerpts are chosen for the similar reason as Excerpt 4-to demonstrate the effective ways of resistance against sexually charged behaviors made by the same perpetrator.

Excerpt 8(1).

Well the first night that we were there, Frank Iafalese, who was the adult advisor who was staying with us, started, when we went to bed that night...took out his flash-light and started playing with himself and everything and he was shining the light to watch and make sure that I was watching and if I was then he would shine it on his face and smile and then I just turned over that night and said,"shut off the light, Frank" and I went to bed and that was all. Then the next night the same thing happened but I just ignored him and everything so nothing happened but Tuesday... yeah, Tuesday night, the third night when we were there, he came on over and was sitting next to the bed by me and he was jacking off and he kept on asking me if I'd ever had a blow job or anything and then he asked me if I'd like one... you know, if he could suck me on anything and he was just about begging me to let him and I told him "NO, get the hell out of here, what are you, a queer... or whatever... and get somebody else if you want something" and that's when he walked on out and presumably got (A) and the next night he walked on over towards me again and tried the same thing and I just told him to get out of here or I'd report him and that's all that ever happened between us two...(During this time) he was doing it and he says, "Hey, watch mine, look how big its getting" and everything and then he asked me if I ever shot or anything and I go "What are 
you, some kind of queer" and he goes, "No, it's real good man, it feels real good...why don't you try it?" and I just told him to get out of here and that's when he got (A) tried.

In the first excerpt, Frank keeps trying to draw the boy attention; it begins without physical contacts (e.g., flashlight face), but develops into a sexual manner (e.g., masturbating himself). Frank shows his erect penis—bragging about it—and asks for reciprocity from a boy victim. During this time, Frank is almost begging the boy to perform sexual behaviors with him. Meanwhile, the boy is strong enough to verbally condemn Frank; he even calls Frank a pejorative name. This incident illustrates the importance of verbal assertion for young boy victims when encountering verbal requests for sexual participation. Thus, the boy's verbal resistance in an aggressive and confident manner was effective to discourage Frank to make further sexual contacts against the boy.

\section{Excerpt 8(2).}

It was the second night of camp, the first week, and he came and got me and took me to the Adirondack and he said "I want to talk to you" and I said "Fine, what about?" and he said, "About (B), the way he runs the troop and everything" and he brought me up to the Adirondack and you know... just laying on the bed... you know... move over...I said "Fine"... and we were talking a little bit and then I felt his hands moving around my waist trying to unzip my pants and I was pushing his hands away... said, "Frank, cut it out, Frank... you know, not now... I don't want to do it... you know... not now," and he said "No, please just let me play around with it a little" and he is kind of stronger than I am and he shoved my 
hands away and started to play around with me and finally I said "If you don't let me go, I'm going to start screaming" and he said, "All right" and then he let me go and I put my pants back together and I went out.

Frank also attempts to molest the second boy victim. While adopting a similar modus operandi that he used on the first boy victim, Frank adds some physical initiation against the boy by running his hands towards the boy's penis and fondling it. Although Frank's tone of voice is mild in persuading the boy, when combined with physical force, the boy feels helpless and his "no" to Frank's sexual advance does not work this time. Finally, the boy attempts to threaten Frank by saying that he is going to scream and let other know about what Frank is doing to him. Then, Frank gets off and leaves the room.

Considering the pre-existing relationships between Frank and the boys through the BSA, it can be inferred that Frank may have used his own discretion about each boy in terms of how much force - either verbal or physical — he would need to subdue each boy before he puts his MO into practice. Also, the boy victims may not be able to articulate the detailed circumstances of each crime scene in their narratives. Above all, in this analysis, a slight difference found in Frank's modus operandi on each boy victim is not as important as each boy victim's resistance pattern. In the second excerpt, the boy exhibits much weaker attitude than the first boy when being sexually approached by Frank. However, the boy is still able to stop Frank from further sexual contact by making a threat to Frank that he (the boy) will start to scream.

Excerpt 8(3).

Yes, one night... Wednesday night. I was sleeping out under the stars...Yes, and he came over to me just as I was coming back from the buffalo showers and he 
said, "Are you hot?" and I said "NO," and so then I felt his hand go inside my pants and I hit him and then he took it out and all and then he went away. Then about 30 minutes later he came out of the Adirondack and he goes, "Can I just touch you once? And I said "No" and then he started again so I said, "well, if you lay one finger on me I'm going to scream so loud that the whole camp will hear me" and then I went back in then that was all that happened while I was there.

The third boy victim uses a physical confrontation in addition to a verbal rejection when Frank touches his penis after some regular conversations are exchanged. The boy hits Frank's hand, and Frank immediately retracts and leaves the room. However, Frank still does not give up on the boy, and tries to touch him again about half an hour later. This time, the boy clearly makes his point by saying that he is going to scream so that other people will know about this incident. It is successful this time; Frank knows that once others know his misbehavior, he is likely to be expelled.

\section{Excerpt 9.}

I am laying on my bed and Tom is sitting there on my bed claiming to stay there until he has listened to the radio and took a short nap. Tom then held on to my feet tightly then slowly moving his arms to my croch[sic] while placing my hand near his penis while he was rubbing my privates I pulled away and he did not leave so I decided to wait it out he then tried again and I tell him to stop he then tells me not to tell anyone next he ask me if he could masturbate in my bed. I say fine and I hurry and leave claiming to go to the bathroom. I go down to the Antelope Lodge and sit on the back porch resting deciding what to do. I then see the lights come on in the Beaver Lodge an[sic] I hurry to the side of the Antelope 
Lodge to see if Tom leaves. As soon as Tom left I ran to the Beaver Lodge by the lake from getting inside and stopped to wait on (A). I then talk to (A) about what happened and went to lay down about 15 minutes later (A) woke me up and brought me down to the camp area. At no time did Tom Expose himself.

It has been discussed in the previous section that the scoutmaster position grants a great deal of authority to the perpetrators; consequently, boy victims have admiration and respect for their scoutmasters. Their relationships are especially built upon a hierarchical structure requiring command and obedience, and the majority of boy victims show unequivocal trust and loyalty to their scoutmasters. The above excerpt, however, also illustrates the amount of trust that a scoutmaster perpetrator has for his boy victim. The boy tries to resist Tom's physical touching on his penis, and he manages to put Tom's hand away. However, Tom would not leave the room. The boy's reaction (e.g., withdrawing Tom's hand) is still interpreted as neutral or indecisive, rather than as assertive rejection. Therefore, Tom attempts to perform the same behavior on the boy, and to proceed to masturbate himself. The boy then pretends that he needs to use the bathroom, and is able to free himself from Tom to ask for help.

As was discussed in the precious section, the majority of the angling perpetrators treat their victims as sexual partners, and most importantly, the perpetrators also exhibit a great deal of trust in their victims in terms of keeping a secret between the two of them. It is noted that Tom also trusts the boy and lets the boy go and use the bathroom believing that the excuse is genuine. Although the bathroom excuse is made up, Tom does not express any doubt and lets the boy go. Regardless of his intention, the boy is able to 
takes advantage of Tom's vulnerability — underestimating the boy's resistance — and to free himself from Tom before the sexual touching gets too serious.

Physical confrontation. Some boy victims reveal that they are able to physically resist the perpetrators' attempts to touch them in a sexual manner. The pattern of physical confrontation and its effectiveness to terminate perpetrators sexual attack are discussed in the following.

Excerpt 10.

When ever[sic] Mark was around me, he always wanted to be next to me or touching me in some fashion. He would hold my hand and give me inappropriate hugs. When sitting next to me he would attempt to rub my legs. He would call my home at night when it would be time for me to go to bed and tell me that he loved me. On a trip with the troop to Snowshoe, West Virginia, in 1986, Mark insisted that I share his bed and room with some other scouts. Everyone I assume was asleep with the exception of Mark and myself. Mark reached over and took my penis in his hand. I immediately struck him with my fist. His excuse was that he wanted to know how big I was. He became upset that I was so alarmed and because in his opinion I was in fact larger than him. When we returned home I told my mother of the incident and began making efforts to transfer to another unit.

Mark demonstrates an angling initiation pattern. First he begins with casual touching such as the boy's hand and legs. Then, Mark develops his behaviors into more intimate manners by hugging the boy and telling the boy that he loves him. Although the boy recognizes Mark's unnatural touching over his body, and becomes uncomfortable 
with too much attention, the boy has not taken any specific action against Mark. The boy's reaction may be attributed to a typical angling-type approach (e.g., subtle and confusing process).

Furthermore, Mark's position as a scoutmaster lowers the boy's guard because the boys learn to obey and respect their scoutmasters. However, as soon as Mark attempts to make a final touching on the boy's penis, the boy instantly resists Mark's touching with physical force. Similar to other angling perpetrators, Mark then comes up with a contingent excuse by saying that he just wants to see how big the boy's penis is. Mark also pretends that he is shocked by the size of the boy, which can be inferred as a trick to make the boy feel proud and the feeling can overpower the sense of anger over Mark.

\section{Excerpt 11.}

But he kept trying to keep me awake. Then he started constantly rubbing my dick and he asked if I enjoyed it. Then I grabbed his hand and told him to leave, but he tried to keep on. I squeezed his hand and told him to get out while I roled[sic] over and he got out. I got up after him and chased him to his tent, then I went straight to (A) tent and told him.

Similar to the previous case, this excerpt also indicates that the boy's physical confrontation — squeezing the perpetrator's hand—is an effective intervention to stop the perpetrator from making further sexual contact. The boy is able to use both verbal and physical threats against the perpetrator, and this may be possible because of the location of the incident. It is found that some boys feel confident and safe to be with others when they face sexual molestation by their scoutmasters. Also, it is found that most of the 
angling perpetrators try to avoid being seen or acknowledged for their sexually motivated behaviors by others out of fear of being suspended from their troops.

Collective intervention. An angling approach occurs in one-on-one settings. Angling perpetrators prefer private places, such as their own residence, so that they can keep their secret identity as child molesters from other people in the BSA. Victims' narratives and/ or internal investigation results from each case indicate that the majority of the scoutmaster perpetrators have multiple victims. Some perpetrators molest several boy victims within a very narrow timeframe, and others have multiple boy victims simultaneously. Having multiple victims sometimes bears a risk of breaking a secret circle. Some boys are willing to share their unpleasant experiences with their scoutmasters; other boys reveal their victimization to their close friends; and lastly, some boys actually witness child molestation committed by their scoutmasters.

\section{Excerpt 12.}

The first thing that Mr. Emory did to me was he kissed me on the mouth and tried to put his tongue in my mouth. I was in the cabin alone and the other guys were outside. Later, I told one of my friends then after that we started staying in groups of two.

The above excerpt illustrates how young boys can exercise their own preventative measures in an effort to stay safe from a known perpetrator, Mr. Emory. Mr. Emory forcibly kisses the boy's mouth. The boy immediately shares and discusses this incident with his friend. Although the two boys do not seek assistance from higher authorities (they will later), at the moment they are able to assess that Mr. Emory's contact is inappropriate, and then, decide to perform a role of suitable guardian for each other. As 
the boy does not directly confront Mr. Emory at the very scene, he is not performing an active guardian role. However, performing a passive guardian role with his friend still enables the boy to stay safe from further sexual advances that Mr. Emory is likely to make in the near future.

\section{Excerpt 13.}

On Sunday July 2, 1972, after a day activities my son (A) was approached by David Beardsley who asked him how the days events went. After talking for a time he requested they go into the tent and talk some more. He talked about requirement for being an Eagle Scout and then he grabbed my son by the arm and pulled him down on the (blank) and put his hand into my son's sexual organs beneath the clothing. My son was terrified and (blank) and Mr. Beardsley continued talking and molesting for approximately 5 mins. The he left the tent.

On Mon the $3^{\text {rd }}$, he again came to camp and talked to the boys about the days event. He took my son into the tent and repeated the same process on the previous night. My son's tent mates (B) was in his (blank) and intervened (?) the action taking place. After the incident my son told (B) what took place and on Tues. Mr. Beardsley came back and had my son by the hand but (B) intervened so nothing happened. That night, Mr. Beardsley did not come back to camp after this. July 3, 1972.

While the previous boys play passive guardian roles for each other by staying away from Mr. Emory as a group, the above excerpt illustrates an active role of a third party guardian, victim's friend. The scoutmaster, Beardsley, implements an angling initiation to lure the boy, (A), into a sexual relationship. (A) states that he is too scared to 
resist. His submissive reaction — no resistance — then leads Beardsley to repeatedly make unwanted touching over the boy's body, including his penis. Since the molestations take place during the scout camp, one of the boy's tent mates sees the two of them while the molestation is going on. Upon the friend's appearance, the molestation is terminated, and (A) shares his victimization with his tent mate. The friend then enacts the role of a capable guardian by intervening in Beardsley's repeated molestation the next day. Owing to the friend's active intervention, the repeated sexual molestations end permanently.

In sum, it can be inferred that angling perpetrators are less likely to carry out sexual molestation while other people, regardless of their age and position, are present at the scene. It is also found that an individual boy victim can serve in an effective guardian role when the acts of resistance are delivered with an appropriate level of assertiveness. In angling initiation, it should be noted, however, that the majority of the boy victims do not realize the perpetrators' intention of verbal and physical cues until they encounter certain behaviors, such as fondling. Furthermore, due to the trust and respect that the boys have had for their scoutmasters, the boys do not resist aggressively.

Resistance pattern during spearfishing contact. In the previous section, it is found that an angling-type initiation is largely used in an attempt to bring boy victims into a state of shock and fear. Furthermore, spearfishing contact is usually made while boy victims are asleep or preoccupied with other tasks including watching movies. Thus, making a sudden attack to those boys enables scoutmaster perpetrators to reduce the risk of being confronted by the boy victims. 
Rolling over is new way of "no." In the previous resistance patterns in angling contact, some boy victims are found to meekly say "no" to their perpetrators in an attempt to avoid or minimize contact. However, most of the angling perpetrators refuse to interpret it as a refusal. Rather, they tend to read it as another way of expressing consent to sexual interaction. Thus, it is found that simply saying "no" is only a temporary solution being unable to permanently terminate the series of molestation by the same perpetrator. The following narrative illustrates how spearfishing perpetrators take victims' reluctant reaction implying "no" to their sexual advance as "yes" to continuation of sexual contact.

Excerpt 14.

Later that night, I was disturbed and woke up, and to my surprise Turk had his hand where it shouldn't have been, down my pants. I guess he thought I was still asleep and I tried to roll over and move away but he just kept on. A little later it would stop and I would just lay there for a while then fall back asleep... This happened again at Red River, at Santa Fe, and again at Post during Sweathog. While pretending he is still sleeping, the boy tries to break the physical contact by rolling over to the other side. However, Turk refuses to read the behavior the way the victim intends. Rather, Turk accepts the passive behavior like rolling over as consent, and then, makes the same sexual molestation to the same victim over and over again.

\section{Excerpt 15.}

He got in his room and I was standing beside the dresser, he was sitting on the bed dressed in a pair of shorts no (blank). I asked if I could get my (blank) out of his closet he said yes then asked if I wanted to see another movie, I called (blank) to 
come in and Mr. Davis told him to stay in the room. I sat at the head of the bed with the cover over me looking at the movie, Nightmare on Elm St, 2. Mr. Davis got in bed and lay down looking at me $1^{\text {st }}$, then he stuck his hand under the cover and started to fondled my penis while looking at TV for a few minutes. I moved my body in a position where he couldn't touch me then I told him I was going to the other room to go to bed. He said OK. The next morning, we went to camp and he didn't say anything or try any (blank). That afternoon, he carried me to my aunt's and I was too embarrassed to tell what happened. The second time happened when (blank) came back from the Y. I went home with Mr. Davis under the assumption that 3 other boys would be there to talk about citizenship. When we got to his house, he gave me a 7 up drink. We went in his study (?) and talked about citizenship but no other boys showed up. After we finished he asked me if I wanted to go home or look at a movie since no one was at my grandma's home, I said look at a movie. We went in his room and I layed[sic] down on my stomach on the bed. The house was hot and he told me I could take off my shirt but I only pulled it over my head he looked at my back and said I needed some lotion on my back. He started lotioning my back then pulled my pants down (blank) my knees and started lotioning my (blank) and pulling my cheeks apart. I looked back at him kicked my foot on the bed and got up and pulled my pants up. Mr. Davis asked me if I was ready to go home and I said yes. He carried me to the service station with out mentioning any thing about what he'd done. It has been discussed that the majority of spearfishing contact does not involve any verbal interaction between boy victims and perpetrators. It is because the 
spearfishing attack occurs while boys are in the middle of sleeping or doing some other tasks that require the boys to pay a great deal of attention. Thus, when the boys find out their penises are being fondled, they instantly become paralyzed and speechless out of shock. The fear and embarrassment then leads the boys to pretend that they are still asleep. The above excerpt, in this context, illustrates how a boy victim tries to be free of unwanted sexual contact that is being made while the boy is watching a movie. Since the boy is not supposed to know what Davis is doing to him—equivalent to remaining asleep - he cannot make any verbal confrontation against Davis. Thus, the boy chooses to roll over, while pretending to watch the movie, in an attempt to avoid further sexual touching. Then, the boy tells Davis that he needs to go to bed.

The boy's reaction— rolling over-is effective in cutting off ongoing sexual contact from Davis for that night. However, the effect of a passive resistance (e.g., rolling over or saying 'no') does not last long. Davis invites the boy to his house and continues to molest the boy while the boy is watching a movie again. This time, the boy is more cautious and watchful about Davis' behaviors. Davis tries to make an excuse to undress the boy blaming the heat in the house. Pretending that he is helping the boy to apply lotion on his back, Davis again starts to fondle the boy's penis. This time, the boy's reactions are more assertive than merely rolling over. The boy fiercely stands up and gets dressed. This is the moment that the boy is playing a role of active guardian for himself. Davis, as other perpetrators do, pretends that nothing happens and offers the boy a ride home.

Excerpt 16. 
On the morning of June 20, 1990 from 1:00am to about 2:00am, John Lowell was in my tent with me watching T.V. I'd known John for about a week and a half, and even though he was 22 years old, he was considered to be just one of the guys in our little group, so when he asked to come over and watch the late show, I'd seen no reason to not do it. While watching some show, I'd fallen asleep around 2:10am. At approximately 3:00am, I woke up out of sleep to feel John's hand probing my genitals. I was shocked. Thinking it was a dream, I rolled over, and when I did so, he placed his hand on my rear. Now I was not only surprised, but mad as well. I said to him to..."get the **** out." He was rather surprised that I was awake. I then told him to get out now...As he was leaving, I told him that “...If I ever hear of anything else like this happening, I'll ****ing kill you.” The above narrative is provided by a 17-year old scout member (also acting as staff). He describes an incident that a 22-years old scout camp staff initiates against him during a campout. It should be noted that the two are almost at the same age, and their relationship is slightly different from the rest of the boy victim-adult scoutmaster relationships. However, the most important point in this excerpt is the behaviors of both the boy and John (the perpetrator). While the boy is asleep, John starts to fondle the boy's penis, which causes a great shock to the boy. The boy is too drowsy to comprehend that John does it on purpose, and the boy just rolls over to the other side. Meanwhile, John cannot interpret the sign of "rolling over" the way it is. Rather, John proceeds to another sexual contact on the boy's rear. Upon touching the boy again, the boy finally gets up angry, and verbally confronts John to the point that John feels 
threatened. The boy also tries to convince John that he will never do the same thing again in the future.

Prompt physical confrontation. The moment that the boys use force to confront their perpetrators is usually when they are touched or fondled on their genital areas. In this regard, the temporal pattern of boy victims' physical confrontation (i.e., moment of termination) is quite similar in both angling and spearfishing contact. However, it should be noted that boy victims' overall pattern of using physical force against their perpetrators are also dependent on the perpetrators' initiation methods. For instance, in angling contact, boy victims gradually increase the level of resistance from merely saying no to physical attack over the course of molestations. In contrast, boy victims who are the subjects of spearfishing molestation usually respond to the perpetrators' touching right away when involving physical force.

\section{Excerpt 17.}

I was to get up in four hours, so after placing my sleeping bag in his truck, I laid down on the bag with my clothes still on. He argued that I should remove my clothing, claiming that scouts should be clean and neat. I refused his proposal and rolled over my back to him. After a short time he laced his arm on my back and slowly moved his arm until his hand was near my lower abdominal region. I was awake during his advances. When his hand and forearm glided around my waist, I very quickly withdraw his hand, proclaiming as I did it that he was acting unnaturally. He mumbled a few words in reply, but I did not wait to hear what he said. I snatched my sleeping bag from the rear of his truck and spent the night alone about fifty feet away. 
The above excerpt tells how effective it is for the boy victim to take an immediate action against sexual advances. Since the sexually molesting behavior is carried out in a spearfishing manner, it is inevitable for the boy to face a certain level of sexual contact made by his scoutmaster. However, as soon as the boy finds out the intention that John (perpetrator) implies in his touching, the boy pushes his hands and walks away from the scene in an infuriated manner. Such actions enable the boy to be free from John's further sexual contact.

Excerpt 18.

I was in bed around 2-2:30 (06/23/89) when I heard Tom talking about something, I didn't know what I was to[sic] nervous to go back to sleep. When I heard him putting on a rubber and he walked over to my bed he had pulled out his penis and tried to put it on my head, and I blocked it with my pillow after a few minutes I grabbed my arrow and stood up and put the arrow in his chest and told him to backoff or I would put the arrow inside him.

In this case, the perpetrator is one of the camp staff. He delivers a spearfishingtype contact to the boy victims, and the level of victim's response overpowers the behaviors made by the perpetrator. The victim's action is acute and swift enough to freeze the perpetrator, and consequently, to bring a full stop to the sexual attempt.

Interventionists. Similar to the boy victims' collective intervention pattern in angling contact, boys in spearfishing contact also perform the roles of guardians because many spearfishing cases take place during the scout activities. It should also be noted that sexually touching boys is an open secret among the boys who are under the care of some spearfishing scoutmasters. In other words, since spearfishing perpetrators treat boy 
victims as disposable sex tools, their behaviors produce multiple boy victims in one troop. Some boys already know what to expect when the night comes at the camp, and tend to practice vigilant guardians' roles among themselves.

Excerpt 19.

On a later camping trip, Mr. Emory asked (B) to sleep in the back room of the Nature Lodge with him. My friend (D) and I were in the main section of the lodge on the top bunk. We looked over the wall and saw Mr. Emory unzip (B) sleeping bag and reach down in (B) pants and rub him. (B) was asleep. We wanted Mr. Emory to stop so we said, "Hello, Mr. Emory," and he quickly covered him up and looked up and waved to us like nothing had happened.

This excerpt demonstrates the ability of boys to use their own assessment about Emory's unusual behaviors. They all exercise good judgment about the situation, and try to help other boys - more vulnerable than them — by actively intervening in the sexual contact that Emory attempts to make against the victim. In further description, it is found that most of the boys, who exercise the intervention strategy against Emory, have been the subjects of Emory's sexual advances before, and the boys share their experience and decided to vigilantly monitor and intervene in Emory's further molestations.

Resistance pattern during handpicking contact. Similar to the handpicking perpetrators' initiation pattern, boy victims' resistance is also simple and precise. Since handpicking molestation usually takes place as a group under the guise of the BSA initiation processes or training sessions, it is possible that multiple boys are subject to sexually charged behaviors at the same time. Regardless of their intention, the target 
boys all share their victimization, and then are able to come up with preventative techniques of their own.

Self-protectors. The following excerpt illustrates an effective strategy of older boys to avoid Mr. Harkeness' sexual contact. Harkness is known to make sexual advances against boys by pretending that it is a part of scout training elements, clearly a handpicking initiation.

Excerpt 20.

On the 2 week trip to Shin-Go-Beek (Summer 1975) Mr. Harkness had the habit of making early morning bed checks to make sure the boys were getting up. On numerous occasions he would sit on top of a boy's sleeping bag so he couldn't move then put his hand inside the scout's sleeping bag and feel around, often in places he shouldn't. Many of the older and more experienced boys got wise to this and when they heard him coming around, would run out the back of the tent... At one of the weekly Boy Scout meetings in 1975 their[sic] was a game night and one of the "games" was to see how fast a scout could take off and then put back on his clothes. Mr. Harkness became angry when several of the older boys refused to participate in this activity.

In the previous section, when boys share their victimization with each other, they tend to serve as guardians to protect each other from further sexual contact by their perpetrators. In other words, they play a role of interventionists. Some are engaged in an active intervention and surveillance to prevent their perpetrator from making sexual advances to any boys in the first place. It is, however, noted that the older boys' preventative actions as a group only benefit themselves, and fail to rescue younger boys 
from Harkeness' sexual attack. Therefore, there is still a group of boys (young ones) who are still being targets of sexual molestation by Harkeness.

\section{Excerpt 21 .}

Related experiences of son on Late Spring (1981) campout. Three boys in one tent. During night one boy was complaining of stomach ache. Lankton entered tent to assist boy and proceeded to rub stomach area of boy. However, following this "treatment" he then turned to her son and also gave him a rub down, including groin area and privates...Several families having older or longer tenured Scouts, after having heard the above from their younger sons, question older sons. Older boys had learned to say "no" when asked to sit in lap and had agreed among themselves never to be alone with Lankton. They stated that "rubdowns" are common experiences when clothed but none had had the experiences the younger boys have had.

As an extension of the previous argument, older boys in the above excerpt know how to avoid the so-called "treatment" made by Lankton. The old boys' prevention strategies include avoiding any type of physical contact in the first place as an exercise of self-protective measures. Thus, older boys refuse to join the "treatment" that begins with sitting on Lankton's lap. Furthermore, they also exercise their own surveillance system, such as not being left alone with Lankton. However, younger boys have not experienced such "treatment," and have not been informed of Lankton's sexual behaviors, and therefore, the younger ones end up being suitable targets for Lankton's "treatment". In summary, this chapter presented various verbal and physical reactions that boy victims exhibited in response to unwanted sexual contacts. Boy victims' resisting actions 
are slightly different depending on the methods of contact that a scoutmaster perpetrator employs when first commencing his sexual touching against the boys (see Table 2).

\section{Table 2}

Effectiveness of Victim Resistance at Termination Stage

\begin{tabular}{|c|c|c|c|}
\hline Behaviors & Angling & Spearfishing & Handpicking \\
\hline $\begin{array}{l}\text { No Resistance: Boy } \\
\text { victims are unable } \\
\text { to make any } \\
\text { resistance out of } \\
\text { fear and shock }\end{array}$ & $\begin{array}{l}\text { - Repeated and } \\
\text { aggravated } \\
\text { molestation }\end{array}$ & $\begin{array}{l}\text { - Repeated and } \\
\text { aggravated } \\
\text { molestation }\end{array}$ & $\begin{array}{l}\text { - Repeated and } \\
\text { aggravated } \\
\text { molestation }\end{array}$ \\
\hline $\begin{array}{l}\text { Verbal Resistance: } \\
\text { Saying "No" to the } \\
\text { contacts }\end{array}$ & $\begin{array}{l}\text { - Temporary } \\
\text { withdrawal of } \\
\text { sexual advances } \\
\end{array}$ & & \\
\hline $\begin{array}{l}\text { Verbal } \\
\text { Confrontation: } \\
\text { Making assertive } \\
\text { verbal } \\
\text { condemnations }\end{array}$ & $\begin{array}{l}\text { - Effective for } \\
\text { permanent } \\
\text { termination when } \\
\text { followed by } \\
\text { reporting to higher } \\
\text { authorities }\end{array}$ & $\begin{array}{l}\text { - Effective for } \\
\text { permanent } \\
\text { termination when } \\
\text { followed by } \\
\text { reporting to higher } \\
\text { authorities }\end{array}$ & \\
\hline $\begin{array}{l}\text { Physical Resistance: } \\
\text { Rolling over to the } \\
\text { other side }\end{array}$ & $\begin{array}{l}\text { - Ineffective to stop } \\
\text { sexual advances }\end{array}$ & $\begin{array}{l}\text { - Ineffective to stop } \\
\text { sexual advances }\end{array}$ & \\
\hline $\begin{array}{l}\text { Physical } \\
\text { Confrontation: } \\
\text { Making physical } \\
\text { resistance with force }\end{array}$ & $\begin{array}{l}\text { - Effective for } \\
\text { permanent } \\
\text { termination when } \\
\text { followed by } \\
\text { reporting to higher } \\
\text { authorities }\end{array}$ & $\begin{array}{l}\text { - Effective for } \\
\text { permanent } \\
\text { termination when } \\
\text { followed by } \\
\text { reporting to higher } \\
\text { authorities }\end{array}$ & \\
\hline $\begin{array}{l}\text { Collective } \\
\text { Intervention: self- } \\
\text { protectors or } \\
\text { Interventionists } \\
\end{array}$ & $\begin{array}{l}\text { - Effective for } \\
\text { temporary } \\
\text { termination (e.g., } \\
\text { avoiding the scene) }\end{array}$ & $\begin{array}{l}\text { - Effective for } \\
\text { temporary } \\
\text { termination (e.g., } \\
\text { avoiding the scene) }\end{array}$ & $\begin{array}{l}\text { - Effective for } \\
\text { temporary } \\
\text { termination (e.g., } \\
\text { avoiding the scene) }\end{array}$ \\
\hline $\begin{array}{l}\text { Reporting to higher } \\
\text { authority }\end{array}$ & $\begin{array}{l}\text { - Effective for } \\
\text { permanent } \\
\text { termination as a } \\
\text { result of removing } \\
\text { perpetrator from the } \\
\text { BSA }\end{array}$ & $\begin{array}{l}\text { - Effective for } \\
\text { permanent } \\
\text { termination as a } \\
\text { result of removing } \\
\text { perpetrator from the } \\
\text { BSA }\end{array}$ & $\begin{array}{l}\text { - Effective for } \\
\text { permanent } \\
\text { termination as a } \\
\text { result of removing } \\
\text { perpetrator from the } \\
\text { BSA }\end{array}$ \\
\hline
\end{tabular}


However, it is found that the boy victims' resistance, either verbal or physical, does not cause any risk of subsequent physical assaults by their perpetrators. Furthermore, aggressive and assertive manners of resistance are found to be more effective in terminating immediate sexual contacts compared to passive and hesitant manners of resistance. Detailed implications of boy victims' resisting behaviors will be discussed in the following chapter. 


\section{CHAPTER 6}

\section{DISCUSSION}

This chapter will begin with a review of the current study focusing on its purpose, processes of analyses, and the analytical foundation of the study. A summary of the analyses from the previous two chapters will then be presented along with the significances of the findings in relation to the existing literature on child molestation. The significant findings include behavioral elements of same-sex child molestation, victim selection, non-coercive actions, double-edged authority, effectiveness of physical and verbal resistance, and lastly, collective guardianship to terminate unwanted sexual contacts. At the end of each topic, practical and safe ways to intervene in incidents of child molestation will be discussed. Child molestation, in this context, refers to ongoing physical contacts being made against child victims in an attempt to arouse sexual gratification.

Findings of this study shed light on implementing practical policies to prevent child molestation within an institutional setting. Children will be able to understand the importance of self-protection when encountering sexually charged situations against their will. By learning structured intervention techniques that reflect the analyses of both victims and perpetrators' behaviors, children will know how to safely resist unwanted sexual contacts while they are away from their primary caregivers.

Before proceeding to the summary of the findings, it should be reminded that this study examined behavioral sequences between boy members and scoutmaster 
perpetrators in ongoing same-sex child molestation. As noted in Chapter 2, few studies have examined same-sex child molestation as a topic of study in its own right. Furthermore, micro-level analysis of behavioral interactions between boy victims and perpetrators has not been conducted. Consequently, little has been known about the dynamics of same-sex child molestation as to how motivated molesters carried out sexual contacts against under-age male victims and how target victims responded to unwanted sexual contacts in an effort to terminate the risk of severe and repeated sexual victimization.

\section{Summary of Current Study}

This study examined physical and verbal interactions from initiation to termination of sexual contacts by magnifying the moments when actual physical contacts were being undertaken. Victims' narratives from 331 case files were analyzed in an effort to understand the unique nature of same-sex child molestation within the Boy Scouts of America. Using the metaphor of a fish farm and fishing, this study examined both protracted physical grooming behaviors and contingent physical contacts of scoutmaster perpetrators to reel boy victims into sexual relationships. As fishermen do not involve violence to catch fish, scoutmaster perpetrators rarely use physical violence against young boy victims when molesting the boys within the Boy Scouts of America.

The findings were then presented with multiple excerpts that best described each thematic category.

Qualitative analyses of behavioral patterns revealed that scoutmasters initiated sexually charged advances on boy victims, and the boy victims, in turn, intervened in an attempt to terminate unwanted sexual molestation. The patterns of physical and verbal 
interactions between the two parties helped to identify effective ways for boy victims to discontinue the ongoing sexual molestation. In addition, the findings of this study suggested safe ways to minimize the risks of subsequent physical and emotional harms when the boys attempted resisting actions against their adult molesters.

Similar to the finding from previous studies that indicated a heterogeneous nature in child molesters' offending patterns and victims selection (see Bard et al., 1989; Bickley \& Beech, 2001; Knight et al., 1989; Wortley \& Smallbone, 2006), victims' narratives for this study revealed that scoutmasters demonstrate three significant behavioral patterns when commencing sexual contacts against boy victims. Each initiation method employed different starting points of physical contacts, and determined the likelihood of escalation or cessation of sexual advances.

Boy members were strictly disciplined and trained at scoutmasters' commands and discretions as to their code of conduct and activities within the Boy Scouts of America. Due to the unique characteristic of the Boy Scouts of America as a male-youth institution, the BSA came across as the site of unparalleled opportunity for scoutmaster perpetrators to not only get close to, but also have control over young boy members. Such a pattern is consistent with previous finding which indicated that child molesters deliberately chose to work in youth-centric organizations in order to gain access to children in order to sexually exploit (Shoop, 2004; Sullivan \& Beech, 2004; van Dam, 2001).

Using a fishing metaphor, to scoutmaster perpetrators, the BSA was a fish farm: It provided the motivated perpetrators with an abundance of resources-young boys. The boy members were easily approachable and available for exploitation for the purposes of 
sexual gratification. Furthermore, strict disciplinary culture required young boy members to obey the commands of their scoutmasters. Plenty of opportunities in victim selection and scout activities thus made the BSA a desirable place for scoutmaster perpetrators to commence and escalate sexual relationships with young boys.

In the meantime, the scout activities, such as campouts, carried the least amount risks to obstruct sexual molestation due to the legitimacy and authority of the position of scoutmasters. Previous studies also mentioned that child molesters in a religious setting that were more likely to be attributed to the power and control vested on youth educators (e.g., ministers and volunteers) through interactions with victims regardless of the characteristics of the surrounding community (Denny, 2015; Fater \& Mullaney, 2000)

The manner of initiating physical contacts that perpetrators had used to achieve their goals within the BSA were akin to various fishing techniques used in a fish farm: angling, spearfishing, and handpicking. The initiation methods of same-sex child molestation were classified according to the involved actions and circumstances while the acts of sexual molestation were taking place. Using different initiation contacts, scoutmaster perpetrators played an integral role in initiating sexual advances against young boys under their charge. Meanwhile, boy victims' reactions to sexual contacts contributed to the termination of unwanted sexual contacts made by scoutmaster perpetrators. Boy victims undertook termination behaviors to a varying degree in an effort to stop the escalations of sexual molestation. Boy victims attempted various resisting actions unless they were completely submissive to sexual contacts due to excessive shock and fear. 
Depending on the degree of resisting actions, victims' behaviors served as termination signals to perpetrators to withdraw from further sexual advances. In some cases, boy victims' reactions were, however, interpreted as positive signals for continuation of sexual advances until the perpetrators achieved sexual gratification, or for an invitation for another physical interaction in the future. To verify the distinctions, victims' physical and verbal reactions were examined on a continuum of the fishing techniques used in each initiation pattern. Significant patterns in boy victims' verbal and physical reactions were then analyzed. The appropriate levels of assertiveness in victim resistance were found to bring perpetrators' sexual behaviors to a full stop without causing any subsequent physical injury on the boy victims.

\section{Analytical Foundation: Elements of Routine Activities Theory}

To understand behavioral sequences in ongoing sexual molestation, elements of the Routine Activity Theory were used as an analytical foundation of this study (see Cohen \& Felson, 1979). From the perspective of the Routine Activity theory, three actors converge in the same time and space in order for a crime to occur. The three elements involve a motivated offender, a suitable target, and an absence of capable guardians (Cohen \& Felson, 1979). However, it should be noted that there were only two actors, boys and scoutmasters, in the course of sexual molestation within the BSA due to the nature of scout activities and selection of isolated locations by scoutmaster perpetrators. Thus, this study extensively examined contingent role switching dynamics of the two actors to cover the aforementioned three roles in the Routine Activity theory.

Scoutmaster perpetrators in the BSA were secondary caregivers; they were expected to protect young boys under their charge while the boys were away from their 
primary guardians (parents). Although scoutmasters were motivated offenders in nature in this analysis, they were granted guardian roles both from the BSA and by the parents of boy victims. Doing so enabled motivated scoutmaster perpetrators to masquerade as capable guardians until they were left with suitable targets at a desirable environment. Then, the scoutmaster deliberately removed their masks of capable and respected guardians, and then, performed their original roles of motivated offenders. This role switching process left the once-filled capable guardian position vacant. Meanwhile, young boys were positioned as suitable targets upon the scoutmaster perpetrators' role change.

Similar to the perpetrators' role switching pattern from capable guardians to motivated offenders at the initiation stage, victims' resistance behaviors against unwanted sexual contacts also served as a significant turning point that shaped the likelihood of escalation of sexual advances. Furthermore, how boy victims resisted their attackers affected the patterns of termination of sexual molestation. Simply speaking, it was found that the "right" resisting actions delivered at the "right" time enabled boy victims to successfully switch their roles from captive targets into capable guardians.

Through this role switching, boy victims not only rescued themselves from further victimization, but also helped to prevent motivated offenders from committing the same molestation against the rest of the scout members. It was inevitable for the boy victims to play a guardian role to protect themselves since the same-sex child molestation within the BSA usually took place while they were only left with their scoutmasters. Thus, this study focused on the degree of resisting actions and appropriate timing that effectively 
helped the boy victims to stop the perpetrators' sexual behaviors from further sexual contacts.

It should be noted that the role switching made by both actors - boys and scoutmasters - were performed in a reciprocal manner. The original position of scoutmasters was motivated offenders. However, they were able to disguise their identities by enacting the role of a scoutmaster, pretending to be capable guardians of young boys. Thus, the change in their positions from capable guardians to motivated offenders occurred when they touched boys in sexual ways. Furthermore, since scoutmasters only used the position of capable guardians to access young boys, scoutmasters no longer played a guardian role.

The boys, however, became suitable targets and capable guardians not of their own accord but from the situational exigencies. As soon as sexual contacts were made against young boys, they became suitable targets regardless of their will. The boys then made attempts to fight their perpetrators in various ways, which was equivalent to the role switching from the targets of molestation to self-protective guardians. Despite their multiple roles, the boys still became victims of sexual molestation. The boys' roles as victims began when scoutmasters began sexually touching them; the boys' roles as capable guardians began during the course of sexual molestation. Thus, it was found that the manners and levels of boy victims' resistance was one of the most important factors that determined the continuation or termination of unwanted sexual contact. In the meantime, the boys performed both victim and guardian roles in the dynamics of samesex child molestation within the Boy Scouts of America. 


\section{Significances of Analyses}

Behavioral elements in child sexual molestation. Sexual abuse involving children has been classified in several ways depending on the methods of contacts, victim age, the use of reward, level of physical force, and other references. Accordingly, types of sex crime against children included physical contact for sexual purposes, molestation, statutory rape, prostitution, pornography, exposure, incest, or other sexually exploitative activities (Malchiodi, 1997). One of the common behavioral elements found in the course of child molestation was an adult offender sexually touching a child's genitals and/or forcing a child to touch an adult's genitals for sexual gratification (see Finkelhor, 1994a; Finkelhor \& Williams, 1988). Similarly, this study also found that the overall goal of sexual molestation in same-sex child molestation was touching/ fondling a boy victim's penis.

Previous literature simply classified child molestation in dichotomously ways, as outcome-oriented measures. This study, however, was conducted to understand the details of sexually charged behaviors that made up same-sex child molestation from initiation to termination. Scoutmaster perpetrators' sexual behaviors against boy victims within the BSA were used to find the most effective manner of termination. Using the behavioral sequences, this study attempted to understand the surrounding circumstances and patterns of actual physical interactions. As a result, it was found that the behavioral sequences were often made up of the following components: hugging, kissing, holding hands, touching legs, laying down, touching boys' genital area, making boys touch perpetrators' genital areas, undressing boys, undressing perpetrators themselves, fondling boys' penis, oral sex to boys, making boys give oral sex to perpetrators, masturbating 
boys, masturbating themselves, making boys masturbate perpetrators, and lastly penetration to boys. These behavioral elements were rank-ordered on a continuum of seriousness, which reflected repetition/ escalation of sexual behaviors depending on victims' reactions. Types of sexual contacts used for each case were determined by the initiation method that each scoutmaster perpetrator had chosen to make first sexual contact against boy victims.

Angling perpetrators were found to begin their molestation by making casual physical contacts, such as holding hands or hugging, on natural occasions. The angling perpetrator took at least two to three steps prior to achieving their goal in child molestation, fondling a boy's penis. Spearfishing perpetrators, however, began their sexual contact straightly with touching/ fondling a boy victim's penis. Since the spearfishing initiation relied on a boy victim's state of shock to a great extent when his scoutmaster grabbed the boy's penis, the spearfishing perpetrator was able to skip some preliminary stages before he achieved his goal of child molestation. Handpicking perpetrators usually began their initiation with undressing boys as a group or freely rubbing on the boys' genital areas because the perpetrators claimed that doing so was a part of scout trainings or initiation rituals.

Knowing how each sexual behavior is connected to the next step is important because the series of sexual behaviors perpetrated by child molesters are always intertwined with victims' resisting behaviors. The findings of this study regarding the elements of same-sex child molestation were significant with this regard. In other words, identified scoutmaster perpetrators' behavioral spectrum, such as an initiation contact, 
was also used to determine the degree and the timing of boy victims' resistance actions that helped to rescue themselves in a safe and effective manner.

Victim selections. Previous researchers argued that the selection of child victims was not made on perpetrators' preference, but on the availability of victims, especially among child molesters in educational professions (Finkelhor \& Williams, 1988). For instance, Calkins-Mercado et al. (2008) argued that the nature of superior position of child molesters in educational settings affected their victim selection patterns to be circumstantial rather than to be fixated. Thus, child molesters in educational professions were more likely to select victims of their targets when they thought were the most accessible and feasible to make sexual contacts regardless of their preference for types of victims.

Previous findings on victim selection partially supported the findings of this study. Scoutmaster perpetrators employed different manners when they first initiated sexual contacts against their target boys. Each initiation method that perpetrators employed took time and effort to a varying degree. For instance, perpetrators who made an angling initiation had to invest the greatest amount of time until their first casual contact with boy victims. The first touching was initiated by holding hands or hugging, which raised little suspicion from the victims. Upon completing a series of sexual contacts as initiation with little to no resistance from the boy victim, the perpetrators gradually increased the level of physical stimuli. In the meantime, the perpetrators still pretended those actions had naturally occurred with no sexual intention.

Thus, it could be argued that victim selections for sexual molestation within youth-oriented institutions still require premeditated strategies by investing time and 
effort to contact the most suitable victims. In other words, victim selection was not entirely contingent upon the availability of children, but was dependent on more fixed factors, such as perpetrators' personal vulnerability and knowledge about their potential victims, which eventually determined each scoutmaster perpetrator's behavioral pattern at the initiation stage. This finding was slightly contrary to the findings in previous child molestation literature, which argued that child victims of sexual molestation in educational settings were chosen by opportunity than preference.

Furthermore, previous studies revealed that child molesters chose younger victims due to their stature, such as smallness and mobility, instead of their gender-based sexuality. This finding suggested that small child victims were objectified for sexual gratification, and such distinctions were attributed to victim's age. Also, it was discussed in previous literature that factors influencing sexual offending behaviors included each party's age, gender, offender motivation, victim/offender relationship, and the perceptions of victims and sexual violence (Bard et al., 1987; Buschman, Wilcox, Spreen, Marshall, \& Bogaerts, 2008; Calstedt et al., 2009; Cox \& Holmes, 2001; Erickson, et al., 1988; Sullvan et al., 2011).

Meanwhile, the BSA victim narratives revealed that the environment affected scoutmasters' perceptions about their victims. As was mentioned previously, the BSA setting was like a fish farm to the motivated scoutmaster perpetrators. An abundance of resources - young boy members - were available all of the time. Since the interactions between boys and scoutmasters were created through extracurricular activities, the position of authority as secondary caregivers also affected perpetrators' perceptions of their victims; their relationships were hierarchical. 
A previous study argued that the number of child victim — either single or multiple - determined child molesters' manner of approaching potential victims (Scully, 1994). Also, victim's age influenced a child molester's perception that younger child victims were more likely to be treated as a sexual object (Lang et al., 1988). However, the current findings suggest that scoutmaster perpetrators' view of boys under their charge became one of the determinants of their method of initiation, instead of boy victim's age or physical figure that were argued in previous studies. It was done regardless of the boy victims' age or the number of victims. Most importantly, the majority of the scoutmaster perpetrators had molested more than one victim at the time of being placed in a confidential file. Rather, the perpetrators' perceptions of their victims were better explained by child molesters' personal vulnerability, such social incompetence and low self-esteem, which eventually determined the manner of initiation in same-sex child molestation.

The angling perpetrators tended to treat their boy victims as sexual partners by way of offering money or favors for sexual interactions. In this sense, angling perpetrators treat their underage victims as men treat prostitutes (see Scully, 1994). Also, as was seen in the analysis on initiation, scoutmasters tried to impress their boy victims by offering to participate in various leisure activities (e.g., shooting, going for movies, and driving lessons) together. Most importantly, the angling perpetrator molested one victim at a time by investing substantial amount time and effort to each victim at a separate incidence. While advancing sexual contacts against boy victims, the angling perpetrators continuously attempted to know how the boys were feeling before they moved onto the next step. 
In this regard, emotional congruence of child molesters could account for scoutmaster perpetrators' angling behaviors (Finkelhor, 1984). Wilson (1999) also revealed that homosexual child molesters tended to interact with children on the child's level, while heterosexual molesters brought child victims' status to an adult level. However, when looking at the within group differences - all members were males in the BSA, this argument was slightly inconsistent with the findings of this study. That is, the way in which scoutmaster perpetrators treated their boy victims was more associated with their initiation methods, rather than sexual orientation or boy victims' characteristics.

Unlike the angling perpetrators who targeted specific victims and developed his contacts gradually, spearfishing perpetrators were not seeking sexual gratification from any particular or specific boy victims. Rather, the spearfishing perpetrators regarded the boy victims as disposable tools because the unsuccessful (resisting) boys could be replaced by new supplies with the least amount of time and efforts required from the perpetrators. Consequently, spearfishing perpetrators preferred their potential victims to be in a preoccupied and distracted state, such as sleeping or watching movies, so that the perpetrators could avoid any unnecessary interactions with the boys that might lead to the boys' resistance.

When the spearfishing perpetrators were confronted, they withdrew from making further sexual contacts against the boys. While the sexual touching was going on, boy victims still frequently pretended that they were asleep out of fear and embarrassment. The victim narratives revealed that the majority of the spearfishing perpetrators did not realize the boys were fully awake during sexual touching. Thus, the perpetrators freely 
took advantage of the boy's state of shock and then pretended nothing had happened later on.

Perpetrators' behaviors could be explained by the feelings of worthlessness and low self-esteem that previous studies indicated as an integral reasons for preference for children (Milner \& Webster, 2005; Marshall, 2003). On the surface, young boys trusted and respected adult scoutmasters. It could be argued that the reason why the motivated perpetrators voluntarily chose to be in a position of authority among young boys is because they did not feel confident about socializing with the same age group. Perpetrators attempted to remedy their emotional starvation and lack of socialization practices by serving scoutmaster roles (Gilgun, 1994).

Although the number of incidents was rare, one of the most notable perpetrator groups was the handpicking perpetrator. While the other two groups of perpetrators targeted individual boy victims at a time in a secured place, the handpicking-type of contact often involved boy victims as a group. Furthermore, this group of perpetrators blatantly made emotional and verbal threats against boy members under the name of scout training processes. Doing so, the handpicking perpetrators easily manipulated the boys to conform to their commands, such as undressing, simultaneously.

This pattern was consistent with a previous study that child molesters in day-care settings used childcare curriculum, such as games and physical activities, as a part of grooming processes. Child victims then became desensitized to sexual behaviors, such as undressing in front of other members, and to normalize such activities (Finkelhor \& Williams, 1988). Similarly, boy victims in handpicking cases did not quite distinguish 
what was wrong in the actions that their scoutmaster demanded to do, and took those actions, such as being naked, as one of the processes of becoming good scouters.

It should be noted that the underlying mechanism of same-sex child molestation within the BSA was the scoutmasters' emotional manipulation of his position of authority. In the two initiation methods, angling and spearfishing, however, the emotional control was carried out implicitly_-perpetrators did not need to verbally demand what they wished boy victims to do. However, in the handpicking initiation, perpetrators explicitly gave verbal instructions to boy victims regarding what to do and how to do it.

Also, handpicking perpetrators were not afraid of their abusive behaviors being recognized by others. Rather, they masqueraded as caring and devoted scoutmasters who performed multiple tasks (e.g., caregiver, educator) for boy victims. In other words, they felt that they could be in a leader's role and redeemed themselves among young boys. As was argued in a previous study, child molesters preferred children in order to seek attention, sense of control, and entitlement that they could not obtain from the same age group (Gilgun, 1994).

Double-edged authority. Scoutmasters within the BSA were required to cover a wide variety of duties, unlike primary educators in educational settings. Teachers primarily interact with their students in the classroom; however, scoutmaster interacted with their troops in their homes, in public, and in remote locations far away from home. It was due to the characteristic of the institution, which provided boy members with a wide range of life skills and involved them into various extracurricular activities in their leisure time. Previous researchers argued that those who could easily gain access to and 
interact with children on a regular basis were more likely to sexually abuse children under their charge (Sullivan \& Beech, 2002; Sullivan, Beech, Craig, \& Gannon, 2011). Both boy members and scoutmasters spent a substantial amount of time engaged in various scouting curricula and activities. In this sense, the victims' narratives revealed that scoutmasters had served not only a role of a scout leader, but also a lifetime advisor and good friend to young boy members of the Boy Scouts of America.

The engagement of extra curricular activities with young boys may be one of the primary reasons that adult scoutmasters may have joined the BSA in the first place. However, the multiple duties of scoutmasters also suggested that the scoutmaster position came across as double-edged swords to perpetrators: Their position earned them an immense respect and authority, yet such privileges also required them to heed extra caution when molesting their victims. Simply speaking, losing his position as a scoutmaster was akin to losing access privileges to a fish farm — loss of potential victims. Thus, in order for a scoutmaster perpetrator not to lose his pool of good resources, the perpetrator rarely used physical force against boy victims when bringing the victims into sexual interactions. They were well aware that use of physical force would lead to the involvement of other adults.

Child molesters in educational professions were widely known for using their position of authority to manipulate young children to conform to sexual desires (Ward \& Keenan, 1999). The use of authority usually manifested in the form of emotional threats, which were implicitly delivered to child victims in the course of educational activities. As other child molesters, scoutmaster perpetrators were found to make good use of their position of authority in various capacities. 
Similarly, the three initiation methods were all delivered based on the implicit norms of the BSA: obedience to commands. The sense of obedience served as an invisible weapon in same-sex child molestation within the BSA. Scoutmaster perpetrators rarely articulated verbal and physical threats. Yet, the majority of the boy victims received such messages that left them with no choice but to remain submissive to the unwanted sexual contacts because of the feelings of fear and embarrassment resulting from the invisible emotional threats.

This current study found that scoutmaster perpetrators were able to take advantage of boy victims' vulnerability (e.g., fear and shame) that was greatly influenced by scoutmasters' position of authority. At the same time, the analysis also revealed that the perpetrator's authoritative position within the BSA could also be used in favor of boy victims when attempting to switch their roles from victims to capable guardians. As will be discussed shortly, victims' verbal and physical resistances were found effective in curbing perpetrators' sexual contacts.

At the same time, it was found that one of the most effective ways of keeping the scoutmaster perpetrators from making further sexual contacts was to make a verbal threat to report to higher authorities or to tell other members at the camp. Such verbal threats were most frequently seen in the course of spearfishing initiation. Upon recognizing scoutmasters were in the middle of touching their body parts, boy victims immediately and assertively confronted and explicitly stated that they would let other people know of such incidents. When boys uttered these types of threats, the scoutmasters stopped fondling and touching the boys. 
Non-coercive actions. Throughout this dissertation, behavioral patterns of scoutmaster perpetrators and boy victims were examined and analyzed. The former were found to be the initiators of sexual contacts, and the latter mainly performed the role of terminating unwanted sexual advances. Through the analyses of physical and verbal interactions between the two parties, one of the noteworthy facts identified from the victims' narratives was that perpetrators rarely used coercive force in the course of initiating and developing sexual contacts boy victims.

The victim narratives revealed that there were few to no victims who were physically injured by perpetrators in the course of resistance. The average goal of sexual molestation was to fondle the boy's penis, and in some cases, to the point of ejaculation. It was not surprising to see few cases reporting serious physical injury as a result of coercive actions by the perpetrators. Scoutmasters rarely engaged any type of physical force, such as hitting, punching, kicking, restraints, and other weapons in an effort to threaten boy victims. In the course of termination, victims' physical or verbal resistance against the perpetrators rarely results in perpetrators' use of physical assault against boy victims.

A previous study revealed that non-physical violence was expected in educational settings because child molesters in such occupations had sufficient information about their potential victims as to how much force they should use to subdue their victims. Gilgun (1994) argued that physically hurting child victims was not the goal of child molesters. Furthermore, Balemba (2010) revealed that offenders who sexually abused children were well aware of the expected range of modus operandi, such as the use of force, before they initiated sexual contacts against the children. 
Child victims had no choice but to comply with their offending plans and to conform to sexual demands. Thus, child molesters knew how much physical force they needed if unforeseen factors, such as victim resistance, intervened in their criminal plots. Non-forcible ways of sexual initiation within the BSA were found throughout the three different initiation methods—angling, spearfishing, and handpicking contacts. Scoutmaster perpetrators seldom made any threats to bring their potential victims into sexual interactions.

The reasons for scoutmasters' not involving coercive actions could be explained in various ways. It might simply be unnecessary for scoutmaster perpetrators to use physical force when performing sexual molestation against young boys under their charge. The authoritative position as a scoutmaster already granted a motivated perpetrator a great deal of privileges, such as respect from boy members.

Most importantly, upon commencing physical contacts, boy victims already experienced emotional vulnerability not only because of the position the perpetrators held, but also the sexually charged touching itself. Therefore, due to the implicit yet mutual agreement on respect for authority, scoutmaster perpetrators were able to accomplish their sexual goals using the least amount of physical force.

Another reason for non-coercive sexual contacts was attributed to the aforementioned perpetrators' personal vulnerability. Although the scoutmaster perpetrators were physically and socially superior to their boy victims, the victim narratives revealed that the majority of angling and spearfishing perpetrators exhibited behaviors that were not consistent with physical and social superiority. Rather than being forceful or confident in their mannerisms, they were almost obsequious and servile when 
they first made sexual contacts with boys. The overly servile behaviors were manifestations of a lack of self-confidence and self-esteem: They were unable to relate to their similar age peers. Similarly, they stopped their behaviors when a boy victim forcefully confronted them.

A previous study indicated that if a potential victim confronted a child molester in an educational profession, the molester was less likely to continue the grooming (Shoop, 2004). Rather, $\mathrm{s} /$ he tended to move and search for another victim, who was less assertive and more submissive (Shoop, 2004). It might be unnecessary for a scoutmaster to devote too much effort to one victim while other boys were still available. This pattern of moving to another victim was one of the most notable features in the spearfishing initiation in that the perpetrators treated boy victims as disposable tools for sexual gratification. In a similar vein, since the BSA was a good opportunity for scoutmaster perpetrators to have unlimited access to young boys, scoutmaster perpetrators were found to be anxious about losing the authoritative position within the BSA. Due to the vulnerability of their position, scoutmaster perpetrators tended not to use coercive actions against boy victims so that they could continue to wear the mask of respected guardians with other potential victims.

Effectiveness of physical resistance. In previous studies, increasing guardianship and target hardening were suggested as a part of preventative models of child molestation (McKillop et al., 2015; Terry \& Freilich, 2012). Implementing such strategies was expected to discourage motivated offenders to further carry out their sexual behaviors against children. The victim narratives of this study also revealed that boy 
victims' resisting actions could also prevent further sexual molestation in their Boy Scout units.

As was mentioned in Chapter 2, previous studies largely defined preventative strategies as actions that should be implemented before physical touching occurred (see Finkelhor et al., 1995; Kenny et al., 2008; Leclerc et al., 2011). In other words, once perpetrators commenced sexual contacts, all the rules that applied "before-contact" stage became nullified. Without detailed strategies for the physical contact stage, boy victims were more likely to be submissive out of shock and embarrassment. Thus, it is imperative to identify effective intervention models that can be easily taught to young children when they are encountering sexually charged physical contacts.

The boy victims' resisting actions were delivered by two different manners: inward and outward resistance. The former represented passive actions, such as rolling over to the other side to avoid a perpetrator's touching. The latter, in contrast, was done in more assertive and active ways - pushing or punching a perpetrator. The current victim narratives revealed that the majority of the boy victims seldom exercised physical resistance against their scoutmaster perpetrators when sexual contacts were ongoing. However, those who used outward physical resistance, such as hitting the perpetrator or pushing him away, were always able to immediately terminate ongoing sexual contacts without causing any subsequent physical assault from the perpetrators. This finding was inconsistent with the previous research on female victims cases which found that aggressive resistance employed by the victim were likely to increase an offender's physical force, which also resulted in more severe injury on victims (Leclerc et al., 2009). Hewitt and Beauregard (2014) also argued that victim resistance made offenders employ 
physical force greater than necessary to subdue their victims. However, in the same-sex child molestation cases within the BSA, the greater physical force boy victims used for resistance, the more immediate and effective termination of sexual contacts took place. Since boy victims were physically inferior to their scoutmaster perpetrators, the effectiveness of physical resistance was significant. It was also noted that the majority of the same-sex child molestation was committed in private locations (e.g., perpetrator's residence). Thus, the boy victims' use of physical resistance should be highlighted not only for its effectiveness, but also for the manner of its delivery in an isolated setting. In the spearfishing cases during scout campouts, it was found effective to permanently terminate sexual contacts when boy victims reported their victimization to higher authorities or colleagues immediately after they physically confronted their perpetrators.

Similar patterns were detected in the angling initiation-termination. As soon as boy victims acknowledged that they were being sexually molested, the boys physically confronted their perpetrators in an assertive manner. Even though such physical assertiveness could not prevent sexual touching from the beginning, boy victims' coercive resistance was effective to stop sexual contacts from being escalated to the point of ejaculation, sexual intercourse or any other form of sexual contact.

It was also noteworthy that many boy victims were found to be hesitant to physically confront their perpetrators. For instance, several spearfishing cases revealed that boy victims simply rolled over to the other side out of the reach from their perpetrators while pretending that they were still asleep. However, physical resistance that was made in a passive way sometime exacerbated the situation. Scoutmaster perpetrators took those behaviors as a green light to proceed to the next sexual contacts. 
Also, the perpetrators often interpreted the passive physical resistance as an invitation to another attack in the future. Once the resisting action did not work, boy victims were more likely to feel helpless and terrified, which led to an ultimate submissive state in response to the perpetrator's subsequent contacts.

For prevention of repeated victimization, it should be reminded that scoutmaster perpetrators tended to seek emotional congruence with young boy victims through sexual interactions. Similarly, from a developmental perspective, the perpetrators' maturity level was almost the same level as young boy victims: They need thorough and painstaking instructions as to what to do and what not to do. It is not enough to assume that a prescribed set of verbal directives will work. Instead, resistance training should take into consideration the potential for interpretive ambiguity on the part of the perpetrators. Furthermore, a scoutmaster perpetrator also exhibited emotional vulnerability to a victim's physical states and mood response while committing sexual molestation against the boy victim. Thus, it is important to instruct young boys that as soon as they acknowledge abnormal and awkward development in their scoutmasters' physical touching, they should actively show their feeling of objection to the perpetrators with physical force, such as pushing the perpetrator away, and leave the scene immediately.

Effectiveness of verbal resistance. Similar to the two different manners of physical resistance (i.e., inward and outward actions), victim narratives revealed that boy victims' verbal resistance could be classified into two types: verbal refusal and verbal confrontation. The distinctive outcomes of these two different resistance methods were noticeable in the angling initiation. One previous study argued that regardless of sexual 
abuse experience, children were not fully able to distinguish potential risk for sexually abusive situations as well as the danger of such activities (Miller-Perrin, 1990). Similarly, boy victims in angling initiation were found to have not been able to distinguish the potential danger that scoutmaster perpetrators implied in their casual touching (e.g., hugging) until the actions escalated to the point of fondling their private body parts. Thus, boy victims' actions of resistance actually began when the perpetrator almost achieved his sexual goal by touching a boy's penis.

Once recognizing the abnormality of the perpetrator's touching, the majority of boy victims first said "no" to the sexual contacts. However, "no" in verbal resistance was equivalent to rolling over in physical resistance. In other words, merely saying "no" implied hesitation. A boy victim became emotionally paralyzed upon having his penis touched by a scoutmaster. The scoutmaster interpreted the boy's "no" as "yes" to further sexual contacts. In this process, scoutmaster perpetrators largely employed verbal persuasion/ manipulation to distract the boy victim and to elicit a more positive sign of consent to sexual interactions. As was seen in the physical resistance, once the first resistance attempt was not successful and the perpetrator's sexual contacts escalated, the boy victim became helpless and submissive to the rest of molesting actions.

Meanwhile, some boy victims were able to verbally confront scoutmaster perpetrators in an assertive manner. Boy victims' verbal resistance in a confrontational manner was found to deliver effective outcomes, not only in terminating ongoing sexual contacts, but also in permanently preventing repeated sexual molestation. It was noted that verbal confrontation did not require boy victims to come up with embellished and logical statements. Rather, the effective verbal confrontation was precise and 
instructional enough to deliver the boy's message to stop the perpetrator from continuing sexual contacts. Furthermore, as was discussed in the previous section, scoutmaster perpetrators were more likely to surrender at the boy victims' verbal confrontation indicating that the boys would bring the current matter to other staff and boy members. Any type of resistance — either physical or verbal—delivered in a confrontational and assertive manner upon recognition of victimization would help to terminate ongoing sexual molestation.

Collective guardianship. One of the most significant resistance patterns found from this study was the boys' (both victims and bystanders) capability of performing a role of collective guardians. Boy members within the BSA served multiple roles, not only as a target of same-sex child molestation, but also as evidence, witness, and most importantly, guardians for themselves. Oftentimes, boy members were seen playing the role of guardians for each other, wittingly or unwittingly.

It should be noted that, similar to the verbal and physical resistance, the patterns of collective guardian roles were also divided into two categories: self-protectors and interventionists. The former was largely found in handpicking cases: Older boy groups had experienced sexual abuse by certain scoutmasters, so they deliberately tried to avoid repeated victimization. However, their guardianship only applied to protect themselves. Young and new boy members were not informed of the perpetrator's behaviors, and therefore, became victims of sexual molestation. The latter, on the other hand, was done both as a group and individually. Some boys shared their experiences with their peers, or witnessed abnormal behaviors being performed by their scoutmasters. Once the stories were shared, the boys actively engaged themselves in the role of interventionists by way 
of avoiding individual contacts with the perpetrator and monitoring his behaviors when he was with other potential victims.

The majority of the boy victims related that they were ashamed and afraid of revealing their victimization to others, such as staff members or their peers.

Nevertheless, each confidential case file revealed that scoutmaster perpetrators seldom had a single victim. In other words, the majority of the scoutmasters had at least one victim at a time and a series of victims or simultaneously regardless of their method of initiation. Therefore, it is important to convince children that they may not be the only victims of sexual molestation; sharing their victimizations with other caregivers (e.g., family and staff) is an important step to rescue them from further victimization.

A previous study found that while the majority of sexual offences occurred in another person's presence, a presence of a third party was rarely developed into a guardian's role to stop the crime due to the distance between the third party and the crime scene (McKillop et al., 2015). Also, simple bystanders nearby the crime scene did not entirely affect perpetrators' decision-making processes to crime. However, the findings from this study was mixed. The victim narratives indicated that when a story of victimization was shared with victim's peers, it was likely that the boys collectively performed the role of capable guardians.

A potential victim pool within the BSA provided scoutmaster near perpetrators limitless supplies to achieve sexual gratification. However, a number of available targets could also mean that there were a number of potential capable guardians, not only to protect themselves, but also to help one another. Findings from this study revealed that boy members monitored a reported scoutmaster's whereabouts and behaviors when he 
was seen with a new target, and then, the boys actively intervened in the scene to separate the potential victim from the perpetrator.

In spite of the scoutmaster perpetrators' preference for isolated locations to carry out sexual molestation to a single victim, the nature of the BSA activities operated in a group also required perpetrators to perform an offender role while other people were around, such as during campouts. Even though scoutmaster perpetrators tended to believe that they had committed a perfect crime with each victim, the victim narratives indicated that some boys had known the molesting behaviors from direct and indirect experiences, and the stories went around as open secrets among the boys. In other words, young boys were capable of delivering self-protection measures for one another, and such vigilant surveillance and monitoring were found effective to interfere with the perpetrator's sexual contacts to other boys.

Both self-protective and peacemaking actions of boy members were found equally effective to reduce the risks of sexual molestation as a whole. However, it should also be noted that no matter how swiftly the boys responded to unwanted sexual contacts as capable guardians, their efforts only yielded short-term solutions: discouraging a scoutmaster perpetrator in an immediate incident. As was frequently mentioned, the Boy Scout settings were perceived as a fish farm by the motivated offenders. When a perpetrator faced an obstacle with one victim, regardless of its orientation, the perpetrator could move to another target. Thus, it should be noted that not only collective guardians, but also the other two resistance methods - verbal and physical confrontations - only resulted in the same temporary outcomes unless the actions at the boys' level were followed by the institutional-level interventions involving adult staff and caregivers. 


\section{Suggestions for Intervention Strategies}

Based on the discussion of significant findings about the behaviors of perpetrators and victims in same-sex child molestation, effective and practical intervention strategies are recommended for youth-centric institutions, such as the Boy Scouts of America, to implement child protection policies.

Despite the continual efforts to implement the SCP perspective through target hardening (e.g., education for potential victims and identifying potential offenders), such preventative strategies have omitted the detailed instructions as to "how" and "when" the child victims should carry out such protective techniques to safely rescue themselves from the threats of not only sexual assaults, but also subsequent physical assaults that their resisting actions may cause (see Leclerc et al., 2015; Terry, 2008).

The new intervention strategies suggested in the following are expected to provide children with details of intervention instructions because they are derived from actual verbal and physical patterns of perpetrators during immediate physical contacts. Avoiding any risk for children to be left with adult caregivers in an isolated place may be one of the most desirable ways to prevent child molestation in the first place. In reality, however, it is nearly impossible for primary caregivers to monitor each and every activity that takes place while their children are away from home. Thus, children should be aware of how to exercise self-protective measures while away from their home. In the following, four important components are recommended for inclusion in effective intervention strategies and to be taught to young audiences to permanently terminate sexual molestation within the youth-centered institutions. 
First, once physical contacts are commenced, it is important for a child victim to minimize the risks of more "serious" and "repeated" sexual advances, such as sexual intercourse. In other words, no matter when the child victim realizes the perpetrator's sexually charged touching - it is usually when the perpetrator touches the boy's genital area - the child victim needs to take action as soon as s/he recognizes it; the victim should immediately let the perpetrator know that s/he knows the intention of the perpetrator. Verbal confrontation is found effective in immediately terminating sexual advances. However, verbal resistance should be assertive enough to convey the confrontational message to the perpetrator. Simply saying 'no' in an attempt to avoid sexual contacts is not an assertive verbal confrontation. Since perpetrators rarely comprehend the underlying meaning of 'no,' it is necessary for child victims to be as assertive and persistent as possible in expressing their objection to the perpetrators' behaviors, such as “I don’t like your behavior because touching other's body is crime”; "I am going to tell Mr. Smith (staff member) that you tried to touch me.”

Second, children can use physical force to fight their perpetrators. Active physical confrontation, not just rolling over to the other side, is effective especially when the molestation takes place during group activities, such as campouts. When other people — peers or staff members — attend the same activities, it is effective for a child victim to physically push or punch the perpetrator with loud verbal protestations. Doing so will not only discourage the perpetrator from continuing his sexual advances, but also to worry about his reputation within the organization.

Third, it should be noted that young children's reactions to sexual molestation vary; some children are able to confront their perpetrators, however, the majority of the 
children begin to feel helpless and vulnerable, unable to stop their perpetrators due to the position of authority that the perpetrators hold in their organization and feelings of shame and embarrassment. Therefore, in the course of prevention education, children should be instructed and reminded that they are not blameworthy for sexual molestation, regardless of their reactions.

Once children feel the burden of blame for letting such incidents happen to themselves, they become more secretive and vulnerable to further victimization. Thus, children should be instructed that after experiencing unwanted sexual touching, they should let other people know about the incidents so that the perpetrators will be brought to the attention of higher authorities, such as parents, staff members, and criminal justice practitioners. In the meantime, children should be convinced that their inability to prevent sexual victimization in the first place is not their fault.

Lastly, it is important to instruct young children to perform a role of collective guardians when they participate in group activities. The BSA cases illustrated that boy members were able to serve as peacekeepers by watching a known perpetrator's sexually charged behaviors and making active interventions when the perpetrator approached another victim. To do so, the boys shared their experiences with one another and stayed together while outdoor activities were going on. To instruct young children, therefore, it is important to tell them that they may not be the only victims of sexual molestation. In addition, their active participations in intervention strategies can protect not only themselves from threats of unwanted sexual contacts, but also the rest of their colleagues from the future molestations. 
Above all, for the aforementioned instructions to bring permanent termination of sexual molestation within youth-centric organizations, it is essential for children to know that all the resisting actions should be followed by one last action: reporting to a higher authority. Children can avoid the development of sexual contacts by exercising the above resistance instructions, such as verbal and physical confrontation. However, any action that rescues the child victim from the immediate physical contacts is a temporary solution, not a long-term termination, within the youth-oriented institutions. The only way to terminate child molestation in the long run is to bring the perpetrator to the attention of appropriate authorities in charge, and to remove the perpetrator from the organization permanently. To do so, children should be instructed to report any sexual incidents they experience/ witness while they are engaged in the youth organizations.

\section{CONCLUSION}

This chapter presented significant findings from analyses of victim narratives about same-sex child molestation within the Boy Scouts of America. Existing studies argued that sexual abuse in childhood resulted in adverse mental and behavioral health outcomes, and such traumatic outcomes impacted the life course of victims. Male victims of sexual abuse displayed aggressive and disruptive behaviors to compensate for the feelings of powerlessness and shame as a result of unwanted victimization and subsequent trauma.

Consistent with these findings, the data for this study revealed that a number of boy victims were reported to experience behavioral and emotional issues, such as depression, hysteria, and suicidal thoughts. For instance, one of the victims committed suicide after a long struggle with self-blame and feeling of shame. Several boys reported 
that they became confused about their sexual identities after repeated molestation by their scoutmasters.

It was also discovered that most of the boy victims were afraid of revealing their victimization. In most cases, it was the boy victims' caregivers (e.g., parents, school teachers) who recognized the boys' change of mood or unusual behaviors including poor work at school, refusal to participate in the BSA activities, and being silent. Furthermore, considering the timeframe when the crimes occurred, many caregivers took sexual molestations case against their boys as a moral issue of an individual scoutmaster, and therefore, did press criminal charge against the perpetrator.

This study was conducted to find the most effective and safest ways of protecting boy victims from unwanted sexual contacts perpetrated by persons of authority within the BSA; this study focused on the sequences of verbal and behavioral interactions between boy victims and scoutmaster perpetrators during a physical contact stage.

According to the analyses, any trivial touching always has a potential to escalate to serious sexual molestation if it is not followed by a resisting action in an acute and assertive manner. Intervention should be made as early as a boy victim recognizes abnormal activities conducted by a scoutmaster. It was found that most of the boy victims first realized their victimization when their perpetrators started to touch their sexual organs. Most boys unambiguously realized the sexual nature of the scoutmaster's advances when they were touched on their sexual organs, and this sexual touching drove the boy victims into the state of shock and fear.

The analyses suggest that young boy victims are most likely to terminate immediate sexual contacts made by their adult scoutmasters by using coercive physical 
and verbal resistance. To be specific, the resisting actions should be physically outward and verbally confrontational, for instance, hitting or punching the perpetrator with force, and making a full statement (e.g., a couple of sentences) to deliver the message of objection to sexual contacts.

It should also be reminded that boy victims are not in a completely disadvantageous position in the dynamics of same-sex child molestation perpetrated by persons of authority. That is, the analyses reveal that adult scoutmaster perpetrators are also vulnerable to their position of authority within the BSA due to the fear of losing the position once his malicious behaviors are brought to other adults' attention. Thus, it is suggested that boy victims should make verbal threats to their perpetrators and rescue themselves from the immediate danger first. Such actions should always be accompanied by the essential follow-up, reporting to another authority including adult staff members and primary caregivers. By doing so, it is necessary that the matter should be handled at an institutional level for prevention in the long run.

Lastly, one of the noteworthy findings of this study is the notion of collective guardianship: Boy members exercise their own self-protection measures to protect not only themselves, but also their colleagues from unwanted sexual attack by their scoutmasters. It is found that older and experienced boy members know whom to avoid and how to respond to the person's sexually charged initiation (e.g., handpicking method); boys as a group can watch for offensive behaviors of "known" perpetrators as well. Thus, it is important to have at least two boy members who feel comfortable with one another as a team and instruct them to stay together during all scout activities. 
Collective guardianship can also be performed via mentorship between young (new) and older boy members.

\section{What the Boy Scouts of America Has Done for Youth Protection?}

Currently, the Boy Scouts of America has been operating a "buddy system" "that requires boys participate in the activities as a pair in an effort to maintain safe scouting. Their age should not be apart more than two years; the buddy members should be likeminded and similar in maturity. The requirement makes it be allowed to have three boys in one buddy group. However, the guidelines for child protection in BSA do not specify the reasons for having a buddy system, nor does it suggest detailed instructions as to how it should be operated, such as instructive reporting procedures. The buddy system is only said to be a safety measure for all scouting activities without providing any details of what kind of risks should be prevented.

Similarly, the BSA safe scouting guidelines emphasize the prohibition of activities with opposite sex members, such as staying in the same tent during a scout campout, without providing specific instruction for prevention of same-sex sexual offences. Furthermore, although the child protection guidelines within the current BSA encourage scout members to report any sign of child abuse to local scout authorities, the overall messages imply that the persons in charge of reporting are adult scoutmasters/ leaders. Thus, young boy members still do not know what to do and how to report when they become victims of child molestation. That being said, this current study is expected to promote an awareness of the danger of same-sex child molestation with an institutional setting and to serve as a foundation of practical prevention strategies that can reach to

\footnotetext{
${ }^{1}$ Child Protection, the Boy Scouts of America http://www.scouting.org/Training/YouthProtection.aspx
} 
boys in all age groups, so that any boy member can easily understand and practice when needed.

\section{LIMITATIONS}

This study is not without limitations. The primary data used for this dissertation are records of allegations that came to the attention of the Boy Scouts of America; each narrative described sexual molestation cases between boy victims and adult scoutmasters. Victim narratives that are used for this study in particular are different from official victim statements because they are not official statements that victims provided to the court or police as part of a criminal investigation. This study entirely relies on the descriptions available in each narrative, which were primarily related by young boys. Thus, the depth of description of each case may be insufficient to understand to grasp the full details of the case. Furthermore, due to the privacy of youth members, details of victim information are not available for analysis, such as victim age and family background. It would have been helpful to know the demographics of each victim to have better understanding of the factors that affect boy victims' different resisting actions, and most importantly, scoutmaster perpetrators' victim selection preferences and behavioral significance depending on victims' age. To remedy this, it is recommended that future study using the same "Ineligible Volunteer" files should also focus on other sources available in each case file, such as scoutmasters' resignation/ defense letters and newspaper clippings. Doing so is expected to provide in-depth understanding of perpetrators' behaviors from their own perspectives in terms of their defense and justifying mechanisms. The future study will eventually help to develop a more practical 
and effective preventative model to prevent same-sex child molestation within institutional settings. 


\section{REFERENCES}

Abbey, A., Clinton-Sherrod, A.M., McAuslan, P., Zawacki, T., \& Buck, P.O. (2003). The relationship between the quantity of alcohol consumed and the severity of sexual assaults committed by college men. Journal of Interpersonal Violence, 18, 813833.

Abel, G.G., Lawry, S.S., Karlstrom, E.M., Osborn, C.A., \& Gillespie, C.F. (1994). Screening tests for pedophilia. Criminal Justice and Behavior, 21, 115-131.

Abel, G.G., \& Rouleau, J.L. (1990). The nature and extent of sexual assault. In W.L. Marshall, D.R. Laws, and H.E. Barbaree (Eds), Handbook of sexual assault. New York: Plenum Press.

Ackerman, J.M., \& Rossomo, D.K. (2015). How far to travel? A multilevel analysis of the residence-to-crime distance. Journal of Quantitative Criminology, 31, 237262.

Allen, C.M., \& Lee, C.M. (1993). Family of origin structure and intra/extrafamilial childhood sexual victimization of male and female offenders. Journal of Child Sexual Abuse, 1(3), 31-46.

Bagley, C., Wood, M., \& Young, L. (1994). Victim to abuser: Mental health and behavioral sequels of child sexual abuse in a community survey of young adult males. Child Abuse \& Neglect, 18, 683-697.

Balemba, S. (2010). Reactions to resistance: The role of contextual factors in sex offending. (Master's Thesis, Simon Fraser University). 
Balemba, S., Beauregard, E., \& Mieczkowski, T. (2012). To resist or not to resist?: The effect of context and crime characteristics on sex offenders' reaction to victim resistance. Crime \& Delinquency, 58, 588-611.

Banse, R., Schmidt, A. F., \& Clarbour, J. (2010). Indirect measures of sexual interest in child sex offenders" A multimethod approach. Criminal Justice and Behavior, 37, 319-335.

Bard, L.A., Carter, D.L., Cerce, D.D., Knight, R.A., Rosenberg, R., \& Schneider, B. (1987). A descriptive study of rapists and child molesters: Developmental, clinical, and criminal characteristics. Behavioral Sciences \& the Law, 5, 203-220.

Beauregard, E. (2010). Rape and sexual assault in investigative psychology: The contribution of sex offenders' research to offender profiling. Journal of Investigative Psychology and Offender Profiling, 7, 1-13.

Beauregard, E., Lussier, P., \& Proulx, J. (2005). The role of sexual interests and situational factors on rapists' modus operandi: Implications for offender profiling. Legal and Criminological Psychology, 10, 265-278.

Beauregard, E., \& Mieczkowski, T. (2011). Outside the interrogation room: The context of confession in sexual crimes. Policing: An International Journal of Police Strategies \& Management, 34, 246-264.

Beauregard, E., \& Mieczkowski, T. (2012). From police interrogation to prison: Which sex offender characteristics predict confession?. Policy Quarterly, 15, 197-214.

Beauregard, E., Deslauries-Varin, N., \& St-Yves, M. (2010). Interactions between factors related to the decision of sex offenders to confess during police interrogation: A classification- tree approach. Sexual Abuse: A Journal of Research and 
Treatment, 22, 343-367.

Beauregard. E., \& Leclerc, B. (2007). An application of the rational choice approach to the offending process of sex offenders: A closer look at the decision-making. Sex Abuse, 19, 115-133.

Beauregard, E., Rebocho, M.F., \& Rossomo, D.K. (2010). Target selection patterns in rape. Journal of Investigative Psychology and Offender Profiling, 7, 137-152.

Beauregard, E., Rossmo, D.K., \& Proulx, J. (2007). A descriptive model of the hunting of serial sex offenders: A rational choice perspective. Journal of Family Violence, 22, 449-463.

Beauregard, E., Proulx, J., Rossomo. K., Leclerc, B., \& Allaire, JF. (2007). Script analysis of the hunting process of serial sex offenders. Criminal Justice and Behavior, 34, 1069-1084.

Beggs, S.M., \& Grace, R. C. (2008). Psychopathy, intelligence, and recidivism in child molesters: Evidence of an interaction effect. Criminal Justice and Behavior, 35, 683-695.

Beitchman, J.H., Zucker, K.J., Hood, J.E., DaCosta, G.A., Akman, D., \& Cassavia, E. (1992). A review of the long-term effects of child sexual abuse. Child Abuse \& Neglect, 16(1), 101-118.

Bickley, J., \& Beech, A.R. (2001). Classifying child abusers: Its relevance to theory and clinical practice. International Journal of Offender Therapy and Comparative Criminology, 45, 51-69.

Brecklin, L. R., \& Ullman, S. E. (2010). The roles of victim and offender substance use in sexual assault outcomes. Journal of Interpersonal Violence, 25, 1503-1522. 
Berg, B. L. 1., \& Lune, H. (2012). Qualitative research methods for the social sciences (8th ed.). Boston: Pearson.

Buschman, J., Wilcox, D., Spreen, M., Marshall, B., \& Bogaerts, S. (2008). Victim ranking among sex offenders. Journal of Sexual Aggression, 14(1), 45-52.

Calkins-Mercado, C., Tallon, J.A., \& Terry, K.J. (2008). Persistent sexual abusers in the Catholic Church: An examination of characteristics and offense patterns. Criminal Justice and Behavior, 35, 619-642.

Carlstedt, A., Nilsson, T., Hofvander, B., Brimse, A., Innala, S., \& Anckarsater, H. (2009). Does victim age differentiate between perpetrators of sexual child abuse? A study of mental health, psychosocial circumstances, and crimes. A Journal of Research and Treatment, 21, 442-454.

Canter, D.V., Bennel, C., Alison, L.J., \& Reddy, S. (2003). Differentiating sex offences: A behaviorally based thematic classification of stranger rapes. Behavioral Sciences and the Law, 21, 157-174.

Clark, R.V., \& Cornish, D.B. (1985). Modeling offenders' decision: A framework for policy and research. In M. Tony \& N. Morris (Eds). Crime and Justice: An Annual Review of Research pp. 147-185). Chicago, IL: University of Chicago Press.

Cohen, L., \& Felson, M. (1979). Social change and crime rate trends: A Routine Activity approach. American Sociological Review, 44, 588-608.

Colton, M., Roberts, S., \& Vanstone, M. (2010). Sexual abuse by men who work with children. Journal of Child Sexual Abuse, 19, 345-364.

Conte, J., Wolf, S., \& Smith, T. (1989). What sexual offenders tell us about prevention 
strategies. Child Abuse \& Neglect, 13, 293-301.

Corovic, J., Christianson, S.A, \& Lars, R.B. (2012). From crime scene actions in stranger rape to prediction of rapist type: Single-victim or serial rapist? Behavioral Sciences and the Law, 30, 764-781.

Cox, R., \& Holmes, W. (2001). A study of the cycle of abuse among child molesters. Journal of Child Sexual Abuse, 10, 111-118.

Daro, D., \& Donnelly, A. C. (2002). Charting the waves of prevention: Two steps forward, one step back. Child Abuse \& Neglect, 26, 731-742.

Denny, A.S. (2015). Sex offenses at Protestant Christian Churches: a typology and examination using social disorganization theory. (Doctoral dissertation, University of Louisville). Retrieved from www. Louisville.edu.

Deslauriers-Varin, N., \& Beauregard, E. (2010). Victims' routine activities and sex offenders' target selection scripts: A latent class analysis. Sexual Abuse: A Journal of Research and Treatment, 22, 315-342.

Deu, N., \& Edelmann, R. J. (1997). The role of criminal fantasy in predatory and opportunistic sex offending. Journal of Interpersonal Violence, 12, 18-29.

Douglas, J., Burgess, A., Burgess, A., \& Ressler, R. (1992). Crime classification manual. New York: Lexington.

Durkin, K.T., Digianantonio, A.L. (2007). Recidivism among child molesters: A brief overview. Mental Health Issues in the Criminal Justice System, 249-256.

Duwe, G., Donnay, W., \& Tewksbury, R. (2008). Does residential proximity matter? A geographic analysis of sex offense recidivism. Criminal Justice and Behavior, 35, 484-504. 
Easton, S. D. (2012). Disclosure of child sexual abuse among adult male survivors. Clinical Social Work Journal, 12, 1-12.

Elo, S., \& Kynga s, H. (2007). The quality content analysis process. Journal of Advanced Nursing, 62(1), 107-115.

Easton, S.D., Coohey, C., Rhodes, A.M., \& Moorthy, M.V. (2013). Posttraumatic growth among men with histories of child sexual abuse. Child Maltreatment, 18, 211220.

Elliott, N., \& Lazenbatt, A. (2005). How to recognize a "quality" grounded theory research study. Australian Journal of Advanced Nursing, 22(3), 48-52.

Erickson, W. D., Walbeck, N., \& Seely, R. K. (1988). Behavioral patterns of child molesters, Archives of Sexual Behaviors, 17, 77-87.

Farrell, D. P., \& Taylor, M. (2000). Silenced by God: An examination of unique characteristics within sexual abuse by the clergy. Counseling Psychology Review, $15,22-31$.

Fater, K., \& Mullaney, J.A. (2000). The lived experience of adult male survivors who allege childhood sexual abuse by clergy. Mental Health Nursing, 21, 281-295.

Feelgood, S., \& Hoyer, J. (2008). Child molester or pedophile? Sociolegal versus psychopathological classification of sexual offenders against children. Journal of Sexual Aggression, 14(1), 33-43.

Los Angeles Times Staff. (2012, October 18). Inside the 'perversion files:' Tracking decades of allegations in the Boy Scouts. The Los Angeles Times, Retrieved from http://spreadsheets.latimes.com/boyscouts-cases/

Felch, J., \& Christensen, K. (2012, October 19). Release of scouts' files reveals decades 
of abuse. The Los Angeles Times, Retrieved from http://www.latimes.com/local/la-me- scouts-oregon-20121019-story.html

Fergusson, D.M., Boden, J.M., \& Horwood, L.J. (2008). Exposure to childhood sexual and physical abuse and adjustment in early childhood. Child Abuse \& Neglect, 32, 607-619.

Finkelhor, D. (1984). Child sexual abuse: New theory and research. New York: Free Press.

Finkenhor, D. (1994a). Current information on the scope and nature of child sexual abuse. Sexual Abuse of Children, 4(2), 31-53.

Finkelhor, D. (1994b). The international epidemiology of child sexual abuse. Child Abuse \& Neglect, 18, 409-417.

Finkelhor, D. (2009). The prevention of childhood sexual abuse. The Future of Children, 19, 169-194.

Finkelhor, D. (2012). Characteristics of crimes against juveniles. Durham, NH: Crimes against Children Research Center.

Finkelhor, D., Asdigian, N., \& Dziuba-Leatherman, J. (1995). The effectiveness of victimization prevention instruction: An Evaluation of children's responses to actual threats and assaults. Child Abuse \& Neglect, 19, 141-153.

Finkelhor, D., \& Ormrod, R. (2001, September). Crimes Against Children by Babysitters. Washington, DC: Juvenile Justice Bulletin.

Finkelhor, D., Ormrod, R., Turner, H., \& Hamby, S. L. (2005). The victimization of children and youth: A comprehensive, national survey. Child Maltreatment, 10, 525. 
Finkelhor, D., Ormrod, R., \& Turner, H. (2007). Re-victimization patterns in a national longitudinal sample of children and youth. Child Abuse \& Neglect, 31, 479-502.

Finkelhor, D., Shattuck, A., Turner, H.A., \& Hamby, S.L. (2014). The lifetime prevalence of child sexual abuse and sexual assault assessed in late adolescence. Journal of Adolescent Health, 55, 329-333.

Finkelhor, D., \& Williams, L. (1988). Nursery crimes: A study of sexual abuse in daycare. Newbury Park, CA: Sage.

Firestone, P., Dixon, K.L., Nunes, K.L., Bradford, J.M. (2005). A comparison of incest offenders based on victim age. Journal of the American Academy of Psychiatry and the Law, 22, 223-232.

Fisher, B., Cullen, F. \& Turner, M. (2000). The Sexual Victimization of College Women. Washington, DC: U.S. Department of Justice.

Franzel, R. R., \& Lang, R. A. (1989). Identifying sexual preferences in intrafamilial and extrafamilial child sexual abusers. Annals of Sex Research, 2, 255-275.

Gilgun, J. F. (1994). Avengers, conquerors, playmates, and lovers: Roles played by child sexual abuse perpetrators. Families in Society: The Journal of Contemporary Human Services, 45, 467-480.

Glasser, M., Kolvin, I., Campbell, D., Glasser, A., Leitch, I., \& Farrelly. (2001). Cycle of child sexual abuse: Links between being a victim and becoming a perpetrator. British Journal of Psychiatry, 179, 482-294.

Groth, A.N., \& Burgess, A.W. (1977). Motivational intent in the sexual assault of children. Criminal Justice and Behavior, 4, 253-264.

Groth, A.N., Hobson, W.F., \& Gary, T.S. (1982). The child molester: Clinical 
observations. In J. Conte \& D.A. Shore (eds.), Social Work and Child Sexual Abuse. New York: Haworth.

Guay, JP., Proulx, J., Cusson, M., \& Ouimet, M. (2001). Victim-choice polymorphia among serious sex offenders. Archives of Sexual Behavior, 3, 521-533.

Hall, R.C.W., \& Hall, R.C.W. (2007). A profile of pedophilia: Definition, characteristics of offenders, recidivism, treatment outcomes, and forensic issues. Mayo Foundation for Medical Education and Research, 82, 457-471.

Hamdi, N.R., \& Knight, R.A. (2012). The relationship of perpetrator and victim substance use to the sexual aggression of rapists and child molesters. Sexual Abuse: A Journal of Research and Treatment, 24, 307-327.

Hanson, R.K., Scott, H., \& Steffy, R.A. (1995). A comparison of child molesters and nonsexual criminals: Risk predictors and long-term recidivism. Journal of Research in Crime \& Delinquency, 32, 325-337.

Hanson, R.K., Steffy, R.A., \& Gauthier, R. (1993). Long-term recidivism of child molesters. Journal of Consulting and Clinical Psychology, 61, 646-652.

Harbers, E., Deslauriers-Varin, N., Beauregard, E., \& Van Der Kemp, J.J. (2012). Testing the behavioral and environmental consistency of serial sex offenders: A signature approach. Journal of Investigative Psychology and Offender Profiling, 9, 259273.

Hazelwood, R.R., Reboussin, R., \& Warren, J.L. (1989). Serial rape: Correlates of increased aggression and the relationship of offender pleasure to victim resistance. Journal of Interpersonal Violence, 4, 65-78.

Hepburn, J.M. (1995). The implications of contemporary feminist theories of 
development for the treatment of male victims of sexual abuse. Journal of Child Sexual Abuse, 3(4), 1-18.

Hewitt, A., Beauregard, E., \& Davies, G. (2012). Catch and release: Predicting encounter and victim release location choice in serial rape events. Policing: An International Journal of Police Strategies \& Management, 35, 835-856.

Hewitt, A., \& Beauregard, E. (2014). Offending patterns of serial sex offenders: Escalation, de-escalation, and consistency of sexually intrusive and violent behaviors. Journal of Investigative Psychology and Offender Profiling, 11, 57-80.

Hunter, S.V. (2006). Understanding the complexity of child sexual abuse: A review of the literature with implications for family counseling. The Family Journal, 14, 349-358.

John Jay College. (2004). The nature and scope of sexual abuse of minors by Catholic priests and deacons in the United States, 1950-2002. Washington, DC: USCCB.

Kaufman, K.L., Hilliker, D.R., Lathrop, P., \& Daleiden, E.L. (1993). Assessing child sexual offenders' modus operandi: Accuracy in self-reported use of threats and coercion. Annals of Sex Research, 6, 213-229.

Kenny, M.C., Capri, V., Thakkar-Kplar, R. R., Ryan, E.E., \& Runyun, M.K. (2008). Child sexual abuse: From prevention to self-protection. Child Abuse Review, 17, 36-54.

Knight, R.A., Carter, D.L., \& Prentky, R.A. (1989). A system for the classification of child molesters: Reliability and application. Journal of Interpersonal Violence, 4, $3-23$.

Konradi, A. (2007). Taking the Stand: Rape Survivors and the Prosecution of Rapists. 
New York: Praeger.

Krebs, C. P., Lindquist, C. H., Warner, T.D., Fisher, B. S., \& Martin, S.L. (2007). The campus sexual assault (CSA) study. Washington, DC: U.S. Department of Justice, Bureau of Justice Studies.

Lang. R., Rouget, A.C., \& van Santen, V. (1988). The role of victim age and sexual maturity in child sexual abuse. Annals of Sex Research, 1, 467-484.

Leclerc, B., Carpentier, J., \& Proulx, J. (2006). Strategies adopted by sexual offenders to involve children in sexual activity. Crime Prevention Studies, 19, 251-270.

Leclerc, B., Feakes, J., \& Cale, J. (2015). Child sexual abuse in youth-oriented organizations: Tapping into situational crime prevention from the offender's perspective. Crime Science, 4(28), 1-12.

Leclerc, B., Lussier, P., \& Deslauriers-Varin, N. (2015). Offending patterns over time: An examination of specialization, sscalation, and de-escalation in the commission of sexual offenses. In Blokland, A., \& Lussier, P. (Eds). Sex Offenders: A Criminal Career Approach. John Wiley \& Sons, Ltd.

Leclerc, B., Proulx, J., Lussier, P., \& Allaire, JF. (2009). Offender-victim interaction and crime event outcomes: Modus operandi and victim effects on the risk of intrusive sexual offenses against children. Criminology, 47, 595-617.

Leclerc, B., Proulx, J., \& McKibben, A. (2005). Modus operandi of sexual offenders working or doing voluntary work with children and adolescents. Journal of Sexual Aggression, 2, 187-195.

Leclerc, B., \& Tremblay, P. (2007). Strategic behavior in adolescent sexual offenses against children: Linking modus operandi to sexual behaviors. Sexual Abuse: A 
Journal of Research and Treatment, 19, 23-41.

Leclerc, B., Wortley, R., Smallbone, S. (2010). Investigating mobility patterns for repetitive sexual contact in adult child sex offending. Journal of Criminal Justice, $38,648-656$.

Leclerc, B., Wortley, R., Smallbone, S. (2011). Victim resistance in child sexual abuse: A look into the efficacy of self-protection strategies based on the offender's experience. Journal of Interpersonal Violence, 26, 1868-1883.

Lussier, P. (2005). The criminal activity of sexual offenders in adulthood: Revisiting the specialization debate. Sexual Abuse: A Journal of Research and Treatment, 17, 269-291.

Malchiodi, C. A. (1997). Breaking the Silence: Art Therapy with Children from Violent Homes. New York: Brunner/Mazel.

Martellozzo, E. (2013). Online Child Sexual Abuse: Grooming, Policing and Child Protection in a Multi-Media World. London: Routledge.

Marshall, W.L., Marshall, L.E., Sachdev, S., \& Kruger, R.L. (2003). Distorted attitudes and perceptions and their relationship with self-esteem and coping in child molesters. Sexual Abuse: A Journal of Research and Treatment, 15, 171-181.

McKillop, N., Brown, S., Wortley, R., \& Smallbone, S. (2015). How victim age affects the context and timing of child sexual abuse: Applying the routine activities approach to the first sexual abuse incident. Crime Science, 4(17), 1-12.

Merrill, L.L., Guimond, J.M., Thomsen, C.J., \& Milner, J.S. (2003). Child sexual abuse and number of sexual partners in young women: The role of abuse severity, coping style, and sexual functioning. Journal of Consulting and Clinical 
Psychology, 71, 987-996.

Miller-Perrin, C. L., Wurtele, S. K., \& Kondrick, P. A. (1990). Sexually Abused and Non-Abused Children's Conceptions of Personal Body Safety. Child Abuse and Neglect, 14, 99-112.

Milner, R.J., \& Webster, S.D. (2005). Identifying schemas in child molesters, rapists, and violent offenders. Sexual Abuse: A Journal of Research and Treatment, 17, 425439.

Moulden, H.M., Firestone, P., \& Wexler, A.F. (2007). Child care providers who commit sexual offences: A description of offender, offence, and victim characteristics. International Journal of Offender Therapy and Comparative Criminology, 51, $384-406$.

Mustaine, E. E., \& Tewksbury, R. (2000). Comparing the lifestyles of victims, offenders, and victim-offenders: A routine activity theory assessment of similarities and differences for criminal incident offenders." Sociological Focus, 33, 339-362.

Mustaine, E. E., \& Tewksbury, R. (2009). Transforming potential offenders into motivated ones: Are sex offenders tempted by alcohol and pornography?" Deviant Behavior, 30, 561-588.

Mustaine, E. E., Tewksbury, R., Corzine, J., \& Huff-Corzine, L. (2014a). Differentiating single and multiple victim child sexual abuse cases: A research note considering social disorganization theory. Journal of child sexual abuse, 23, 38-54.

Mustaine, E. E., Tewksbury, R., Huff-Corzine, L., Corzine, J., \& Marshall, H. (2014b). Community characteristics and child sexual assault: Social disorganization and age. Journal of Criminal Justice, 42, 173-183. 
National Sexual Violence Resource Center, Child sexual abuse prevention overview. 2011.

Pawlak, A. E., Boulet, J. R., \& Bradford, J. M. (1991). Discriminant analysis of the sexual functioning inventory with intrafamilial and extrafamilial child molesters. Archives of Sexual Behavior, 20, 27-34.

Prently, R.A., Knight, R.A., \& Lee, A.F.S. (1997). Risk factors associated with recidivism among extrafamilial child molesters. Journal of Consulting and Clinical Psychology, 65, 141-149.

Proulx, J., Perreault, C., \& Ouimet, M. (1999). Pathways in the offending process of extrafamilial sexual child molesters. Sexual Abuse: A Journal of Research and Treatment, 11, 117-129.

Pryor, D. W. (1996). Unspeakable acts: Why men sexually abuse children. NYU Press.

Qyayle, E., \& Taylor, M. (2001). Child seduction and self-representation on the Internet. Cyberpsychology \& Behavior, 4, 597-608.

Repucci, N.D., \& Hauggard, J.J. (1989). Prevention of child sexual abuse: Myth or reality. American Psychologist, 44, 1266-1275.

Robertiello, G., \& Terry, K.J. (2007). Can we profile sex offenders? A review of sex offender typologies. Aggression \& Violent Behavior, 12, 508-518.

Rossmo, D.K. (1997). Geographic profiling. In J. L. Jackson, \& D.A. Bekerian (Eds.), Offender profiling: Theory, research and practice (pp. 159-175). Chichester, UK: John Wiley \& Sons.

Sample, L.L., \& Bray, T.M. (2006). Are sex offenders dangerous? Criminology \& Public Policy, 3, 59-82. 
Scarce, M. (2001). Male on Male Rape: The Hidden Toll of Stigma and Shame. Basic Books.

Scully, D. (1994). Understanding Sexual Violence: A Study of Convicted Rapists. New York: Routledge.

Shechory, M., \& Ben-David, S. (2005). Aggression and anxiety in rapists and child molesters. International Journal of Offender Therapy and Comparative Criminology, 49, 652-661.

Shoop, R.J. (2004). Sexual exploitation in schools: How to spot it and stop it. Thousand Oaks: Sage Publications.

Sigmon, S.T., Greene, M.P., Rohan, K.J., \& Nichols, J.E. (1997). Coping and adjustment in male and female survivors of childhood sexual abuse. Journal of Child Sexual Abuse, 5(3), 57-75.

Simon, L.M.J., Sales, B., Kaszniak, A., \& Kahn, M. (1992). Characteristics of child molesters: Implications for the fixated-regressed dichotomy. Journal of Interpersonal Violence, 7, 211-225.

Simon, L.M.J. (2000). An examination of the assumptions of specialization, mental disorder, and dangerousness in sex offenders. Behavioral Sciences and the Law, 18, 175-308.

Sjostedt, G., Langstrom, N., Sturidsson, K., \& Grann, M. (2004). Stability of modus operandi in sexual offending. Criminal Justice and Behavior, 31, 609-623.

Smallbone, S.W., \& Wortley, R.K. (2004). Criminal diversity and paraphilic interests among adult males convicted of sexual offenses against children. International Journal of Offender Therapy and Comparative Criminology, 48, 175-188. 
Spataro, J, Mullen, P.E., Burgess, P.M., Wells, D.L., \& Moss. S.A. (2004). Impact of child sexual abuse on mental health. The British Journal of Psychiatry, 184, 416421.

Stermac, L.S., Hall, K., \& Henskens, M. (1989). Violence among child molesters. The journal of Sex Research, 26, 450-459.

Sullivan, J., \& Beech, A. (2002). Professional perpetrators: Sex offenders who use their employment to target and sexually abuse the children with whom they work. Child Abuse Review, 3, 153-167.

Sullivan, J., \& Beech, A. (2004). A comparative study of demographic data relating to Intra- and extra-familial child sexual abusers and professional perpetrators. Journal of Sexual Aggression, 10, 39-50.

Sullivan, J., Beech, A.R., Craig, L.A., Gannon, T.A. (2011). Comparing intra-familial and extra-familial child sexual abusers with professionals who have sexually abused children with whom they work. International Journal of Offender Therapy and Comparative Criminology, 55, 56-74.

Terry, K.J. (2008). The nature and scope of child sexual abuse in the Catholic Church. Criminal Justice and Behavior, 35, 549-569.

Terry, K.J. (2013). Sexual Offenses and Offenders: Theory, Practice and Policy $\left(2^{\text {nd }}\right.$ Ed.). New York: Cengage Learning.

Terry, K.J. (2015). Child sexual abuse within the Catholic Church: A review of global perspectives. International Journal of Comparative and Applied Criminal Justice , 39,139-154.

Terry, K.J., \& Akerman, A. (2008). Child sexual abuse in the Catholic Church: How 
situational crime prevention strategies can help create safe environments. Criminal Justice and Behavior, 35, 643-657.

Terry, K.J., \& Freilich, J. D. (2012). Understanding child sexual abuse by Catholic priests from a situational perspective. Journal of Child Sexual Abuse, 21, 437-455.

Terry, K., \& Tallon, J. (2004). Child sexual abuse: A review of the literature. The Nature and Scope of the Problem of Sexual Abuse of Minors by Priests and Deacons, 1950-2002. Washington, DC: United States Conference of Catholic Bishops.

Tewksbury, R. (2007). Effects of sexual assaults on men: Physical, mental, and sexual consequences. International Journal of Men's Health, 6, 22-34.

Tewksbury, R., \& Mustaine, E. E. (2003). College students' lifestyles and self- protective behaviors: Further considerations of the guardianship concept in Routine Activity theory. Criminal Justice and Behavior, 30, 302-327.

Topping, K.J., \& Barron, I.G. (2009). School-based child sexual abuse prevention programs: A review of effectiveness. Review of Educational Research, 79, 431463.

Tutty, L.M. (1997). Child sexual abuse prevention programs: Evaluating who do you tell. Child Abuse \& Neglect, 21, 869-881.

Ullman, S.E. (1998). Does offender violence escalate when rape victims fight back? Journal of Interpersonal Violence, 13(2), 179-192.

Ullman, S.E., \& Brecklin, L.R. (2000). Alcohol and adult sexual assault in a national sample of women. Journal of Substance Abuse, 12, 1-16.

Ullman, S.E., \& Knight, R.A. (1992). Fighting back: Women's resistance to rape. Journal of Interpersonal Violence, 7, 31-43. 
Ullman, S.E., \& Knight, R.A. (1993). The efficacy of women's resistance strategies in rape situations. Psychology of Women Quarterly, 17, 23-38.

United States Administration for Children \& Families, Child Maltreatment 2012: Reports from the States to the National Child Abuse and Neglect Data Systems-National statistics on child abuse and neglect. 2012.

van Dam, C. (2001). Identifying child molesters: Preventing child sexual abuse by recognizing the patterns of the offenders. New York: Haworth Maltreatment and Trauma Press.

Violato, C., \& Genuis, M. (1993). Problem in research in male child sexual abuse: A review. Journal of Child Sexual Abuse, 2, 33-54.

Walsh, K., Fortier, M., \& DiLillo, D. (2010). Adult coping with childhood sexual abuse: A theoretical and empirical review. Aggressive Violent Behavior, 15(1), 1-13.

Ward, T., \& Keenan, T. (1999). Child molesters' implicit theories. Journal of Interpersonal Violence, 14, 821-838.

Warren, J.L., Reboussin, R., Hazelwood, R.R., Cummings, A., Gibbs, N., \& Trumbetta, S. (1998). Crime scene and distance correlates of serial rape. Journal of Quantitative Criminology, 14, 35-59.

Weinrott, M.R., \& Saylor, M. (1991). Self-report of crimes committed by sex offenders. Journal of Interpersonal Violence, 6, 286-300.

Weiss, K.G. (2010). Male sexual victimization: Examining men's experiences of rape and sexual assault. Men and Masculinities, 12, 275-298.

White, M.D., \& Terry, K.J. (2008). Child sexual abuse in the Catholic Church: Revisiting the rotten apples explanation. Criminal Justice and Behavior, 35, 658-678. 
Williams, R., Elliott, I.A., \& Beech, A. R. (2013). Identifying sexual grooming themes used by internet sex offenders. Deviant Behavior, 34, 135-153.

Wilson, R. J. (1999). Emotional congruence in sexual offenders against children. Sexual Abuses: A Journal of Research and Treatment, 11, 33-47.

World Health Organization. (2006). Preventing child maltreatment: A guide to taking action and generating evidence. Geneva: WHO. Retrieved from www.who.int/violence_injury_prevention/publications/violence/child_maltreatme $\underline{\mathrm{nt} / \mathrm{en} /}$

Wortley, R. K., \& Smallbone, S. W. (2006). Applying situational principles to sexual offenses against children. In R. Wortley \& S. Smallbone (eds.), Situational prevention of child sexual abuse. Crime prevention studies. Monsey, NY: Criminal Justice Press.

Young, S. (1997). The use of normalization as a strategy in the sexual exploitation of children by adult offenders. Canadian Journal of Human Sexuality, 6, 285-295.

Zilney, L. A., \& Zilney, L. J. (2009). Reconsidering Sex Crimes and Offenders: Prosecution or Persecution? New York: Praeger. 
CURRICULUM VITAE

Leah Catherine Jihee Shon (née Jihee Lee)

\section{CURRENT POSITION}

\section{Doctoral Candidate (ABD)}

Department of Criminal Justice

College of Arts and Sciences

University of Louisville

Brigman Hall 106

Louisville, KY, USA 40208

Leah.shon@,louisville.edu

\section{EDUCATION}

Ph.D. June 2016

Department of Criminal Justice

University of Louisville, Louisville, Kentucky

Dissertation: Same-sex child molestation within the Boy Scouts of America:

Initiation and Termination in victim narratives

Chair: Dr. Richard Tewksbury

M.S. $\quad$ May 2012

Department of Criminology and Criminal Justice

Indiana State University, Terre Haute, Indiana

B.A. May 2006

Department of Human Justice

University of Regina, Regina, Saskatchewan, Canada

B.A. February 2002

Department of English Language and Literature

Sook Myung Women's University, Seoul, Korea 
RESEARCH INTERESTS

Sex Crimes

Qualitative Research Methods

Sexual Violence against Children

Immigration Crime \& Criminal Investigation

WORK EXPERIENCE

2014 JAN - Present

2012 AUG - 2012 DEC

2006 DEC - 2013 MAY
Department of Criminal Justice

University of Louisville, Research Assistant/ Instructor

Korean National Police Agency

Foreign Affairs Division (Rank: Senior Police)

Investigation of Foreign Nationals

National Security \& Intelligence. Seoul, Korea

2011 JAN - 2012 MAY Department of Political Science

Indiana State University, Graduate Research Assistant

\section{PUBLICATIONS}

Shon, L. J. (accepted). International Criminal Court Detention Center. In Kerley, K., Copes, H, Li, S. D., Lane, J., \& Sharp, S., F. (Eds.) The Encyclopedia of Corrections. Wiley-Blackwell.

Shon, P., \& Lee, J. (accepted). Evidence of convergent validity: A comparative analysis of sentencing verdicts and newspaper accounts of South Korean parricides. Asian Journal of Criminology

Barton-Bellessa, S., Lee, J., \& Shon, P. (2015). Correcting the misattributions, falsehoods, and errors about Alfred Adler's psychological theory of crime in introductory criminology textbooks: Moving Adler's theory of crime forward. Journal of Individual Psychology, 71(1), 34-57.

Avdija, A. S., \& Lee, J. (2014). Does electronic monitoring home detention program work? Evaluating program suitability based on offenders' post-program recidivism status. Justice Policy Journal, 11(1), 1-15.

Barton-Bellessa, S. M, \& Lee, J. (2012). Attitudes and Myths about Crime and Punishment. Pp 9-13 in Shannon M. Barton-Bellessa \& Geoffrey Golson (Eds.) Encyclopedia of Community-Based Corrections. Thousand Oaks, CA: SAGE. 
Shon, L. J. "Re-offending patterns of serial same-sex child molesters." Paper presented at the Annual Meeting of the American Society of Criminology. Washington DC. November 2015.

Andreescu, V. \& Shon, L. J. 'Korean and American Police Officers' Perceptions of Professional Integrity: A Comparative Analysis." Paper presented at the Annual Meeting of the American Society of Criminology. Washington DC. November 2015.

Rausch, C., Andreescu, V. \& Shon, L. J. "Heterosexism and Homophobia in the Russian Federation: Public Attitudes Towards Sexual Minorities' Civil Rights." Poster presented at the Annual Meeting of the American Society of Criminology. Washington DC. November 2015.

Shon, L. J. "How molesters carry out offenses against boys: Exploring techniques of execution by using victim statements within the Boy Scouts of America." Paper presented at the XXXIth International Congress of Law and Mental Health. Vienna, Austria. July 2015.

Shon, L. J., \& Andreescu, V. "Seoul, Republic of Korea: Perceptions of safety in a capital city." Paper presented at the Annual Meeting of American Society of Criminology. San Francisco. November 2014.

Shon, L. J. "How molesters carry out offenses against boys: Exploring techniques of execution by using victim statements within the Boy Scouts of America." Paper presented at the International Academy of Law and Mental Health. Vienna, Austria. July 2015.

Hayden, T. C. \& Shon, L.J. "Exploring resiliency characteristics of children of YNOW program for children of incarcerated parent." Poster presented at the Annual Meeting of American Society of Criminology. San Francisco. November, 2014.

Shon, P., Lee, J., \& Barton-Bellessa, S. M. "Evidence of convergent validity in two divergent sources of archival data: A comparative analysis of sentencing verdicts and newspaper accounts of parricide in South Korea, 1995-2012." Paper presented at the Annual Meeting of the Midwest

Criminal Justice Association. Chicago. September, 2014.

Shon, P., \& Lee, J. "Temporal sequencing and offender behavior in attempted and completed double parricides: An exploratory study using regional and appellate court records in South Korea (1995-2012)." Paper presented at "Honour Thy Father and Thy Mother": Violence

Against Parents in the North of Europe, International Workshop. Department of History, University of Tampere, Finland. Sponsored by the Joint Committee for Nordic Research Councils for the Humanities and the Social Sciences, Tampere, Finland. May 2014. 
Barton-Bellessa, S. M., Lee, J., \& Shon, P. "What are we teaching our students in introductory criminology textbooks?: Ignorance, misattributions, and errors about the psychological theory of crime of Alfred Adler." Paper presented at the Annual Meeting of the American Society of Criminology. Chicago. November 2012.

Lee, J. "Electronic Monitoring Home Detention program in a Midwestern county." Preliminary Paper presented at the Annual Meeting of the Midwest Criminal Justice Association. Chicago. September 2011.

TEACHING ASSIGNMENT

Spring 2016

CJ 305-1 Criminal Behavior

Lecturer

Fall 2015

CJ 305-02 Criminal Behavior

Organizing Study Groups as a Teaching Assistant

PROFESSIONAL DEVELOPMENT

Fall 2015 - Spring Graduate Teaching Assistant Academy

2016

Developing teaching strategies \& Creating a civil classroom culture

Spring 2015- Fall 2015 Graduate Teaching Workshops

Diversity in the classroom; Teaching toolbox; How to use blackboard in class

\section{PROFESSIONAL AFFLIATIONS}

Member of the American Society of Criminology (2012-Present)

Member of the Midwest Criminal Justice Association (2011-Present)

Member of Alpha Phi Sigma (The National Criminal Justice Honor Society, 2011-Present)

\section{REFERENCES}

Dr. Richard Tewksbury

Professor

Department of Criminal Justice

University of Louisville

Email:

Richard.tewksbury@louisville.edu ratewk01@exchange.louisville.edu

Phone: (502)852-0379 


$\begin{array}{ll}\text { Dr. Viviana Andreescu } & \text { Associate Professor } \\ & \text { Department of Criminal Justice } \\ \text { University of Louisville } & \text { Email: } \\ & \text { Viviana.andreescu@louisville.edu } \\ \text { V0andr01@louisville.edu } & \\ & \text { Phone: (502)852-0378 } \\ & \text { Professor } \\ & \text { Department of Criminal Justice } \\ & \text { Indiana State University } \\ & \text { Email: } \\ \text { Dr. Shannon M. Barton } & \text { Shannon.Barton-Bellessa@indstate.edu } \\ & \text { Phone: (812)237-8332 }\end{array}$

